ETIENNE BIASOTTO

\title{
UM PROCEDIMENTO DE ANÁLISE PARA A REPOTENCIAÇÃO DE LINHAS DE SUBTRANSMISSÃO DE 34,5 KV PARA 69KV
}





\section{UM PROCEDIMENTO DE ANÁLISE PARA A REPOTENCIAÇÃO DE LINHAS DE SUBTRANSMISSÃO DE 34,5 KV PARA 69KV}

Dissertação apresentada à Escola de Engenharia de São Carlos, da Universidade de São Paulo, como parte dos requisitos para a obtenção do Título de Mestre em Engenharia Elétrica.

Área de Concentração: Sistemas Elétricos de Potência Orientador: Prof. Dr. Mário Oleskovicz 
AUTORIZO A REPRODUÇÃO E DIVULGAÇÃO TOTAL OU PARCIAL DESTE TRABALHO, POR QUALQUER MEIO CONVENCIONAL OU ELETRÔNICO, PARA FINS DE ESTUDO E PESQUISA, DESDE QUE CITADA A FONTE.

Ficha catalográfica preparada pela Seção de Tratamento da Informação do Serviço de Biblioteca - EESC/USP

Biasotto, Etienne
B579p Um procedimento de análise para a repotenciação de linhas de subtransmissão de $34,5 \mathrm{kV}$ para $69 \mathrm{kV} /$ Etienne Biasotto ; orientador Mário Oleskovicz. -- São Carlos, 2009 .

Dissertação (Mestrado-Programa de Pós-Graduação em Engenharia Elétrica e Área de Concentração em Sistemas Elétricos de Potência) -- Escola de Engenharia de São Carlos da Universidade de São Paulo, 2009.

1. Linhas aéreas de transmissão de energia elétrica. 2. Repotenciação - procedimento de análise. 3. Elevação

da classe de tensão. 4. Linhas de subtransmissão.

5. Classe de $34,5 \mathrm{kV}$. 6. Classe de $69 \mathrm{kV}$. 7. ATP.

8. ATPDraw. 10. FLUX®. I. Título. 
FOLHA DE JULGAMENTO

Candidato: Engenheiro ETIENNE BIASOTTO.

Dissertação defendida e julgada em 04/12/2009 perante a Comissão Julgadora:

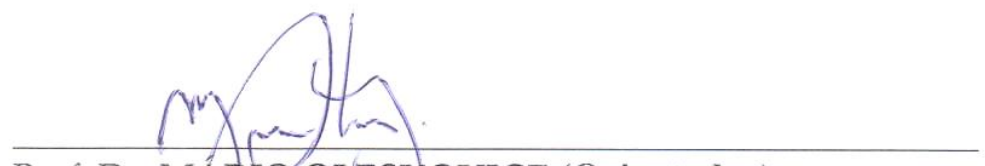

Aprovado

Prof. Dr. MÁRIO OLESKOVICZ (Orientador)

(Escola de Ensenharia de São Carlos/USP)
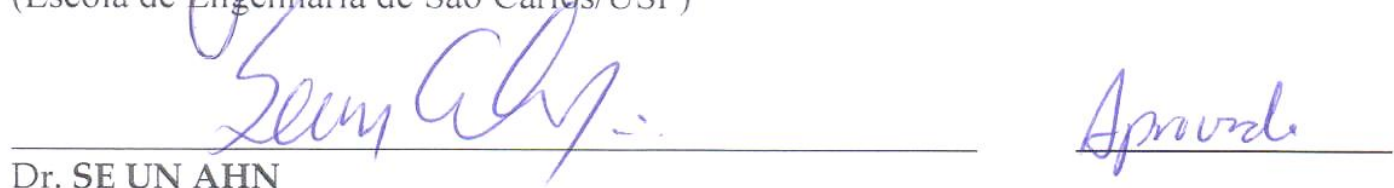
(CPFL)

Losí Carbos de melo Vievia frémo APROVADO Prof. Dr. JOSÉ CARLOS DE MELO VIEIRA JÚNIOR

(Escola de Engenharia de São Carlos/USP)

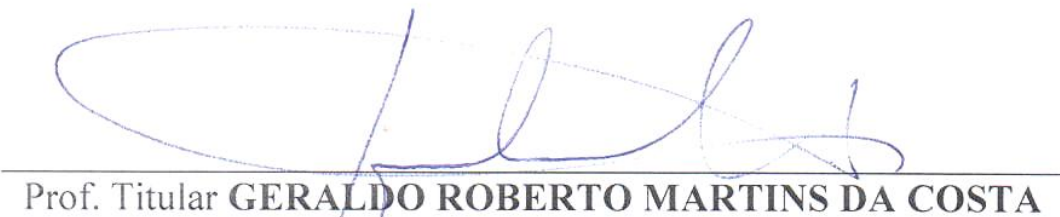

Coordenador do Programa de Pós-Graduação em Engenharia Elétrica e Presidente da Comissão de Pós-Graduação 



\section{Dedicatória}

Aos meus pais, Wilson e Helena, às minhas irmãs Mirella e Milenne, e a todos os que acreditaram na realização desse trabalho. 


\section{Agradecimentos}

À Deus, primeiramente, por minha existência e por iluminar meus passos.

Ao Prof. Dr Mário Oleskovicz, pela orientação, confiança e paciência com que me atendeu ao longo dessa caminhada.

Aos professores Denis Vinicius Coury e José Carlos de Melo Vieira Júnior, pelos conselhos e pela agradável companhia, e aos demais professores do programa que acrescentaram tanto à minha formação.

Aos amigos que tive a felicidade de encontrar no decorrer dessa trajetória, em especial: Aldir, Alexandre, Breno, Daniel, Eduardo, Gerson, Gustavo, Helson, Hermes, Lucas, Monaro, Patrick, Ricardo, Samuel, Sérgio, Ulisses, enfim, a todos com quem pude desfrutar tão valiosos momentos.

À Camila, companheira de todos os momentos, pela atenção, carinho, paciência e amor.

Ao meu pai, Wilson, e à minha irmã, Milenne, pelas correções e disponibilidade em ler meu trabalho.

À minha mãe, Helena, e à minha irmã Mirella, pelo apoio e incentivo em todos os momentos.

A todos os funcionários da Escola de Engenharia de São Carlos - USP, pela atenção e cordialidade. 


\section{Sumário}

Resumo

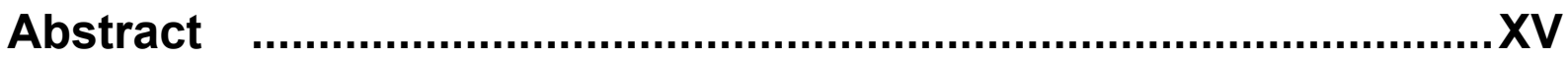

Lista de Figuras .....................................................................XVII

Capítulo 1 Introdução ......................................................................21

Capítulo 2 Apreciação dos Estudos Sobre Repotenciação ...............25

2.1 - Fatores que determinam o custo do transporte de energia elétrica..............26

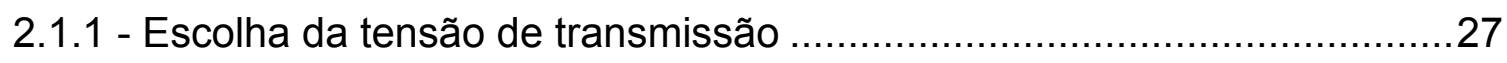

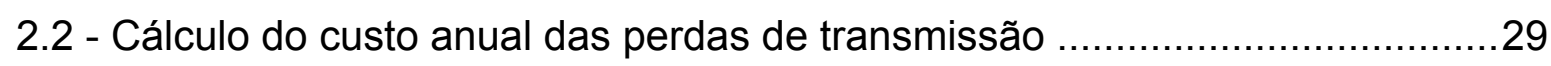

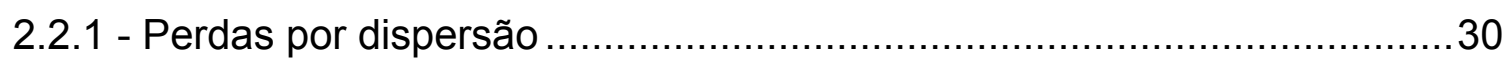

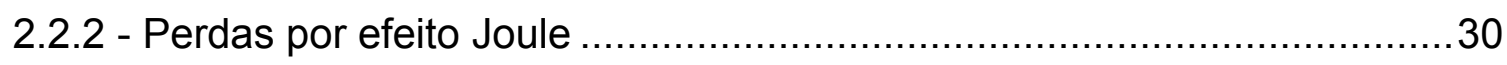

2.2.3 - Determinação do custo da energia perdida ................................... 33

2.3 - Cálculo do custo da instalação ................................................. 35

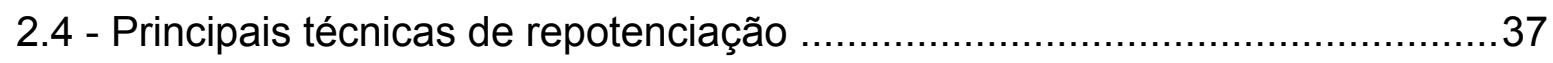

2.4.1 - Alteração do limite térmico da linha de transmissão ..........................38

2.4.2 - Recondutoramento da linha de transmissão .................................. 38

2.4.3 - Elevação da tensão operativa da linha de transmissão .......................39

2.5 - Trabalhos técnico-científicos defendidos sobre a repotenciação de linhas de

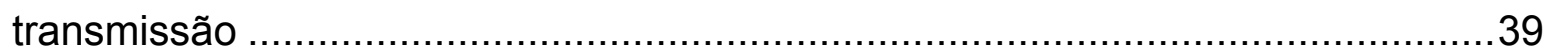

Capítulo 3 Procedimento a ser Aplicado para a Repotenciação de

Linhas de Subtransmissão ...............................................................49 
3.1 - Escolha da linha candidata à repotenciação ............................................. 51

3.1.1 - Análises das linhas candidatas....................................................... 51

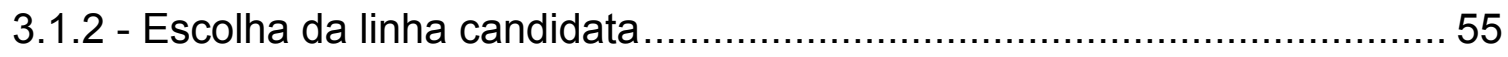

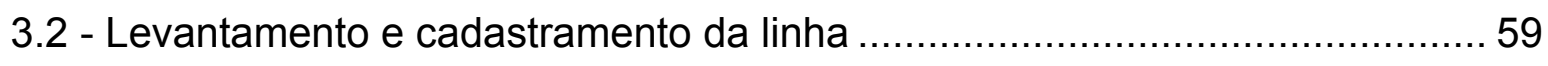

3.3 - Escolha do método de repotenciação ………………............................... 61

3.3.1 - Alteração do limite térmico da linha de transmissão................................. 62

3.3.2 - Recondutoramento da linha de transmissão ........................................ 63

3.3.3 - Elevação da tensão operativa da linha de transmissão.......................... 65

3.4 - Aspectos ambientais da repotenciação ...................................................... 75

Capítulo 4 Simulações Computacionais no Processo de

Repotenciação de Linhas de Subtransmissão................................. 79

4.1 - Modelagem da linha via a interface Atpdraw ............................................. 80

4.2 - Simulações sobre o sistema em análise .................................................... 82

4.2.1 - Simulações sobre o sistema de 34,5 kV ............................................. 84

4.2.2 - Simulações sobre o sistema expandido de 69 kV ................................ 95

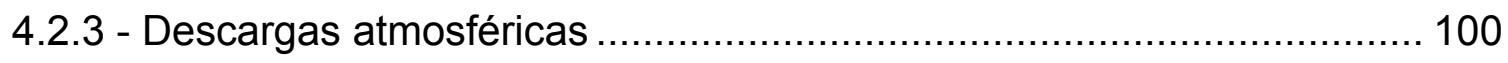

Capítulo 5 Alternativas para a Melhoria de Desempenho .............. 107

5.1 - Simulações pertinenentes aos isoladores associados aos sistemas de 34,5 e

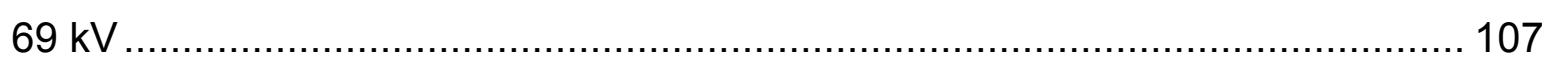

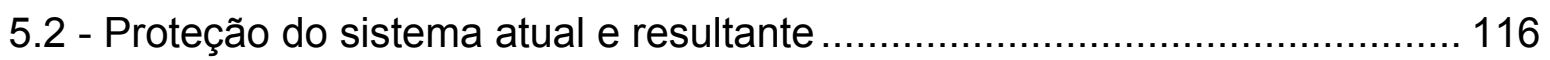

5.2.1 - Proteção do sistema de 34,5 kV ....................................................... 116

5.2.2 - Proteção do sistema de 69 kV ..................................................... 118

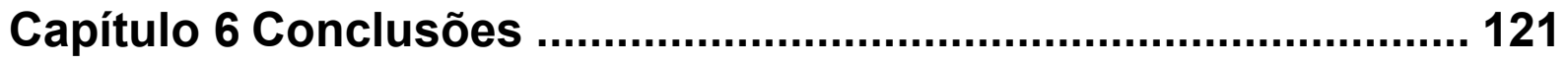


6.1 - Continuidade da pesquisa 124

Referências Bibliográficas........................................................127 


\section{Resumo}

\section{BIASOTTO, E. Um procedimento de análise para a repotenciação de linhas de} subtransmissão de 34,5 KV para 69,5 KV. São Carlos, 2009, p. 134. Dissertação de Mestrado - Escola de Engenharia de São Carlos, Universidade de São Paulo.

Como parte de um projeto de Pesquisa e Desenvolvimento (P\&D) mais amplo, que está sendo desenvolvido pela Escola de Engenharia de São Carlos - USP e Companhia Paulista de Força Luz (CPFL), com previsão de conclusão para 2010, este trabalho tem por objetivo apresentar os principais procedimentos para a realização da repotenciação de linhas de subtransmissão de $34,5 \mathrm{KV}$ para $69 \mathrm{KV}$. Para atingir esse objetivo, é realizada inicialmente uma apreciação do estágio atual dos estudos sobre o tema, abordando inclusive outros métodos além daquele que será objeto específico desse estudo. Em seguida, discutem-se tópicos relevantes dos métodos apresentados de forma que, esse estudo, além de cumprir o já mencionado objetivo específico de apresentar soluções para aumentar a capacidade de transmissão de uma determinada linha, mantendo a sua faixa de servidão, indicará parâmetros válidos para a realização de outros projetos da mesma natureza. Sequencialmente são apresentadas as etapas desenvolvidas para a operacionalização da repotenciação de uma linha, a começar pela escolha da mais adequada, a seleção do método a ser utilizado, levando-se em consideração tanto a alteração do limite térmico da linha quanto à elevação de sua tensão operativa e os aspectos ambientais que envolvem a repotenciação. Finalmente, fazendo uso dos softwares ATP, através da interface gráfica ATPDraw (empregado para as 
simulações de transitórios eletromagnéticos) e do Flux®, para as simulações dos campos elétricos em torno dos isoladores, realizou-se um conjunto de simulações computacionais pertinentes para um bom conhecimento do funcionamento da linha de subtransmissão a ser repotenciada na classe de interesse. Todas as etapas e as conclusões preliminares sobre o assunto delineado serão apresentadas neste documento.

Palavras-chave: Repotenciação, Procedimento de Análise, Elevação da Classe de Tensão, Linhas de subtransmissão, Classe de $34,5 \mathrm{kV}$, Classe de $69 \mathrm{kV}$, ATP, ATPDraw e FLUX®. 


\section{Abstract}

\section{BIASOTTO, E. A procedure of analysis for repowering subtransmission lines} from $34.5 \mathrm{KV}$ to $69 \mathrm{KV}$. São Carlos, 2009, $134 \mathrm{f}$. Mastering Thesis. Escola de Engenharia de São Carlos. Universidade de São Paulo.

As part of a wider Research and Development project, which is being developed between Escola de Engenharia de São Paulo - USP and Companhia Paulista de Força e Luz (CPFL), scheduled to be finished in 2010, this work aims to present the main procedures to perform a repowering on subtransmission lines from $34.5 \mathrm{KV}$ to $69 \mathrm{KV}$. To achieve this purpose, an assessment of the current studies about the subject is carried out, including an approach of other methods besides the one which is going to be the specific object of this study. After this, relevant points about the main methods are discussed in such a way that this study, in addition to serve its specific purpose, that is to present solutions in order to increase the transmission capacity of a determined line, keeping its right-of-way, can also point out valuable parameters which can be used to develop other projects of similar nature. Sequentially, the steps followed to operationalize the line repowering are presented, starting with the choice of the most suitable line, the selection of the method to be used, and taking into consideration both the change in the line thermal limit and the elevation on its operating voltage and also the environmental aspects involving repowering. At last, making use of ATP software throughout ATPDraw graphical interface (which is used to simulate electromagnetic transients) and Flux ${ }^{\circledR}$, that simulates electrical fields around insulators, it is carried out a set of computational 
simulations which are relevant to a good knowledge of the line subtransmission running. All the steps and preliminary conclusions about the subject are going to be outlined on this document.

Keywords: Repowering, Analysis Procedure, Raising the Voltage Class, Subtransmission lines, Class 34.5 kV, Class 69 kV, ATP, ATPDraw e FLUX®. 


\section{Lista de Figuras}

Figura 2-1 - Evolução das potências a serem transmitidas (Fonte: Fuchs, 1979, p.

$525)$

Figura 3-1- Principais passos a serem tomados durante os estudos de repotenciação de linhas de transmissão.

Figura 3-2 - Estrutura do Tipo "G" .56

Figura 3-3 - Estrutura do Tipo "A" 57

Figura 3-4 - Estrutura do Tipo "B" 57

Figura 3-5 - Estrutura do Tipo "E". 58

Figura 3-6 - Estrutura do Tipo "HS" 58

Figura 3-7 - Estrutura do Tipo "HT" 59

Figura 3-8 - Seqüência cronológica dos principais tópicos a serem analisados durante a repotenciação de uma determinada linha 65

Figura 3-9 - Seqüência das simulações computacionais realizadas para o sistema original e para o repotenciado. 67

Figura 4-1 - Modelo simplificado da linha .80

Figura 4-2 - Tela inicial do componente LCC 81

Figura 4-3 - Tela para a entrada dos dados representando os condutores do sistema simulado

Figura 4-4 - Modelo simplificado representando uma situação de falta monofásica. 85 Figura 4-5 - Formas de ondas da tensão nas fases "A", "B" e "C" após a ocorrência de um curto-circuito no meio da linha, envolvendo a fase "A" com conexão a terra, resistência e ângulo de incidência da falta de $10 \Omega$ e $0^{\circ}$, respectivamente .85 
Figura 4-6 - Formas de ondas da tensão nas fases "A", "B" e "C" após a ocorrência de uma falta bifásica envolvendo as fases "A" e "B" do sistema em análise, com uma resistência e ângulo de incidência da falta de $10 \Omega$ e $0^{\circ}$, respectivamente. . 86

Figura 4-7 - Formas de ondas da tensão nas fases "A", "B" e "C" após a ocorrência de uma falta bifásica com o envolvimento do terra ("AB-T"), com uma resistência e ângulo de incidência da falta de $10 \Omega$ e $0^{\circ}$, respectivamente.

Figura 4-8 - Forma de onda da tensão nas três fases devido a uma falta trifásica aplicada no meio da linha do sistema em análise com uma resistência e ângulo de incidência da falta de $10 \Omega$ e $0^{\circ}$, respectivamente. 88

Figura 4-9 - Forma de onda da tensão nas três fases devido a uma falta trifásica envolvendo o terra, aplicada no meio da linha do sistema em análise, com uma resistência e ângulo de incidência da falta de $10 \Omega$ e $0^{\circ}$, respectivamente. 89

Figura 4-10 - Modelagem da linha de 34,5 kV expandida (modelo detalhado)........ 90

Figura 4-11 - Modelagem de uma falta monofásica aplicada na linha em estudo. .. 90

Figura 4-12 - Formas de ondas da tensão nas fases "A", "B" e "C" após a ocorrência de uma falta na fase "A" do sistema em análise, com uma resistência e ângulo de incidência da falta de $10 \Omega$ e $0^{\circ}$, respectivamente. 91

Figura 4-13- Formas de ondas da tensão nas fases "A", "B" e "C" após a ocorrência de uma falta bifásica envolvendo as fases "A" e "B" do sistema em análise, com uma resistência e ângulo de incidência da falta de $10 \Omega$ e $0^{\circ}$, respectivamente. . 92

Figura 4-14 - Formas de ondas da tensão nas fases "A", "B" e "C" após a ocorrência de uma falta bifásica com o envolvimento do terra ("AB-T"), com uma resistência e ângulo de incidência da falta de $10 \Omega$ e $0^{\circ}$, respectivamente. 93 
Figura 4-15 - Forma de onda da tensão nas três fases devido a uma falta trifásica, aplicada no meio da linha do sistema em análise, com uma resistência e ângulo de incidência da falta de $10 \Omega$ e $0^{\circ}$, respectivamente.

Figura 4-16 - Forma de onda da tensão nas três fases devido a uma falta trifásica envolvendo o terra, aplicada no meio da linha do sistema em análise, com uma resistência e ângulo de incidência da falta de $10 \Omega$ e $0^{\circ}$, respectivamente

Figura 4-17 - Formas de ondas da tensão nas fases "A", "B" e "C" após a ocorrência de uma falta na fase "A" do sistema em análise, com uma resistência e ângulo de incidência da falta de $10 \Omega$ e $0^{\circ}$, respectivamente. 96

Figura 4-18- Formas de ondas da tensão nas fases "A", "B" e "C" após a ocorrência de uma falta bifásica ("AB"), com uma resistência e ângulo de incidência da falta de $10 \Omega$ e $0^{\circ}$, respectivamente.

Figura 4-19- Formas de ondas da tensão nas fases "A", "B" e "C" após a ocorrência de uma falta bifásica com o envolvimento do terra (“AB-T"), com uma resistência e ângulo de incidência da falta de $10 \Omega$ e $0^{\circ}$, respectivamente. 98

Figura 4-20 - Formas de ondas da tensão nas fases "A", "B" e "C" após a ocorrência de uma falta trifásica, com uma resistência e ângulo de incidência da falta de $10 \Omega$ e $0^{\circ}$, respectivamente.

Figura 4-21 - Formas de ondas da tensão nas fases "A", "B" e "C" após a ocorrência de uma falta trifásica, com o envolvimento do terra, com uma resistência e ângulo de incidência da falta de $10 \Omega$ e $0^{\circ}$, respectivamente. 99

Figura 4-22 - Uma situação de descarga atmosférica aplicada diretamente sobre um ponto em específico do sistema em análise 101

Figura 4-23 - Descarga atmosférica incidente sobre a fase "A" do sistema em análise, aplicada e medida próxima ao meio da linha. 
Figura 4-24 - Descarga atmosférica incidente na fase "A", aplicada e medida na extremidade da linha próxima à Usina de Salto Grande. 103

Figura 4-25 - Descarga atmosférica incidente na fase "A", aplicada na extremidade da linha próxima à Usina de Salto Grande e medida em um ponto próximo ao meio da linha. 104

Figura 4-26 - Sobretensões originadas na extremidade da linha conectada à subestação de Souzas devido a uma descarga atmosférica aplicada na extremidade oposta da linha 105

Figura 5-1 - Isolador modelado com a malha utilizada para os cálculos dos elementos finitos. 109

Figura 5-2 - Linhas de potencial para a tensão de pico de fase do sistema de 34,5 $\mathrm{kV}$. 110

Figura 5-3 - Isolador com os campos elétricos associados representados por cores.

Figura 5-4 - Linhas de potencial para um isolador de $34,5 \mathrm{kV}$ com uma tensão aplicada no condutor de $69 \mathrm{kV}$.

Figura 5-5 - Isolador com seus campos elétricos representados por cores e seus valores para uma tensão de $69 \mathrm{kV}$.

Figura 5-6 - Instante de tempo onde foram amostrados os valores de tensão de cada fase para a conseqüente aplicação nos condutores. 114

Figura 5-7 - Linhas de potencial observadas sobre os isoladores para um valor de tensão positivo para a fase "B" e negativo para as fases " $A$ " e "C". 115

Figura 5-8 - Campo elétrico observado sobre os isoladores para um valor de tensão positivo para a fase "B" e negativo para as fases " $A$ " e "C". 116 


\section{Capítulo 1 Introdução}

Nos últimos anos, o consumo de energia elétrica vem aumentando significativamente, o que induz ao desenvolvimento de novas tecnologias para que essa demanda seja suprida da melhor maneira possível. Isso implica não somente pela busca de novas tecnologias que devem primar pela geração da energia, mas também pela evolução necessária nos sistema de transmissão e de distribuição dessa energia até os pontos de conexão com os consumidores finais.

Como fato, tem-se que a grande demanda do sistema elétrico faz com que as linhas de transmissão sofram um aumento na solicitação de seus componentes, exigindo que novas linhas sejam construídas. Porém, com a construção de novas linhas, além dos impactos ambientais, tem-se também altos investimentos, o que torna essa alternativa, atualmente, menos atrativa. Nesse âmbito, é importante encontrar alternativas que se utilizem das linhas já existentes para transportar uma maior quantidade de energia, respeitando-se o meio ambiente. Contudo, tais soluções devem ser tecnicamente viáveis e economicamente passíveis de implementação, levando-se em consideração os conceitos e a qualidade da energia fornecida como produto.

Nesse contexto, a repotenciação surge como uma alternativa a ser analisada nos estudos de expansão do sistema de transmissão. Essa técnica permite aumentar a capacidade de transporte de energia a baixo custo em função das instalações já existentes (Oliveira, 2000). Para justificar o porquê do reaproveitamento das instalações já existentes, é importante salientar que boa parte 
dos sistemas de transmissão, projetados sob princípios conservadores há algumas décadas, na maioria das vezes, respeitavam uma boa margem de segurança em virtude da carência de tecnologias mais precisas. No entanto, com o avanço da tecnologia e da disponibilidade de materiais e equipamentos, é possível então, viabilizar uma reengenharia nos projetos das linhas de transmissão existentes, aumentando assim as suas respectivas capacidades de transmissão sem acarretar em maiores problemas ambientais e econômicos.

Pelos apontamentos iniciais expostos, já se pode observar que a intenção dessa pesquisa é o de apresentar um procedimento para a mudança (conversão) da classe de tensão de certas redes de subtransmissão (muitas das vezes caracterizada como de distribuição primária). Neste caso em específico, as classes de tensão em análise envolvem as de 34,5 e 69 kV, onde se buscará aumentar a capacidade de transmissão da linha, sem alterar sua faixa de servidão e suas licenças ambientais. Essa alteração vislumbra algumas mudanças no sistema atual, levando em consideração que ele opera, como já mencionado anteriormente, com uma grande margem de segurança em relação aos isoladores, distância entre os condutores e suas bitolas, além de outras características físicas que serão ressaltadas no decorrer da apresentação da pesquisa realizada.

Sumarizando, a pesquisa tem por objetivo principal o desenvolvimento de um procedimento eficiente para analisar as vantagens e desvantagens técnicoeconômicas desta transformação, considerando-se a simulação do sistema atual e a do resultante, e observando, também, as características físicas e geográficas da rede primária. 
Para atingir o objetivo acima mencionado e expor todas as etapas intermediárias ao processo, a presente dissertação será divida em cinco capítulos, sendo o primeiro deles a própria apresentação do trabalho.

No segundo capítulo, serão apresentados os aspectos fundamentais relacionados à repotenciação de linhas de transmissão, bem como uma apreciação dos principais trabalhos publicados na área em questão.

No terceiro capítulo, serão apontados alguns itens importantes que servirão como delimitadores na seleção de uma linha para a repotenciação e, na seqüência, um procedimento para a repotenciação das linhas de transmissão será proposto. Nesse capítulo, serão apresentadas algumas etapas que virão a delinear o desenvolvimento e os procedimentos para se alcançar a conversão desejada.

O quarto capítulo será reservado para o desenvolvimento de uma análise sobre os resultados alcançados através das simulações realizadas na linha escolhida de $34,5 \mathrm{kV}$, bem como na de $69 \mathrm{kV}$, que será o produto dessa conversão.

O quinto capítulo apresentará algumas simulações computacionais voltadas para a melhoria do desempenho da linha com relação ao aumento da classe do nível básico de isolamento (NBI), e serão comentadas as funções de proteção utilizadas no sistema de $34,5 \mathrm{kV}$, bem como o que deverá ser feito/considerado para que o sistema opere na nova classe de tensão de $69 \mathrm{kV}$.

Para a conclusão apresentada no sexto capítulo desta dissertação, serão compiladas as principais idéias aplicadas ao longo desse trabalho. 


\section{Capítulo 2 Apreciação dos Estudos Sobre Repotenciação}

O transporte da energia elétrica, desde as unidades geradoras aos centros de consumo, é um processo cujos custos podem representar uma parcela considerável dos investimentos totais da produção dessa energia. Em razão desse fato, busca-se tanto a redução do custo do transporte do kWh de uma linha de transmissão como o avanço de técnicas que permitam o aumento da capacidade de transporte dessas linhas.

Contudo, as variáveis envolvidas nesse processo de minimização de custos são muitas e seus valores nem sempre são obtidos de forma simples. Como exemplos, podem ser citados as perdas de energia elétrica devidas ao efeito Corona (Fuchs, 1979), que são de difícil determinação e contribuem para reduzir o rendimento das linhas de transmissão. Ressalta-se então, a necessidade de um criterioso planejamento das redes de transmissão de energia elétrica, que deve contemplar o atendimento da crescente demanda com elevado grau de confiabilidade e com um mínimo de perdas associadas.

Aliada aos aspectos econômicos, a transmissão da energia elétrica está condicionada a certas restrições de caráter ambiental que, não obstante de serem procedentes, nos últimos tempos têm sido um forte obstáculo na constituição de novas faixas de passagem e no licenciamento de novas obras (Oliveira, 2000). Como exemplos mais corriqueiros dessas restrições, citam-se as desapropriações 
de áreas e a interferência eletromagnética causada pelos campos elétricos e magnéticos das linhas.

A necessidade de atendimento da crescente demanda a um baixo custo e elevada confiabilidade, juntamente com as dificuldades no licenciamento de novas linhas de transmissão de energia elétrica, são dois fatores fundamentais que têm levado as empresas do setor de energia a buscar alternativas de baixo custo para o aumento da capacidade de transmissão da energia elétrica das linhas de transmissão, aproveitando a infra-estrutura já existente. Neste sentido, a repotenciação de linhas de transmissão tem se mostrado uma alternativa interessante para atingir esse objetivo (Silva e Baumann, 1997; Oliveira, 2000; Costa et al., 2001).

No contexto apresentado, este capítulo contempla aspectos julgados importantes em relação à repotenciação de linhas de transmissão. Inicialmente, será realizada uma introdução aos fatores determinantes do custo do transporte da energia elétrica, abordando os custos das perdas na transmissão e os custos de instalação. Em seguida, as principais alternativas técnicas para efetuar a repotenciação e os aspectos ambientais associados a essa ação serão apresentados. Por fim, será feita uma sucinta apresentação dos trabalhos correlatos encontrados.

\section{1 - FATORES QUE DETERMINAM O CUSTO DO TRANSPORTE DE ENERGIA ELÉTRICA}

O processo de obtenção do menor custo na transmissão de energia elétrica requer um equacionamento técnico-econômico otimizado na busca de variáveis que 
permitam uma solução técnica viável e que resulte no menor custo possível. A obtenção dessa solução, do ponto de vista desse trabalho, consiste em estabelecer uma relação entre dois fatores aparentemente antagônicos:

- o custo da energia "perdida" na transmissão; e

- o custo das instalações.

Cabe relembrar que as perdas na transmissão de energia são devidas ao efeito Corona e ao efeito Joule (Fuchs, 1979). Elas representam um montante de energia produzida ou adquirida que deixará de ser vendida pela empresa, caracterizando-se como prejuízo. Enquanto as perdas devidas ao efeito Joule decrescem com o aumento da tensão de operação, as que se devem ao efeito Corona aumentam. Em contrapartida, ambas diminuem com o aumento da bitola dos condutores. Percebe-se, portanto, que a redução das perdas envolve o aumento do custo das instalações. Logo, os investimentos realizados para a redução das perdas e o aumento da confiabilidade das linhas de transmissão devem produzir retorno de capital investido no prazo determinado como vida útil da instalação. Dessa forma, uma análise técnico-econômica deve abranger todos os fatores que influenciam os custos das perdas e todos os elementos que compõem o custo da instalação. Entre esses fatores, destaca-se a tensão de transmissão da energia elétrica, que será abordada em maiores detalhes a seguir.

\subsection{1 - ESCOLHA DA TENSÃO DE TRANSMISSÃO}

A tensão de transmissão está fortemente relacionada às perdas de energia e também aos custos da instalação. Para cada nível de tensão, existirá uma solução otimizada que atenda à minimização dos custos do transporte de energia elétrica. 
Entre os critérios empregados para a escolha da tensão de transmissão, dois podem ser citados segundo Fuchs (1979):

a) Fórmula de Still: é mais adequada para linhas de transmissão com comprimentos maiores do que $30 \mathrm{~km}$. A tensão a ser adotada é a tensão padronizada mais próxima do valor obtido pela expressão (2.1).

$$
U \cong 5,5 \cdot \sqrt{0,62 \cdot L+\frac{P}{100}} \quad[k V]
$$

Em que:

$U$ - tensão entre fases, em kV;

$L$ - comprimento da linha, em $\mathrm{km}$;

$P$ - potência média a transmitir, em $\mathrm{kW}$.

b) Critério da potência natural: é normalmente utilizado em linhas de grande porte. Segundo esse critério, para cada tensão há um valor ótimo de potência a ser transmitida e vice-versa. Esse valor pode não ser o que resulte em mínimas perdas, porém é o mais utilizado, tendo em vista que $Z_{o}$ (impedância natural da linha, em $\Omega$ ) independe do comprimento da linha, sendo dependente do logaritmo da relação entre a distância entre condutores e seus raios. Assim, a tensão escolhida será determinada por (2.2).

$$
U=\sqrt{P \cdot Z o} \quad[k V]
$$

Em que: 
$U$ - tensão entre fases, em kV;

$Z_{0}$ - impedância natural da linha, em $\Omega$;

$P$ - potência média a transmitir, em kW.

Outro fator importante a se considerar na escolha da tensão de transmissão são as tensões já adotadas nos sistemas vizinhos. Dentro de um mesmo sistema, o número de tensões diferentes deve ser o mínimo possível, no sentido de evitar eventuais problemas decorrentes de interligações em níveis diferentes.

Nesta dissertação de mestrado, da maneira como a mesma foi conduzida, serão abordados fundamentalmente aspectos técnicos relacionados à escolha da tensão de transmissão, sendo que nenhuma ênfase será dada diretamente aos aspectos econômicos. Isso ocorre porque, na prática, um estudo econômico rigoroso para a escolha do nível de tensão somente é justificado caso se deseje introduzir novos níveis de tensão no sistema, pois a faixa de tensões existentes para a operação da linha é relativamente restrita.

\section{2 - CÁLCULO DO CUSTO ANUAL DAS PERDAS DE TRANSMISSÃO}

Conforme já abordado, o retorno do capital investido em um sistema de transmissão de energia elétrica deve ser dentro do prazo estabelecido como vida útil da instalação. Como a vida útil desse tipo de empreendimento compreende várias décadas, dependendo da estrutura utilizada (Fuchs, 1979), é comum efetuarem-se os cálculos em termos de custos anuais. Logo, o custo da energia "perdida" também é calculado anualmente. A seguir, será feita uma breve análise de custo das perdas na transmissão de energia elétrica. 


\subsection{1 - PERDAS POR DISPERSÃO}

As perdas por dispersão são devidas, principalmente, ao efeito Corona. São perdas difíceis de serem calculadas, pois dependem dos gradientes de potencial na superfície dos condutores e das condições meteorológicas ao longo das linhas. Assim, elas podem ser nulas quando o tempo está bom, mas podem atingir valores elevados sob condições de chuvas intensas. Portanto, a avaliação anual dessas perdas requer um processamento estatístico das condições meteorológicas da região com dados horários de muitos anos (Fuchs, 1979).

Em linhas bem dimensionadas, o valor médio das perdas por dispersão deve estar entre 2 e $8 \mathrm{~kW} / \mathrm{km}$, sendo que os valores mais baixos correspondem a linhas de transmissão da classe $220 / 230 \mathrm{kV}$ e os mais altos a linhas da classe $500 / 525 \mathrm{kV}$. Tais valores são indicativos, mas podem ser empregados em cálculos econômicos. Para tensões menores, como as utilizadas neste trabalho, as perdas por dispersão podem ser desprezadas (Fuchs, 1979).

\subsection{2 - PERDAS POR EFEITO JOULE}

Antes de proceder à determinação das perdas por efeito Joule, ressalta-se que nos cálculos econômicos o aumento anual da demanda e, por conseguinte, o aumento da energia a ser transmitida deve ser considerado. Assim, é imprescindível elaborar um estudo da evolução das demandas, que normalmente obedeça à curva da Figura 2-1. Nesse estudo, os cálculos devem ser realizados considerando-se um valor médio da potência a ser transmitida, que pode ser determinado a partir da curva $P=f(n)$ na Figura 2-1, em que $P$ representa a potência e $n$ os anos. A área 
OABCD representa a energia total transmitida em $n$ anos, que corresponde à área retangular OBC'D', cuja ordenada é $P_{n}$. Isso equivale à operação da linha de transmissão durante $n$ anos transmitindo a potência $P_{n}$. Em termos matemáticos, tem-se que a energia transmitida $(E)$ pode ser calculada por (2.3) (Fuchs, 1979).

$$
E=P_{n} \cdot n=P_{O}+\int_{0}^{n_{1}} p(n) \cdot d n+\int_{n_{1}}^{n} P_{\text {máx }} \cdot d n \quad[k W h]
$$

Onde $P_{\text {máx }}$ é o valor máximo da potência transmissível ao final de $n_{1}$ anos e $P_{0}$ é a potência a ser transmitida inicialmente na entrada de serviço da linha.

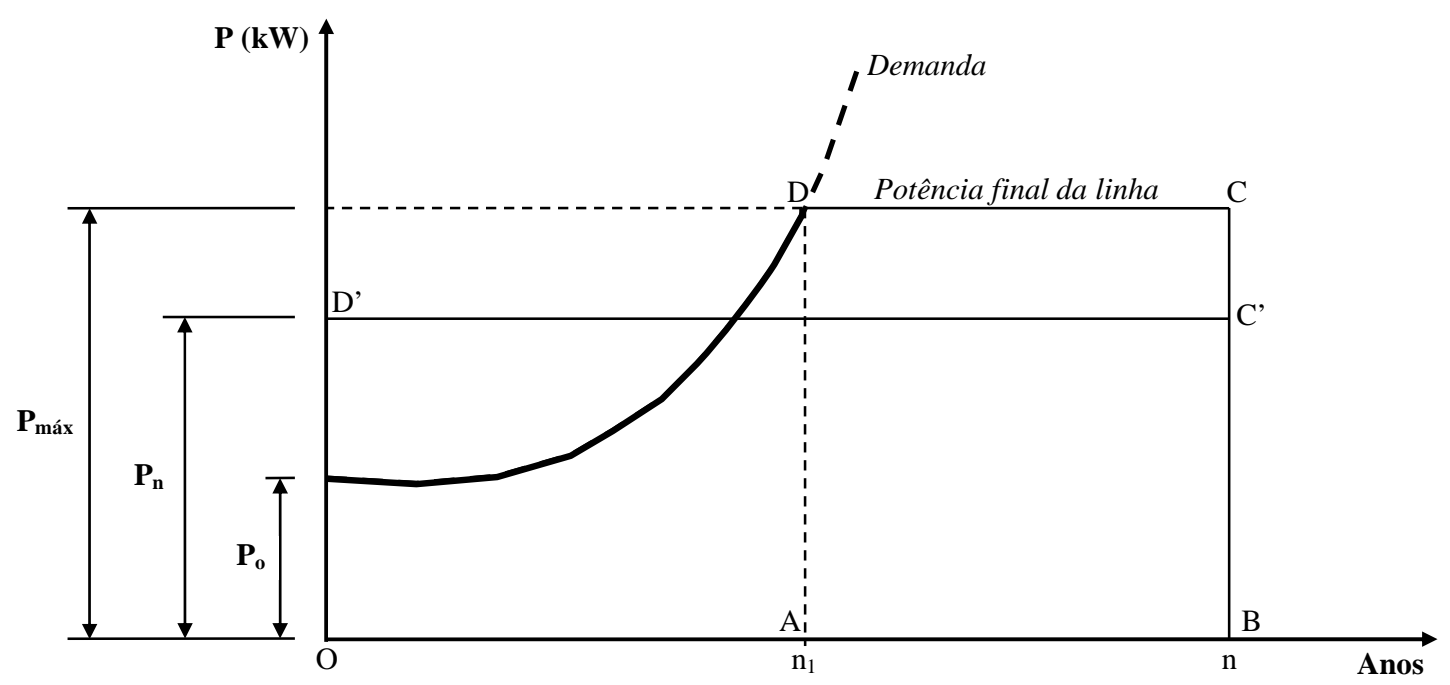

Figura 2-1 - Evolução das potências a serem transmitidas (Fonte: Fuchs, 1979, p. 525).

O valor de $p(n)$ pode ser obtido por (2.4), considerando uma taxa de crescimento anual da demanda igual a $t$, em $n_{1}$ anos.

$$
p(n)=P_{\text {máx }}=P_{O} \cdot(1+t)^{n_{1}} \quad[k W]
$$

Da expressão (2.4), obtém-se o valor de $n_{1}$, conforme (2.5). 


$$
n_{1}=\frac{\ln \left(\frac{P_{\text {máx }}}{P_{O}}\right)}{\ln (1+t)} \text { anos }
$$

Sendo $P_{n}$ a potência média transmitida nos $n$ anos. A potência perdida $(\Delta P)$ pode ser obtida pela expressão (2.6).

$$
\Delta P=3 \cdot I_{n}^{2} \cdot R=3 \cdot\left(\frac{P_{n}}{\sqrt{3} \cdot U \cdot \cos \phi}\right)^{2} \cdot R \quad[k W]
$$

Portanto, a energia perdida em $n$ anos será determinada por (2.7).

$$
\Delta E=3 \cdot 8760 \cdot n \cdot R \cdot\left(\frac{P_{n}}{\sqrt{3} \cdot U \cdot \cos \phi}\right)^{2} \quad[k W h]
$$

Ou, em média por ano:

$$
\Delta E_{n}=3 \cdot 8760 \cdot R \cdot\left(\frac{P_{n}}{\sqrt{3} \cdot U \cdot \cos \phi}\right)^{2} \quad[k W h / a n o]
$$

Nas expressões de (2.6) a (2.8), $\cos \phi$ é o fator de potência no receptor da linha de transmissão, $R$ (medida em $\Omega$ ) é a resistência à corrente alternada determinada na freqüência do sistema e à temperatura de $75^{\circ} \mathrm{C}$.

Tendo em vista que em um sistema elétrico as demandas variam instantaneamente de acordo com a necessidade dos consumidores, os cálculos das perdas por efeito Joule devem considerar essas variações. Para tanto, torna-se necessário definir o fator de carga do sistema elétrico. Esse fator pode contemplar 
horizontes de tempo de um dia, meses ou anos. Nesta seção, será utilizado o fator de carga anual (FC) que pode ser definido por (2.9).

$$
F C=\frac{P_{D m}}{P_{\text {Dmáx }}}
$$

Em que $P_{D m}$ é o valor da demanda média, em kW e $P_{D m a ́ x}$ é o valor da demanda máxima, em kW, considerando um ano de operação.

O fator de carga anual é normalmente menor do que o de um dia típico de operação, porém é mais uniforme. Assim, pode ser considerado fixo durante o período de exame. Essa característica faz com que ele seja muito utilizado para os cálculos econômicos. Portanto, a expressão para o cálculo da energia anual "perdida" devido ao efeito Joule é dada por (2.10).

$$
\Delta E_{n}^{\prime}=3 \cdot 8760 \cdot R \cdot F C \cdot\left(\frac{P_{n}}{\sqrt{3} \cdot U \cdot \cos \phi}\right)^{2} \quad[k W h / a n o]
$$

\subsection{3 - DETERMINAÇÃO DO CUSTO DA ENERGIA PERDIDA}

A determinação dos custos das perdas pode ser tratada como a etapa mais crítica de toda a análise econômica, pois quanto maiores esses custos, maior será também o montante de investimentos necessários para a minimização das perdas. Portanto, devem-se buscar soluções economicamente viáveis que considerem todos os elementos envolvidos, como por exemplo, o custo das perdas e o custo de eventuais alterações nas instalações, dentre outros. 
Neste contexto, segundo Fuchs (1979), há diversos critérios para a fixação do preço da energia perdida, que podem levar a resultados distintos. Para exemplificar, o autor destaca os dois critérios a seguir:

1. A energia "perdida" é considerada como lucro que a empresa deixa de auferir. Assim, considerando $L_{P}$ como sendo o lucro por kWh que a empresa deixa de realizar, tem-se:

$$
C E=3 \cdot 8760 \cdot R \cdot F C \cdot L_{P} \cdot\left(\frac{P_{n}}{\sqrt{3} \cdot U \cdot \cos \phi}\right)^{2} \quad U . M . / \text { ano }
$$

Sendo:

$C E$ - o custo da energia "perdida"; e

U.M. - a unidade monetária.

2. O preço da energia "perdida" é fixado em função de seu custo real no ponto de entrega. Considera-se que o preço do kWh é composto de duas partes: o custo de produção e o custo proporcional à potência máxima perdida $\left(P_{M}\right)$. Neste caso, considera-se também uma parcela de investimentos necessários para suprir as perdas, que deve ser calculada sobre o custo de todas as instalações de produção e obras correlatas, até o ponto de entrega da energia elétrica. Usualmente, a parcela anual é tomada como uma taxa fixa $I$, Portanto, tem-se:

$$
C E=3 \cdot 8760 \cdot R \cdot F C \cdot C_{P} \cdot\left(\frac{P_{n}}{\sqrt{3} \cdot U \cdot \cos \phi}\right)^{2}+3 \cdot R \cdot I \cdot C_{S} \cdot\left(\frac{P_{M}}{\sqrt{3} \cdot U \cdot \cos \phi}\right)^{2} \quad U . M . / \text { ano (2.12) }
$$


Sendo:

$C_{P}$ - o custo da produção de 1 kWh em U.M.; e

$C_{S}$ - o custo da instalação até o ponto de entrega da energia por kW instalado.

Quando se trata de uma linha de interligação entre sistemas, somente a primeira parte de (2.12) deve ser utilizada, sendo $C_{P}$ o preço que a empresa tem que pagar à fornecedora de energia elétrica, no ponto de entrega.

Finalmente, para considerar o aumento do custo da produção de energia elétrica devido ao aumento dos custos dos combustíveis e demais encargos, podese substituir $C_{P}$ em (2.12) por $C_{P} \cdot\left(1+t_{e}\right)^{n}$, em que $t_{e}$ é a taxa anual de aumento dos custos da produção de energia elétrica. Similarmente, uma correção nos custos da instalação pode ser realizada substituindo $C_{S}$ em (2.12) por $C_{S} \cdot\left(1+t_{i}\right)^{n}$, sendo $t_{i}$ a taxa anual de aumento dos preços da instalação de equipamentos e/ou dispositivos no sistema como, geradores, transformadores, condutores, etc.

\section{3 - CÁLCULO DO CUSTO DA INSTALAÇÃO}

Nesta seção, serão apresentados, sucintamente, os principais fatores que influenciam no cálculo dos custos da instalação de uma linha de transmissão. Esses fatores se aplicam tanto ao projeto de uma nova linha quanto a projetos de repotenciação de linhas de transmissão de energia elétrica. Neste último caso, alguns fatores poderão ser desconsiderados em função da técnica de repotenciação adotada. As técnicas alternativas para repotenciação de linhas de transmissão serão abordadas no item 2.4. 
Em linhas gerais, o custo anual da instalação é composto dos seguintes elementos:

- Custo da obra em quotas anuais $\left(\mathbf{C}_{0}\right)$ : diversos estudos devem ser realizados de forma independente para cada solução viável, considerando uma estimativa da vida útil da instalação e um orçamento bastante detalhado da obra. Esses estudos devem abranger:

- estudos adicionais e projetos;

- administração e fiscalização da obra;

- materiais, estruturas, cabos, ferragens, isoladores, fundações, equipamentos de compensação, desapropriações, etc.; e

- mão-de-obra, encargos sociais e trabalhistas.

- Encargos financeiros anuais $\left(\mathbf{C}_{B}\right)$ : devem considerar despesas relativas à obtenção de financiamentos e os juros totais até o final da amortização dos empréstimos.

- Custo anual de manutenção e de operação $\left(\mathbf{C}_{M}\right)$ : deve considerar as despesas previstas para manutenção e operação das linhas, estimadas para o mesmo prazo de amortização do investimento.

Finalmente, o custo anual da linha de transmissão $\left(C_{A}\right)$ será:

$$
C_{A}=\frac{1}{(1+i)^{n}} \cdot\left[\left(C_{O}+C_{M}\right) \cdot\left(1+t_{i}\right)^{n}+C_{B}\right] \quad \text { U.M./ano }
$$

Sendo:

i - a taxa de recuperação do capital; 
$t_{i}-\quad$ a taxa anual de aumento de custos; e

$n$ - o número de anos fixado como vida útil da linha.

No caso da repotenciação de linhas de transmissão, os custos envolvidos podem ser muito inferiores do que os relacionados a novos empreendimentos. Por exemplo, como as faixas de passagem já estão definidas, não há a necessidade de desapropriações. Outro ponto importante, é que, dependendo da técnica adotada para a repotenciação, pode não haver necessidade de substituição das estruturas, cujos custos podem variar enormemente para uma mesma classe de tensão (Fuchs, 1979). Portanto, todas as expressões para o cálculo do custo anual de uma linha de transmissão podem ser utilizadas no caso da repotenciação, desde que as devidas adaptações sejam feitas.

\section{4 - PRINCIPAIS TÉCNICAS DE REPOTENCIAÇÃO}

A repotenciação de linhas de transmissão foi uma alternativa encontrada para aumentar a capacidade da transmissão das linhas já existentes de maneira mais rápida e menos burocrática que a instalação de uma linha nova. Uma das grandes vantagens em repotenciar uma linha de transmissão é o aproveitamento da faixa de servidão já determinada, economizando tempo com a liberação de novas faixas pelo órgão responsável, bem como o custo das indenizações que poderiam vir a existir com a liberação de novas faixas de servidão.

Existem, basicamente, três métodos para aumentar a capacidade de transmissão de uma linha de transmissão. Esses métodos serão sucintamente tratados a seguir. 


\subsection{1 - ALTERAÇÃO DO LIMITE TÉRMICO DA LINHA DE TRANSMISSÃO}

O limite térmico reflete diretamente nas características termodinâmicas da linha de transmissão e determina a máxima corrente elétrica que ela pode transportar até atingir a temperatura limite definida em projeto. No entanto, a máxima corrente elétrica (ampacidade) é influenciada pelas condições ambientais locais, como os ventos e a temperatura ambiente. Estudos mostram que a variação da velocidade dos ventos e da temperatura ambiente podem tanto provocar uma redução da ampacidade da ordem de $35 \%$, quanto aumentos superiores a $100 \%$, em relação aos dados de projeto da linha de transmissão (Oliveira, 2000).

\subsection{2 - RECONDUTORAMENTO DA LINHA DE TRANSMISSÃO}

Basicamente, essa alternativa consiste em substituir os condutores da linha de transmissão existente por outros com maior capacidade de condução de corrente, tentando manter as condições mecânicas dos condutores antigos, evitando assim o reforço das estruturas. Neste contexto, existem várias técnicas de recondutoramento, cuja escolha está condicionada a estudos de viabilidade técnica e econômica (Silva e Baumann, 1997; Oliveira, 2000). As principais técnicas são citadas a seguir e serão discutidas no item 3.3:

- recondutoramento mantendo 1 condutor por fase;

- recondutoramento com a instalação de mais um subcondutor por fase;

- recondutoramento com expansão do feixe de subcondutores existentes; e 
- recondutoramento utilizando cabos termorresistentes.

\subsection{3 - ELEVAÇÃO DA TENSÃO OPERATIVA DA LINHA DE TRANSMISSÃO}

Nesta alternativa, a tensão de operação da linha de transmissão é elevada mantendo-se os condutores atuais. Trata-se de um procedimento que requer amplas modificações no sistema elétrico, pois além da linha afetada, as subestações nas quais ela está ligada devem ser adaptadas para o novo nível de tensão. As possíveis reformas na linha e a necessidade de um novo isolamento possibilitam aumentar sua capacidade de transmissão de maneira rápida, proporcionando um aumento da confiabilidade de operação, com custos em torno de $15 \%$ a $20 \%$ dos custos de uma linha de transmissão nova (Oliveira, 2000).

Ressalta-se, nesse momento, que essa será a alternativa aplicada neste projeto. Maiores detalhes do porque da escolha desta alternativa serão posteriormente colocados.

\section{5 - TRABALHOS TÉCNICO-CIENTÍFICOS DEFENDIDOS SOBRE A REPOTENCIAÇÃO DE LINHAS DE TRANSMISSÃO}

No contexto delineado, Silva e Baumann (1997) avaliaram as possíveis alternativas para a repotenciação de uma linha de transmissão de circuito duplo de 138 kV. O trabalho apresenta uma avaliação paramétrica das alternativas consideradas no estudo de viabilidade, definindo em linhas gerais as alterações necessárias em cada alternativa e fornecendo estimativas de custos e parâmetros elétricos. A repotenciação foi cogitada no sentido de se reduzir perdas e também 
como alternativa para garantir o suprimento à ENERSUL (Empresa Energética do Mato Grosso do Sul) no caso de atraso da geração térmica a gás prevista para aquele estado.

A avaliação paramétrica abordada estabelece o aumento do SIL (capacidade de transporte de potência de uma linha) e a redução de perdas de cada alternativa em relação à situação atual. Já a análise da viabilidade econômico-financeira das alternativas determina os benefícios (vendas adicionais e redução de perdas) e

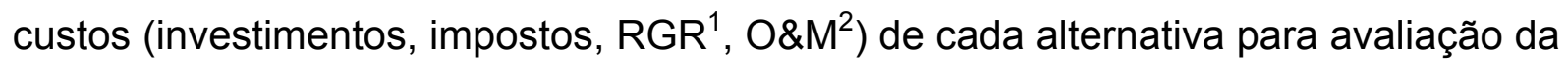
receita líquida anual e da taxa interna de retorno. Cabe ressaltar que os custos são preliminares e têm por objetivo indicar as alternativas mais promissoras, que, numa outra fase, seriam analisadas em maior detalhe quanto à viabilidade técnica e desempenho operacional.

De acordo com a avaliação dos autores, as duas melhores alternativas do ponto de vista econômico são:

a) O recondutoramento mantendo o condutor existente e lançando um novo condutor fino e paralelo, com a função exclusiva de melhorar o SIL da linha.

b) O recondutoramento em conjunto com a elevação da tensão de operação da linha.

A primeira alternativa apresenta receita líquida mais constante, as melhores taxas de retorno e o menor nível de complementação do investimento, no caso de vida econômica reduzida e, ainda, é a alternativa que exige o menor nível de

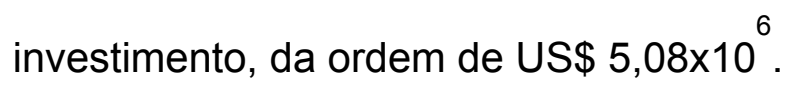

\footnotetext{
${ }^{1}$ Reserva Global de Reversão (RGR), estipulada pelo Governo Federal em 1971. Em 1999, a ANNEL impôs para todas as distribuidoras de energia um pagamento de 2,5 a $3 \%$ do total de sua receita operacional.

${ }^{2}$ Custos de Operação e Manutenção (O\&M).
} 
Já para o caso da segunda alternativa de repotenciação, os autores a consideraram em duas etapas. Na primeira se faria o recondutoramento, e na segunda, diante de uma possível frustração da geração térmica no Mato Grosso do Sul, se faria a elevação de tensão.

Conforme apresentado pelos autores, observou-se que a vida útil econômica é um dos fatores de maior impacto na viabilidade das soluções propostas e, avaliando essas alternativas sob a incerteza deste fator, observa-se que 0 recondutoramento é que se revela mais robusto num cenário mais conservador. A elevação da tensão em conjunto com o recondutoramento só se viabiliza numa perspectiva mais otimista quanto à vida útil da linha.

Moreira et. al. (1999) enfatizam que as empresas concessionárias de energia elétrica necessitam urgente e rapidamente aumentar a capacidade de transmissão das suas redes de energia elétrica, com qualidade e custos mínimos, visando à redução dos crescentes riscos de racionamento. Nesse trabalho, os autores afirmam que o reisolamento e as reformas de linhas de transmissão (LTs) na COPEL (Companhia Paranaense de Energia) têm permitido incrementar de uma maneira rápida e significativa a capacidade de transmissão com o conseqüente aumento na confiabilidade na operação a um custo de 15 a $20 \%$ do valor de uma LT nova. O objetivo do trabalho foi o de descrever a experiência da COPEL nas soluções adotadas para o reisolamento e reforma de 21 linhas de transmissão no período de 1982 a 1997. Nesse período foram reisolados $1.152 \mathrm{~km}$ de LTs, ou seja, $17,8 \%$ da totalidade do seu sistema de transmissão na época. Destes $1.152 \mathrm{~km}$ de linhas reisoladas, 835,3 km correspondem ao reisolamento de $69 \mathrm{kV}$ para $138 \mathrm{kV}$ e 316,7 km de 88 kV para 138 kV. As primeiras LTs reisoladas estão em operação desde 1983 e os dados sobre desligamentos coletados até a data da publicação do 
trabalho indicam que o desempenho destas é equivalente ao das outras linhas de $138 \mathrm{kV}$. Logo, os autores apontam que, apesar das diversas dificuldades encontradas, o reisolamento é uma medida economicamente conveniente e tecnicamente viável.

Segundo Oliveira (2000), a crescente demanda do sistema elétrico brasileiro e a preocupação ambiental requerem estudos para que seja ampliada a capacidade de transmissão sem deixar de satisfazer nenhuma dessas questões. Assim, torna-se fundamental o desenvolvimento de técnicas que permitam aumentar a capacidade de transporte de energia a baixo custo com as instalações existentes. Neste meio, a recapacitação de linhas aparece como uma alternativa a ser analisada. O trabalho apresenta alternativas de técnicas de recapacitação de linhas de transmissão, segundo a ótica do dimensionamento elétrico e da determinação das distâncias mínimas de coordenação de isolamento necessárias na torre. Busca-se então, maximizar a energia transportada por área ocupada pela faixa da linha de transmissão. Neste sentido, reduz-se a necessidade de negociação de novas faixas de passagens e o impacto ambiental, bem como, dá-se uma maior agilidade na ampliação da capacidade de transporte da malha existente.

É necessário também, segundo a autora, que o solo e a topografia da região do traçado da linha em operação sejam conhecidos, além de realizar um enfoque detalhado sobre as condições ambientais destas regiões, não só para o dimensionamento elétrico, mas também para as condições mecânicas das torres.

A autora conclui que a recapacitação das linhas de transmissão em operação é possível para a maioria dos casos e enfatiza que os levantamentos de dados meteorológicos reais da região de cada linha em questão devem ser estudados com o intuito de se alcançar a recapacitação otimizada dessa linha. 
Conforme o exposto pode-se inferir que as técnicas de recapacitação, que permitam a continuidade da operacionalidade da linha para sua implantação estão em vantagem em relação às demais. Dentre elas, a alteração do limite térmico da linha ou a mudança da tensão nominal devem ser analisadas, considerando-se o sistema elétrico interligado como um todo, admitindo as subestações existentes, seus níveis de tensão e a alteração dos fluxos de potência nas linhas devido a estas mudanças.

Já em Da Costa et al. (2001), encontram-se estudos desenvolvidos no sentido de avaliar a possibilidade de recapacitação de uma linha de transmissão do sistema da EPTE (Empresa Paulista de Transmissão de Energia Elétrica). Dentre outros aspectos, são abordados critérios de projeto, atendimento à potência requerida a médio e longo prazo, análises estruturais das torres e fundações, reforços, avaliação de corrosão nos elementos enterrados, estimativa das perturbações elétricas previstas e proposição de medidas mitigadoras de impactos ambientais, uma vez que parte da linha de transmissão está inserida em área de preservação ambiental. Com a repotenciação, mesmo que haja a necessidade de substituição de algumas estruturas, principalmente as submetidas a elevadas solicitações mecânicas, o caráter impactante da linha é significativamente atenuado, sobretudo em função da aplicação de técnicas construtivas que venham a dispensar a remoção da vegetação nativa. Conclusões preliminares desse trabalho conduzem para a possibilidade de reaproveitamento de parcela considerável das torres de transmissão instaladas permitindo, desta forma, a mudança da classe de tensão de 230 kV para 345 kV. Considerando avaliações relativas à previsão de demanda futura e a necessidade de conexões adicionais para a confiabilidade do sistema interligado, os autores afirmam que a proposta apresentada se mostra bastante 
interessante, tanto do ponto de vista econômico quanto aos aspectos de redução dos impactos ambientais decorrentes da implantação de linha de transmissão em área de preservação ambiental. Além disso, segundo as previsões de alterações do setor elétrico brasileiro na época de publicação do trabalho, sua proposta apresentase ainda mais atraente do ponto de vista financeiro, pois a repotenciação viria a atender às necessidades em médio prazo, cerca de 7 a 8 anos, reduzindo 0 investimento imediato por parte dos poderes públicos. Finalmente, os autores recomendam que, sempre que possível, a alternativa de repotenciação de linhas de transmissão deve ser avaliada nos estudos preliminares de ampliação do sistema elétrico face às sensíveis reduções de custo que podem ser obtidas.

Fonseca e Cimini (2003) apresentam uma análise da vida útil de cabos condutores de alumínio com alma de aço (CAA) para linhas aéreas de transmissão de energia elétrica em função de seu limite de resistência mecânica à tração e à fadiga. Fatores da vida útil são apresentados juntamente com uma metodologia implementada para essa análise. Uma vez que a análise da viabilidade do projeto de repotenciação em questão utiliza os mesmos cabos condutores já presentes nas linhas, um estudo do envelhecimento dos cabos fez-se mais do que necessário. A metodologia implementada apresenta resultados conservativos em relação à perda de resistência mecânica do cabo condutor. O valor calculado pela metodologia é $136 \%$ acima do valor encontrado nos ensaios. O trabalho também apresentou resultados conservativos em relação à análise da perda da resistência à fadiga do cabo condutor nos casos de recapacitação. Conforme apontado pelos autores, nos casos em que a linha de transmissão manteve suas características originais, foi necessário o desenvolvimento de curvas que representassem os diferentes níveis de tensão dinâmica que o condutor estaria submetido e a quantidade de ciclos 
representativos destes níveis de tensão. Com essas curvas foi possível analisar a influência das características da região sobre a vida útil do cabo condutor. Para os casos de recapacitação de linha de transmissão, o resultado final apresenta-se conservativo em relação à análise tanto de perda de resistência mecânica quanto à fadiga. Por outro lado, para linhas de transmissão com suas características originais (linhas novas), o resultado final se mostra conservativo somente em relação à vida útil residual devido à perda de resistência mecânica, ou seja, para análise da resistência à tração do cabo condutor. Paralelamente a essas conclusões, os autores afirmam que novos estudos e ensaios são necessários com o objetivo de otimizar a metodologia e reduzir a diferença entre os resultados práticos e teóricos.

Dutra et. al. (2005) tratam de uma contribuição técnica que apresenta a experiência da Eletrosul Centrais Elétrica S.A. na recapacitação de linhas de transmissão em $230 \mathrm{kV}$. O trabalho consistiu na troca do cabo condutor ACSR (Aluminum Conductor Stell Reinforced) Grosbeak existente, pelo cabo termoresistente TACSR (Thermal-resistent Aluminum-alloy Conductors, Aluminum-clad Steel-reinforced) Grosbeak e a recapacitação no reforço de suportes auto-portantes de aço galvanizado. São relatados aspectos que levaram à escolha desta solução, aspectos de engenharia de projeto e construção, ensaios dos materiais, critérios de projeto e execução de reforços dos suportes. Os resultados mostraram que a Eletrosul aumentou a capacidade de transmissão de energia das linhas repotenciadas em $50 \%$, sendo necessário um investimento reduzido em relação à construção de uma nova linha de transmissão. Um aspecto importante é que se utilizou a mesma faixa de segurança, reduzindo a zero os impactos ambientais e sociais do recondutoramento, que seriam significativos, caso se optasse pela construção de novas linhas. Além disso, outro benefício da repotenciação foi o 
atendimento aos curtos prazos estabelecidos para a viabilização das obras, tendo em vista que estas foram consideradas emergenciais. A recapacitação e repotenciação dessas linhas resultaram em um benefício sistêmico, reconhecido pelo ONS, sendo a empresa transmissora ressarcida dos custos envolvidos.

Stephan e Costa (2007) apresentam a experiência da Eletrosul na recapacitação e repotenciação de linhas de transmissão em 138, 230 e 500 kV, fazendo uma síntese dos principais procedimentos para análise e verificação da adequação de uma linha de transmissão, tendo em vista sua repotenciação e/ou recapacitação. Esses autores apresentam também procedimentos efetuados durante as fases de estudo de viabilidade técnico-econômica, anteprojeto, projeto e construção das linhas repotenciadas e/ou recapacitadas. Nesse trabalho são apresentados os conceitos sobre os quais foram baseados os critérios de avaliação dos componentes das linhas, como suportes e fundações, bem como os principais aspectos das metodologias utilizadas para tal.

Silva et.al. (2007) abordam a reforma da linha de transmissão de $230 \mathrm{kV}$ que interliga a subestação de Bandeirantes à subestação de Brasília Geral, construída em 1959/1960 e transferida a FURNAS Centrais Elétricas S.A. em 1971. Essa linha vinha operando com pouca carga e, mesmo assim, apresentava diversos vãos com cabo baixo, que eram corrigidos, caso a caso, pelas equipes de manutenção de FURNAS. Ficou definido que essa linha iria alimentar a Subestação (SE) Pirineus, o que ocasionaria o aumento da carga e o agravamento do problema de cabo baixo. Tal fato acarretou a necessidade de realizar uma reforma da linha em larga escala. Assim, o trabalho consistiu em descrever o levantamento de campo, os estudos, as soluções adotadas e os trabalhos de campo realizados para esta reforma. A metodologia adotada para a reforma da linha em questão se mostrou altamente 
eficiente e econômica. O trabalho todo, contando com as interrupções causadas por problemas de autorização para desligamentos e atraso na entrega de materiais foi realizado em 189 dias corridos. O custo total do empreendimento foi de $\mathrm{R} \$$ 2.287.477,57 (dois milhões, duzentos e oitenta e sete mil, quatrocentos e setenta e sete reais e cinqüenta e sete centavos). O custo ELETROBRÁS de uma linha nova de 230 kV similar, com 160 km, seria de $R \$ 41.479 .606,40$ (quarenta e um milhões, quatrocentos e setenta e nove mil, seiscentos e seis reais e quarenta centavos). Portanto, o custo da reforma correspondeu a 5,5\% do custo de uma LT similar nova, com um prazo de execução muito menor.

Como observado, a repotenciação de linhas de transmissão vem sendo estudada no Brasil há mais de vinte anos, devido às urgentes necessidades em expandir tanto a produção quanto a distribuição de energia elétrica, em virtude do acentuado desenvolvimento econômico e do significativo crescimento populacional que o país tem apresentado.

Pelo que se expôs anteriormente, é possível observar que os estudos apresentados buscam sempre a otimização da transmissão de energia tendo em conta, como fator determinante, os resultados econômicos.

De fato, admite-se que a repotenciação exige um estudo econômico para a determinação de qual método se adotará para realizá-la.

Nessa dissertação, porém, não serão realizados estudos econômicos pelo fato de a empresa concessionária que realizará a operação apresentar um interesse propriamente técnico para alterar o nível de tensão de todas as suas linhas de 34,5 kV para $69 \mathrm{kV}$.

Cabe frisar que o presente trabalho caracteriza-se em verificar a possibilidade de realizar a repotenciação dessas linhas, em vez de desativá-las e 
construir novas linhas em seus lugares. A meta, doravante, será apresentar os principais passos necessários para a repotenciação de linhas, desde o início dos estudos, à escolha do método e ao encaminhamento da obra.

No capítulo que segue, será analisado um procedimento em específico a ser aplicado no processo da repotenciação das linhas de transmissão em interesse. 


\section{Capítulo 3 \\ Procedimento a ser Aplicado para a Repotenciação de Linhas de Subtransmissão}

Como anteriormente apresentado, o objetivo deste trabalho é estabelecer um procedimento para a repotenciação de linhas de subtransmissão, tomando-se como exemplo uma linha de $34,5 \mathrm{kV}$. É importante ressaltar que esta pesquisa, poderá servir como base ou parâmetro para a execução de outros serviços em redes da mesma natureza.

Com este intuito, será utilizado um fluxograma, representado na Figura 3-1, com o objetivo de ilustrar os principais passos a serem tomados durante os estudos de repotenciação de linhas de transmissão.

De uma maneira bem didática, visando facilitar o entendimento do leitor, o fluxograma será apresentado em duas partes. Na primeira parte, tem-se um fluxograma principal (Figura 3-1) e, na segunda, outros dois, sendo os três utilizados no desenvolvimento do trabalho como um todo.

O fluxograma da Figura 3-8, será empregado para melhor explicar o método de elevação da tensão operativa da linha, e o da Figura 3-9, para analisar os passos durante as simulações computacionais pertinentes ao estudo.

Vale ressaltar que, apesar de serem tratados três métodos de repotenciação, a ênfase recairá sobre o método de elevação do nível de tensão, uma vez que a CPFL (Companhia Paulista de Força e Luz), empresa concessionária com a qual foi feita uma parceria para o desenvolvimento desta pesquisa, 
demonstrou maior interesse por essa face da questão, devido às suas linhas apresentar características que tornam esse método de repotenciação mais atrativo quando comparado aos demais. Essas características serão explicitadas no item 3.1 que segue.

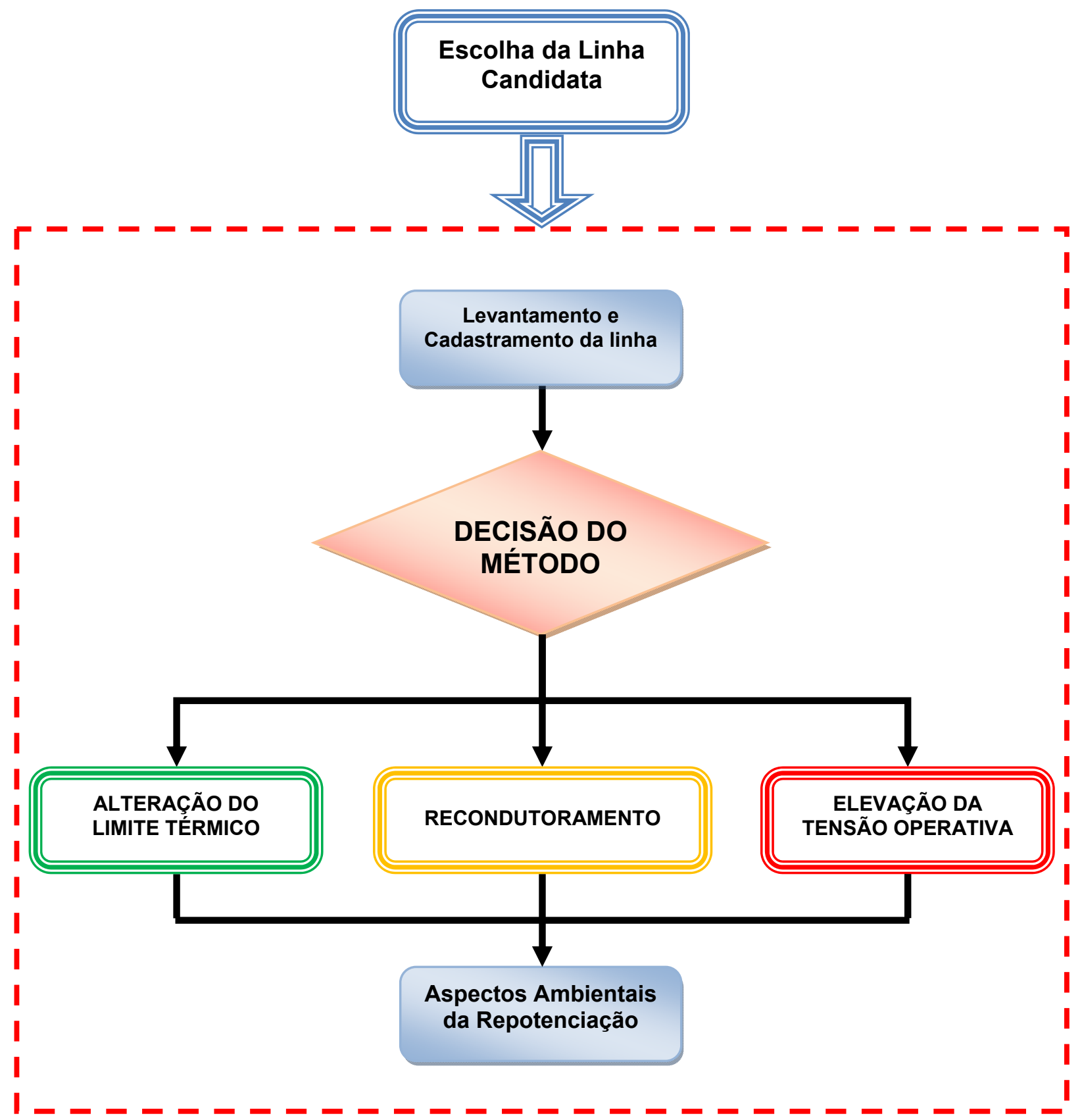

Figura 3-1- Principais passos a serem tomados durante os estudos de repotenciação de linhas de transmissão. 
A seguir, serão tratados com mais detalhes os itens mencionados no fluxograma acima apresentado.

\section{1 - ESCOLHA DA LINHA CANDIDATA À REPOTENCIAÇÃO}

De uma maneira em geral, levantaram-se pontos favoráveis e desfavoráveis que podem ser observados nas linhas quanto à repotenciação.

Dentre os pontos favoráveis (positivos), e que devem ser considerados na escolha do sistema, tem-se:

- A existência do sistema de 69 kV em uma das subestações, o que facilitaria a ligação da linha de 34,5 kV à classe escolhida.

- Configurações com linhas curtas e sem clientes a elas conectados.

- Linhas com necessidade de obras de melhorias.

Já entre os pontos desfavoráveis (negativos), observaram-se os seguintes itens:

- Algumas linhas apresentavam a responsabilidade de alimentar de forma isolada cidades próximas.

- Conexão entre três subestações, o que viria a dificultar manobras para a conversão física.

- Dificuldade de obras, como por exemplo, a localização da linha sobre área urbana.

\subsection{1 - ANÁLISES DAS LINHAS CANDIDATAS}

Como já comentado anteriormente, esse trabalho foi realizado em conjunto com uma concessionária de energia elétrica regional que se propôs a disponibilizar 
quatro linhas para a realização dos estudos. Essa disponibilização se deve ao fato da intenção da empresa em eliminar de seu quadro de linhas, futuramente, as que operam em $34,5 \mathrm{kV}$. Neste intuito, esse conjunto de quatro possíveis linhas, candidatas à repotenciação, foi analisado. Cabe frisar que destas quatro, apenas uma foi utilizada no seguimento dos estudos relacionados à repotenciação, muito embora, todas elas apresentassem viabilidade técnica para tal procedimento. A seguir são tratados alguns pontos referentes às quatro linhas analisadas e que foram decisivos para a definição da linha para o primeiro estudo de repotenciação.

\section{Linha: Usina Salto Grande - Souzas}

A linha de transmissão responsável por transmitir a energia gerada pela pequena usina hidrelétrica de Salto Grande até o distrito de Souzas, localizada na região de Campinas, foi uma das possíveis linhas a ser repotenciada. A linha possui um comprimento total de $8,9 \mathrm{~km}$ e opera na classe de tensão de $34,5 \mathrm{kV}$.

Essa linha conta com pontos positivos e negativos à sua repotenciação que serão listados abaixo:

Pontos positivos:

- A existência do sistema de $69 \mathrm{kV}$ na subestação (SE) de Souzas facilitaria a ligação da linha de 34,5 kV na classe de tensão de 69 kV.

- Possibilidade de conexão com a linha de 69 kV entre Souzas e Itatiba.

- Redução de aproximadamente $1,5 \mathrm{~km}$ da linha, pois será eliminado o trecho que atravessa dois condomínios.

- Possibilidade das cargas conectadas próximas a PCH (Pequena Central Hidrelétrica) de Salto Grande serem alimentadas pela própria PCH. 
- Linha curta e sem clientes conectados à mesma.

Pontos negativos:

- Necessidade de ser realizada uma análise de conexão desta PCH para outras SEs, devido à existência de cargas essenciais alocadas próximas à $\mathrm{PCH}$ de Salto Grande.

\section{Linha: Usina Jaguari - Morungaba}

Essa linha é responsável pela ligação da usina de Jaguari até o município de Morungaba, localizado a $45 \mathrm{~km}$ de Campinas. Essa linha possui uma extensão total de 11,6 km. Apesar de ser uma das candidatas, ela apresenta um fator negativo que é a responsabilidade de alimentar de forma isolada a cidade de Morungaba. Outros pontos de prós e contras quanto à repotenciação dessa linha seguem abaixo.

Pontos positivos:

- Uma futura e eminente conversão física da LT 34,5 kV Usina Jaguari-Souzas para $69 \mathrm{kV}$.

Pontos negativos:

- Indefinição dos prazos do PESE (Plano de Expansão da Transmissão).

- Conexão entre três SEs dificultando manobras para a conversão.

- Única fonte de energia para a cidade de Morungaba.

- Consumidor Tecelagem Alpina. 


\section{Linha: Usina Gavião Peixoto - Tabatinga}

A usina de Gavião Peixoto é interligada a Tabatinga, que fica localizada a 125 km de Ribeirão Preto, e faz parte da mesorregião de Araraquara. Essa linha possui um comprimento total de $27 \mathrm{~km}$ e como todas as outras analisadas, possui pontos positivos e negativos, os quais estão listados abaixo:

Pontos positivos:

- Existência do sistema de 69 kV na subestação de Gavião Peixoto.

- Fim do sistema de 34,5 kV em Gavião Peixoto.

Pontos negativos:

- Possui cliente (Usina Santa Fé) conectado ao longo da linha.

- Dificuldade de obras, pois um grande trecho da linha está localizado sobre área urbana (Gavião Peixoto e Nova Europa).

- Única fonte de energia para a cidade de Tabatinga;

\section{Linha: Araçatuba - Santo Antônio do Aracanguá}

Essa linha de transmissão interliga a Subestação de Araçatuba a Santo Antônio do Aracanguá, localizada a aproximadamente 37 km de Araçatuba.

O comprimento total dessa linha é de $31,7 \mathrm{~km}$. Essa distância, elevada com relação às demais linhas analisadas, já é um ponto negativo a ser considerado. Outros pontos positivos e negativos com relevância estão listados a seguir. 
Pontos positivos:

- Existência do sistema de $69 \mathrm{kV}$ na subestação de Araçatuba.

- Linha com necessidade de obras de melhorias.

- Eliminação do sistema 34,5 kV na subestação de Araçatuba.

- Liberar o bay de $15 \mathrm{kV}$ para a distribuição.

Pontos negativos:

- Cliente conectado ao longo da LT (DAE Água e Esgoto S/A).

- Única fonte de energia para a cidade de Santo Antônio do Aracanguá;

\subsection{2 - ESCOLHA DA LINHA CANDIDATA}

Dentre as quatro linhas analisadas, a linha que parte da Usina Salto Grande até a Subestação Souzas foi a que apresentou uma maior facilidade para o estudo de repotenciação.

Deve-se enfatizar o fato de que a linha escolhida apresenta um comprimento de aproximadamente $8,9 \mathrm{~km}$, o menor dentre as quatro candidatas, significando, por via de conseqüência, o menor custo quando da necessidade inicial de um levantamento e cadastramento da rede, uma vez que normalmente o custo do referido levantamento é calculado por quilômetro de linha.

Outro ponto favorável e que deve ser ressaltado, é a ausência de cargas conectadas na linha escolhida, o que facilitará um eventual teste do comportamento da linha com a elevação da tensão de operação de 34,5kV para 69 kV.

Para fins ilustrativos, apresentam-se a seguir, nas Figuras de 3-2 a 3-7, as diferentes estruturas encontradas na LT escolhida. 
A Figura 3-2 apresenta uma estrutura do tipo "G" (Padrão CPFL (a)). Da inspeção visual realizada em campo, observou-se que a isolação é feita através de uma cadeia de isoladores em quantidade adequada para a operação na classe de $69 \mathrm{kV}$, porém, o pino de jumper é para a classe de $34,5 \mathrm{kV}$. Além disso, foi constatado durante a inspeção visual que a condição de conservação dos materiais como poste, cruzeta, isoladores e demais acessórios não estava adequada.

A Figura 3-3 apresenta uma estrutura do tipo "A" (Padrão CPFL(b)), com todos os acessórios em bom estado de conservação. Porém, a estrutura possui isoladores do tipo pino de $34,5 \mathrm{kV}$. Pode-se adiantar que essa estrutura deverá sofrer alterações para a realização da elevação da tensão operativa da linha.

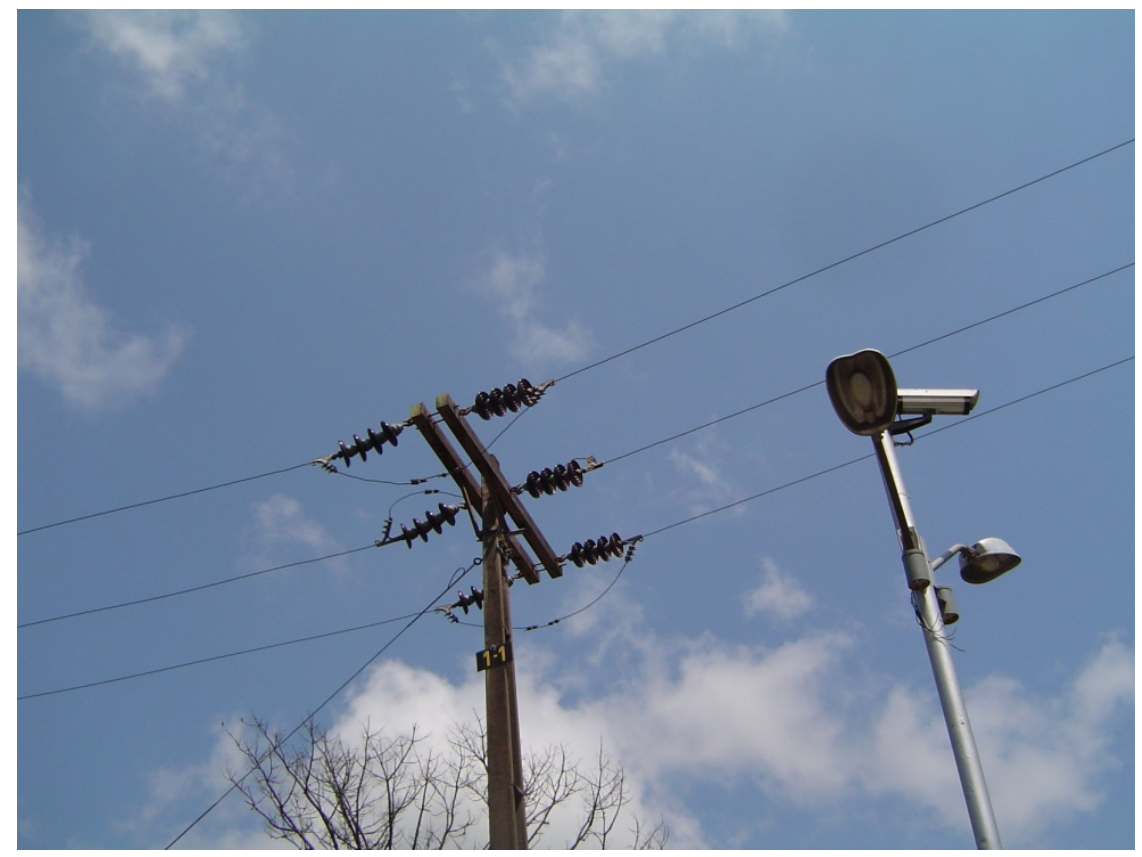

Figura 3-2 - Estrutura do Tipo "G" 


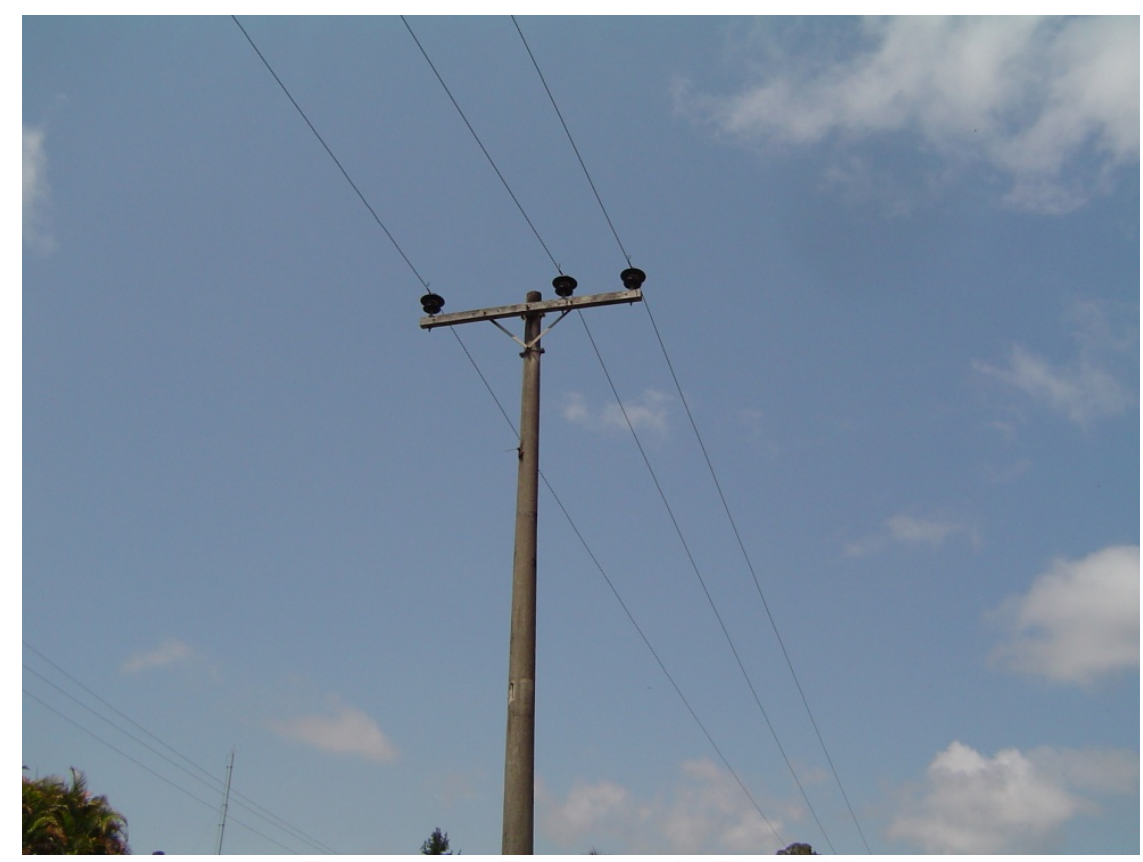

Figura 3-3 - Estrutura do Tipo "A"

A Figura 3-4 apresenta uma estrutura do tipo "B", com as mesmas características de isolação da estrutura anterior (Padrão CPFL(c)).

Observa-se na Figura 3-5, uma estrutura do tipo "E" com dimensões diferentes das anteriores (Padrão CPFL(d)). Apesar do espaçamento dos condutores serem maior do que as estruturas anteriores, os isoladores nessa estrutura são da classe de $34,5 \mathrm{kV}$.

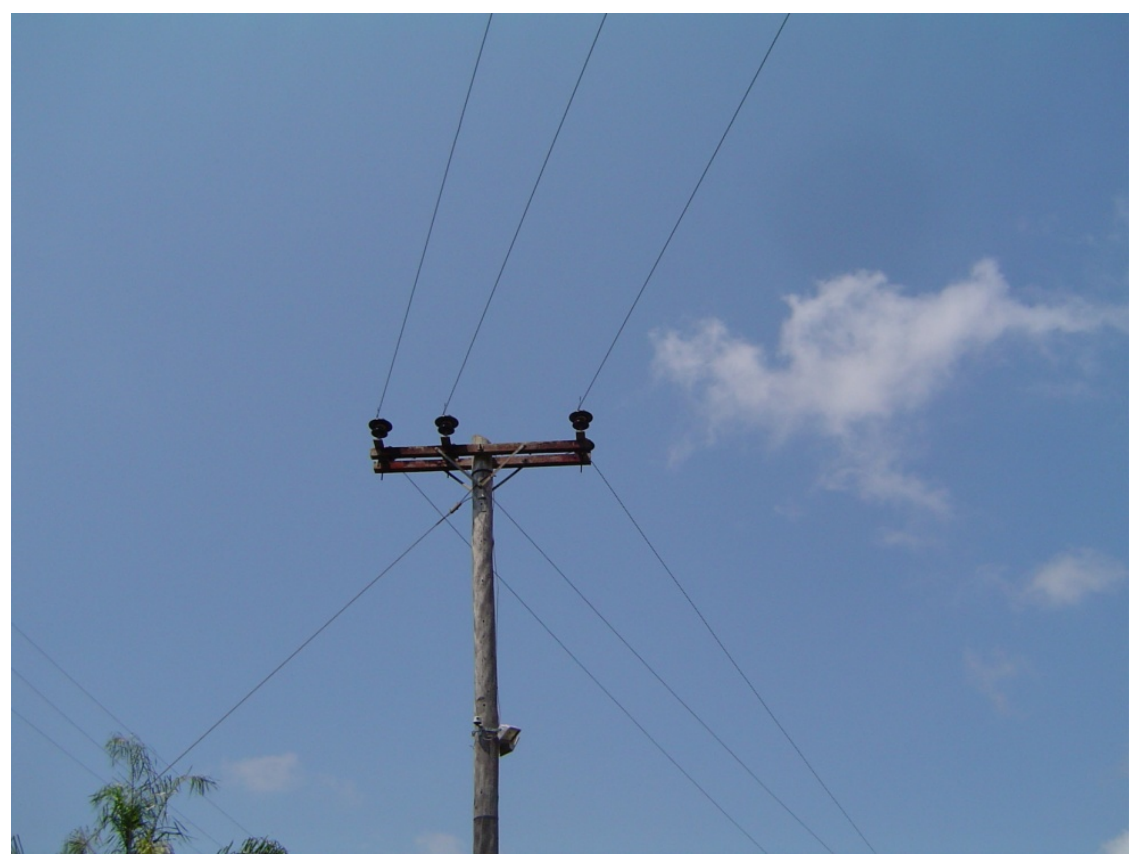

Figura 3-4 - Estrutura do Tipo "B" 


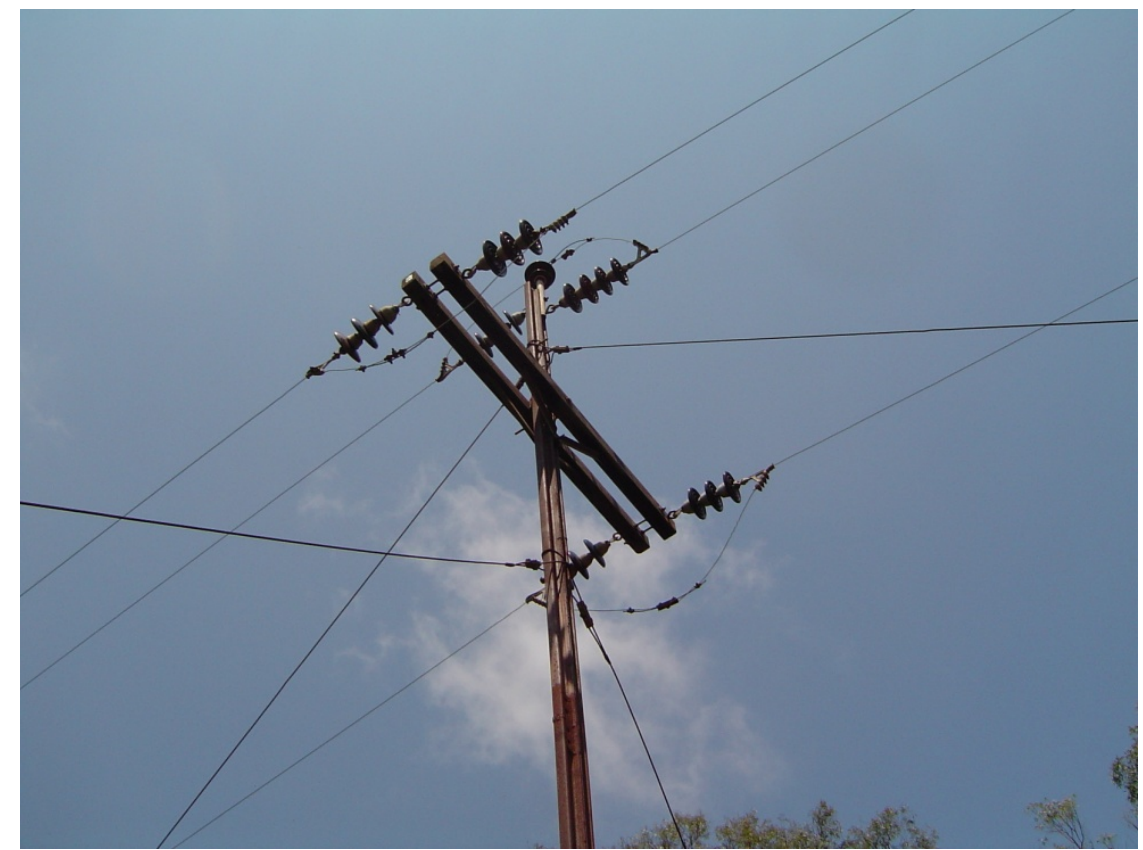

Figura 3-5 - Estrutura do Tipo "E"

Na Figura 3-6 tem-se uma estrutura que apresenta um espaçamento bem maior do que as anteriores e com uma cadeia de isoladores em suspensão adequada para a classe de 69 kV (Padrão CPFL(e)).

A estrutura apresentada na Figura 3-7, apresenta dimensões semelhantes à mostrada na figura anterior, porém, os isoladores dessa estrutura são da classe de 34,5 kV (Padrão CPFL(f)).

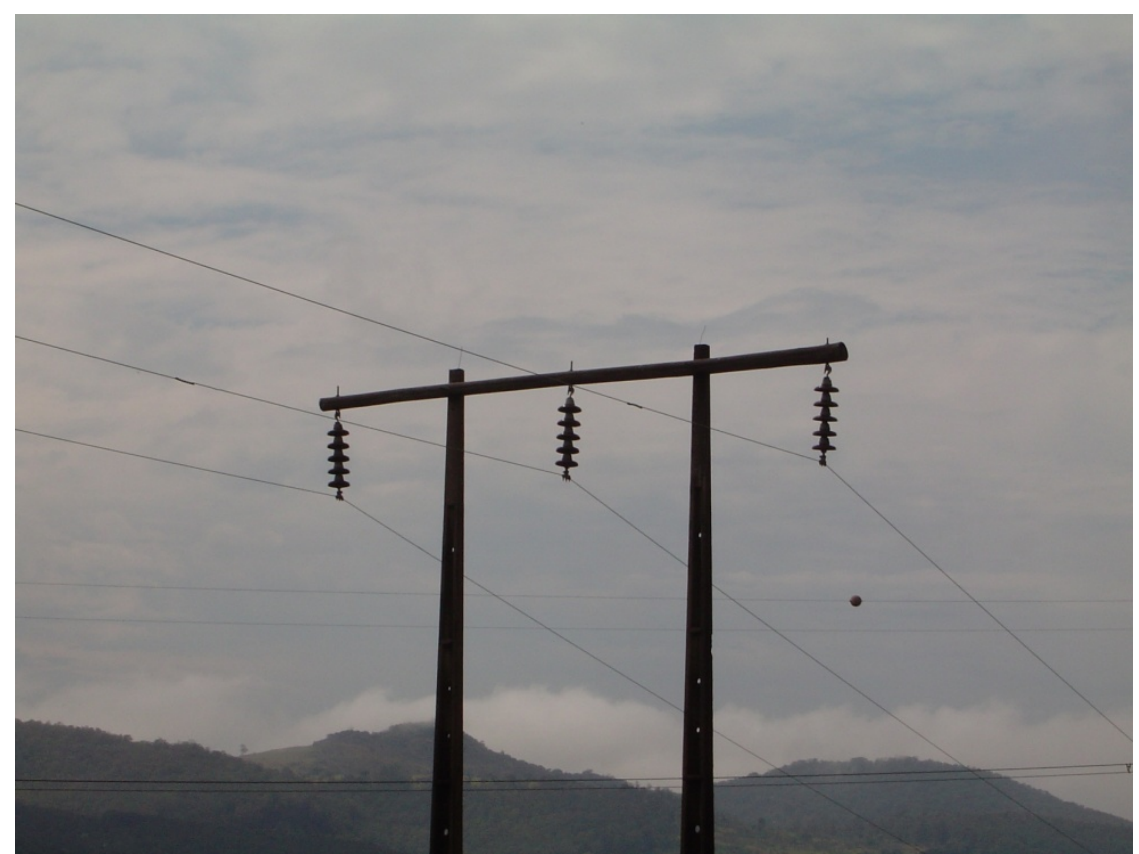

Figura 3-6 - Estrutura do Tipo "HS" 


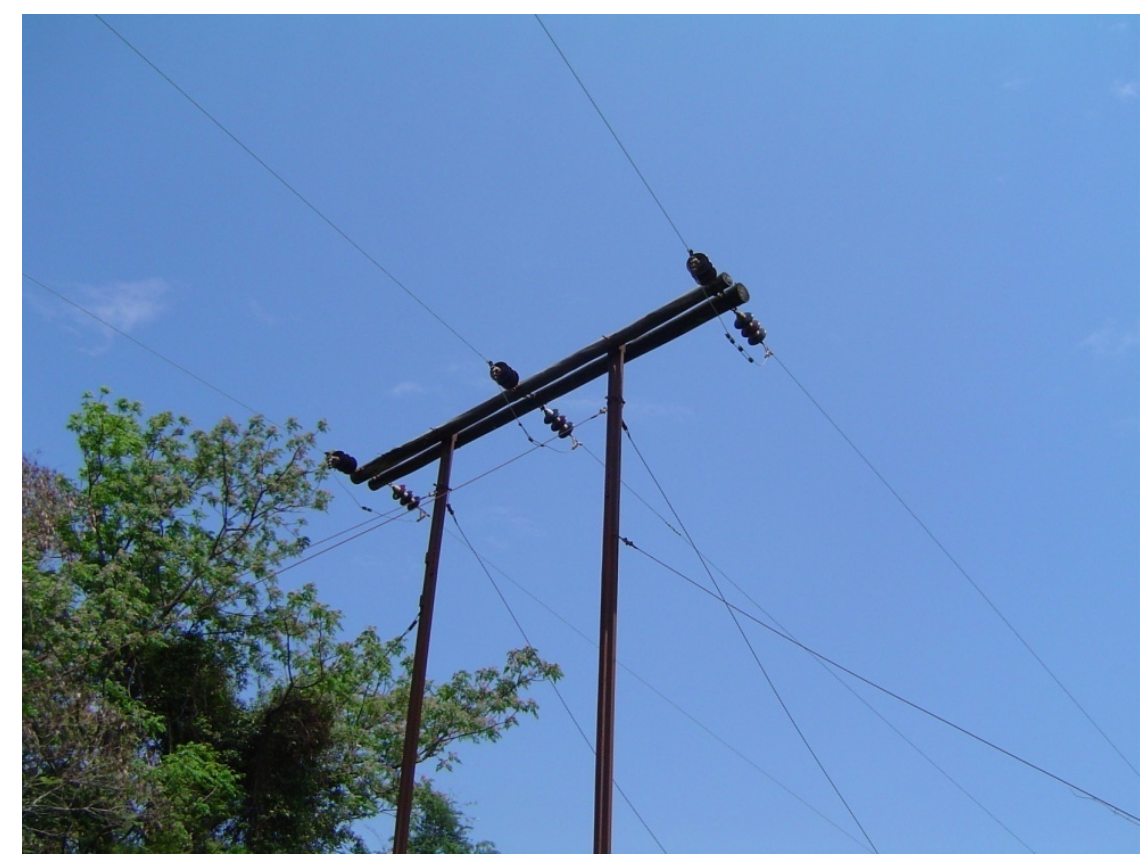

Figura 3-7 - Estrutura do Tipo "HT"

Pelas fotos apresentadas, pôde-se notar que algumas estruturas que fazem parte dessa linha são mais robustas com relação à isolação, como as estruturas do tipo "HT" - Padrão CPFL(f), "HS" - Padrão CPFL(e) e "E” - Padrão CPFL(d), as quais apresentam um bom espaçamento entre as fases, e isoladores mais robustos do que os do tipo pino encontrados nas estruturas tipo "A" e "B". Essas são algumas das informações que deverão ser analisadas durante a etapa de levantamento e cadastramento da linha em campo, que será inclusa na metodologia de repotenciação de linhas de transmissão exposta nesse trabalho.

\section{2 - LEVANTAMENTO E CADASTRAMENTO DA LINHA}

A etapa de levantamento e cadastramento da linha é importantíssima para o andamento do processo de repotenciação das linhas de transmissão, pois as linhas a serem repotenciadas são, normalmente, antigas e trazem consigo o desgaste causado pelas intempéries e pelo tempo de uso das suas instalações. Por serem 
antigas, outro problema que pode surgir é a discrepância entre os dados da concessionária a respeito da linha, visto que várias alterações não atualizadas no projeto inicial podem ter sido realizadas para a manutenção e a reparação do sistema, bem como por mudanças da geografia local.

Para a definição da escolha do método de repotenciação, é importante saber o estado atual das estruturas, isoladores, a distância entre os condutores e o solo. Esses dados serão necessários desde a etapa de escolha do método de repotenciação até a etapa das simulações computacionais, pois esta necessitará das informações levantadas em campo.

O levantamento dos dados da linha deve ser feito levando-se em consideração as observações referentes às estruturas exibidas nas fotos contidas no item 3.1.1. Além desses itens, a análise deve conter os seguintes tópicos:

- Levantamento topográfico

As repotenciações são, normalmente, realizadas em linhas antigas e que têm sua topografia modificada pelo tempo. Esse tópico deve ser feito levando-se em consideração a localização e o nivelamento do eixo central da linha de transmissão, com nivelamento dos perfis laterais, esquerdo e/ou direito, e o levantamento planialtimétrico de todos os elementos, obstáculos e acidentes existentes na faixa de servidão da linha de transmissão.

- Inspeção visual terrestre

A inspeção visual terrestre traz informações do estado de conservação dos componentes e deve considerar a parte estrutural da linha, que abrange postes, cruzetas e estaiamentos. Além destes, outros aspectos que devem ser considerados durante a inspeção visual são a parte de isolação da linha (isoladores e pinos), os acessórios (conectores, ganchos, grampos, conchas) e os condutores. No item 
3.1.1, foram feitos alguns comentários a respeito das seis estruturas expostas, tratando de itens que devem ser analisados durante essa inspeção visual terrestre.

- Medição de resistividade do solo

É interessante acrescentar esse tópico no decorrer das atividades de levantamento dos dados da linha. O valor da resistividade do solo torna-se um item importante, pois alguns softwares de transitórios eletromagnéticos, como o ATP, levam esse dado em consideração, para o cálculo dos parâmetros elétricos da linha, nas suas simulações.

Após realizar essa etapa de levantamento de dados da linha de transmissão, pode-se proceder à escolha do método que será utilizado para a repotenciação da linha.

\section{3 - ESCOLHA DO MÉTODO DE REPOTENCIAÇÃO}

Após a análise das características apresentadas na seção anterior e constatada a necessidade e viabilidade de repotenciação de uma linha de transmissão, pode-se passar à análise de qual alternativa técnica adotar. Essa escolha é feita em função de um estudo de viabilidade técnica e econômica que pode ser apresentado pela empresa concessionária de energia elétrica e/ou por uma empresa de consultoria contratada. Nessa análise, são considerados aspectos como, por exemplo, a previsão do aumento da demanda e a vida útil das instalações.

A escolha do método depende de características particulares de cada linha, além de depender de necessidades específicas da empresa concessionária proprietária devendo-se analisar cada caso separadamente. 
As principais técnicas de repotenciação de linhas de transmissão já foram mencionadas no capítulo dois desse trabalho, e suas peculiaridades serão analisadas a seguir.

\subsection{1 - ALTERAÇÃO DO LIMITE TÉRMICO DA LINHA DE TRANSMISSÃO}

Para elevar o limite térmico definido no projeto inicial da linha, é de suma importância a análise das condições ambientais locais, com o objetivo de procurar valores reais menos conservadores. É importante observar os valores ambientais reais submetidos à linha, tendo sempre em conta que esses valores podem ter sido estabelecidos pelo projetista de forma conservadora, dadas as condições técnicas da época. Após a determinação mais exata desses dados pode-se, por exemplo, elevar a corrente que percorre a linha, aumentando a temperatura de operação sem que haja uma dilatação desse condutor que venha a comprometer a distância mínima de segurança entre condutor e solo.

Além disso, as seguintes ações devem ser realizadas:

- As flechas em todos os vãos da linha devem ser recalculadas.

- As distâncias entre o condutor e o solo devem ser verificadas em todos os vãos da linha quanto à violação dos limites de distância mínima de segurança estabelecido em normas.

- Determinação dos vãos críticos para a violação da distância mínima de segurança e a escolha técnica para evitar o problema. 


\subsection{2 - RECONDUTORAMENTO DA LINHA DE TRANSMISSÃO}

Todos os métodos de recondutoramento devem ser analisados técnica e economicamente. A seguir, será abordado cada método de recondutoramento observado na literatura correlata.

\section{- Recondutoramento mantendo um condutor por fase}

Nesse caso, o novo condutor é selecionado de forma a apresentar características mecânicas similares ao antigo, porém com maior capacidade de condução de corrente.

- Recondutoramento com a instalação de mais de um subcondutor por fase

Essa alternativa consiste em adicionar em cada fase um condutor mais fino que o atual em local definido por estudos elétricos e mecânicos. Nestes estudos, é possível determinar a bitola e posição do subcondutor que maximiza a capacidade de transmissão de potência. Entretanto, devido às limitações das estruturas, a solução ótima nem sempre é tecnicamente viável.

- Recondutoramento com expansão do feixe de subcondutores existentes

Essa alternativa se aplica em linhas com vários subcondutores por fase e consiste em alterar o número e a disposição geométrica desses condutores de forma a aumentar a capacidade de transmissão da linha. Tais alterações são determinadas por meio de estudos que buscam a melhor distribuição do campo elétrico nos 
condutores, capaz de provocar um aumento significativo da capacidade de transmissão.

\section{- Recondutoramento utilizando cabos termorresistentes}

A utilização de cabos termorresistentes é uma alternativa bem atraente dos pontos de vista técnico e econômico. Esses cabos são constituídos por uma liga, em que são acrescentados alguns aditivos no alumínio puro. Com isso, considerando-se cabos de mesma bitola, um cabo termorresistente pode operar com temperatura de até no máximo $150^{\circ} \mathrm{C}$, sem que haja violação dos limites de distância entre condutor e solo, apresentando uma capacidade de condução de corrente cerca de $50 \%$ superior à de um cabo de alumínio convencional. Para este, a temperatura máxima de operação em regime contínuo é cerca de $90^{\circ} \mathrm{C}$. Outra vantagem da aplicação de cabos termorresistentes frente aos cabos de alumínio convencionais é que, para a mesma bitola, ambos os cabos apresentam o mesmo peso por km e a mesma carga de ruptura.

Quando se trata de aspectos econômicos, o custo final de um cabo termorresistente pode ser $10 \%$ superior ao de um cabo convencional. Além disso, as perdas por efeito Joule e os investimentos na regulação de tensão também são maiores. Contudo, o aumento da potência transmitida é expressivo, tornando essa alternativa de repotenciação uma técnica atraente no sentido de buscar a otimização dos investimentos na expansão do sistema de transmissão de energia elétrica (Oliveira: 2000, p. 16). 


\subsection{3 - ELEVAÇÃO DA TENSÃO OPERATIVA DA LINHA DE TRANSMISSÃO}

Como destacado anteriormente, o enfoque desse trabalho é a elaboração de um procedimento de repotenciação que se utiliza do método de elevação da tensão operativa da linha. Portanto, a esse tópico será dada uma atenção especial. Ressalta-se o fato da linha escolhida para a realização da repotenciação apresentar algumas estruturas e isoladores aptos a operarem com uma tensão de $69 \mathrm{kV}$. Acredita-se, portanto, que seja esta a solução mais viável.

O fluxograma na Figura 3-8 apresenta, em uma seqüência cronológica, os principais tópicos a serem analisados durante a repotenciação de uma determinada linha. Esses tópicos serão explicados no decorrer dessa seção.

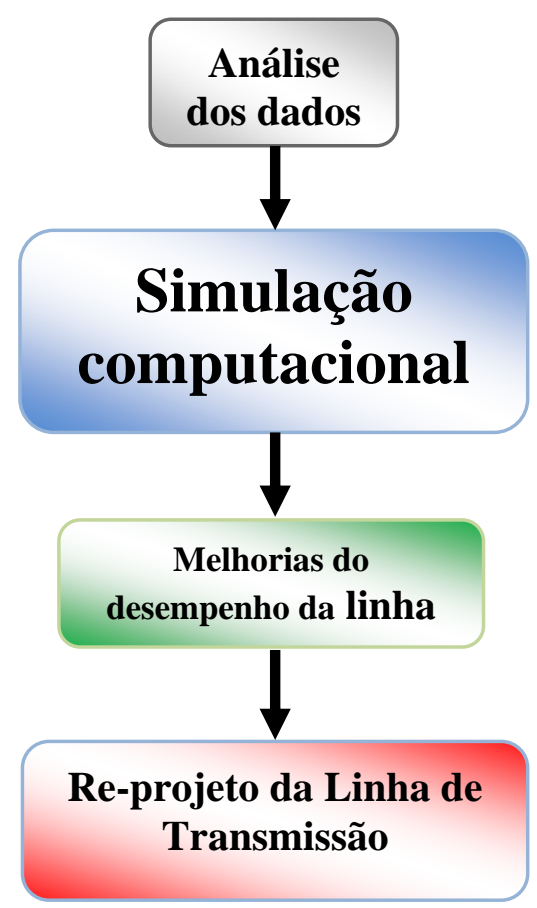

Figura 3-8 - Seqüência cronológica dos principais tópicos a serem analisados durante a repotenciação de uma determinada linha 


\subsubsection{1 - ANÁLISE DOS DADOS}

Depois de analisar o fluxograma apresentado no início deste capítulo (Figura 3-1), pode-se notar que a segunda etapa a ser realizada durante uma repotenciação de linha é o seu levantamento e cadastramento em campo. Tendo em mãos todos os dados levantados durante os trabalhos de campo, deve-se fazer uma análise detalhada dos mesmos, pois essas informações serão de fundamental importância no decorrer das outras etapas necessárias para prosseguir com a repotenciação dessa linha.

A análise servirá também para comprovar se todos os dados necessários para o devido andamento do projeto foram realmente levantados e condizem com as características e expectativas de uma linha de $34,5 \mathrm{kV}$. Essa análise também é fundamental para que os envolvidos no projeto tenham um bom conhecimento da realidade da linha de transmissão existente.

\subsubsection{2 - SIMULAÇÃO COMPUTACIONAL}

Mesmo que o enfoque principal desse trabalho não seja em torno das simulações computacionais, entende-se que essa atividade é uma importante etapa dentre as que compõem os estudos de repotenciação de linhas. Dessa maneira, esse item será abordado neste trabalho, não de forma exaustiva, mas buscando apresentar os conceitos mais relevantes para o encaminhamento das simulações pertinentes.

É interessante esclarecer que as simulações podem ser realizadas por qualquer software que contemple transitórios eletromagnéticos, como por exemplo, o 
software ATP (EEUG, 1987), o PSCAD (PSCAD/EMTP, 2005) e o Power Factory (DIgSILENT, 2007), dentre outros. Para maior facilidade didática, as simulações computacionais foram divididas em quatro partes expostas em ordem cronológica, como apresentado pelo fluxograma da Figura 3-9.

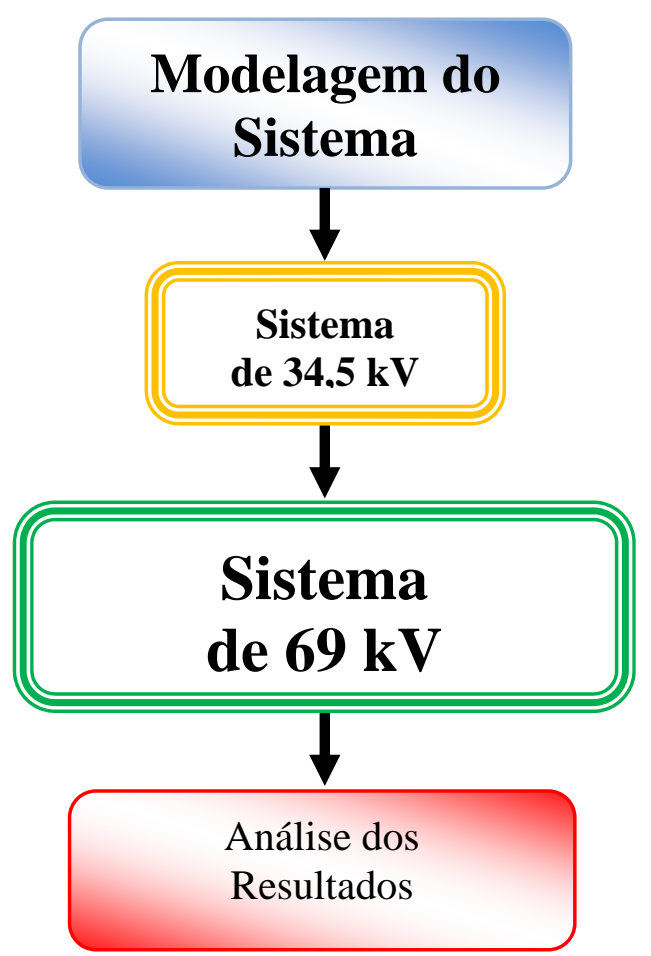

Figura 3-9 - Seqüência das simulações computacionais realizadas para o sistema original e para o repotenciado.

Para um bom conhecimento da linha, devem ser realizadas diversas simulações computacionais do sistema de $34,5 \mathrm{kV}$ e do futuro sistema de $69 \mathrm{kV}$. Inicialmente, essas simulações deverão contemplar a situação de operação em regime permanente, para que o modelo seja validado. Posteriormente, faz-se necessário que sejam aplicadas situações de curtos-circuitos (situações de faltas) sobre o sistema, contemplando os onze tipos de curtos-circuitos existentes, desde os monofásicos aos trifásicos - terra. Esses curtos devem ser aplicados variando o ponto e o ângulo de incidência, bem como o valor da resistência de falta. Como fato, tem-se que as descargas atmosféricas serão as situações indesejáveis mais 
significativas durante os estudos de transitórios eletromagnéticos nessa classe de tensão. Sendo assim, para esta pesquisa em questão, as simulações deverão abordar descargas atmosféricas com magnitudes da corrente de descarga desde 1 kA até $20 \mathrm{kA}$, pois essa é uma margem que contempla a maioria dos casos de descargas atmosféricas que possam vir a ocorrer (DIESENDORF, 1974). Para a aplicação em análise, vale comentar que, além de variar a magnitude da corrente de descarga, deve-se aplicar a descarga em vários pontos da linha, observando o comportamento da tensão gerada pela corrente de descarga em vários pontos da linha.

Já com referência aos chaveamentos de bancos de capacitores e as energizações de linhas, por exemplo, sabe-se também que estes podem gerar no sistema, transitórios eletromagnéticos que podem vir a comprometer a isolação da linha (WATSON; ARRILLAGA, 2003). Porém essas situações são mais prejudiciais ao sistema, quando comparadas às descargas atmosféricas, somente para linhas de transmissão com tensões superiores a 400 kV, o que não é o caso do estudo em análise.

\section{MODELAGEM DO SISTEMA}

Cabe antecipar que, por ser a modelagem do sistema uma importante etapa da pesquisa, em um capítulo à parte, serão apontadas todas as considerações e observações decorrentes. Cabe adiantar que fazendo uso dos dados levantados em campo, pode-se modelar a linha de maneira a encontrar resultados bem próximos dos reais.

A modelagem da linha como um todo, deve levar em consideração a sua estrutura e disposições geométricas como: a altura a meio vão, as distâncias entre fases e condutores, a resistividade do solo, o comprimento da linha, o diâmetro do 
condutor, a tensão, a potência de curto-circuito nos barramentos, entre outras informações pertinentes ao estudo.

Existem na literatura e em termos de aplicação, alguns tipos de modelagens matemáticas para a realização dos cálculos. O software ATP, por exemplo, através da sua interface ATPDraw (EEUG, 1987) e de seu componente LCC (Line/Cable Constants), disponibiliza cinco métodos para a modelagem matemática, a saber:

- Bergeron

- $\mathrm{Pl}$

- JMarti

- Semlyem

- Noda

Cada um dos cinco métodos listados possui suas peculiaridades. Não se abordarão todos eles, uma vez que o objetivo desse trabalho é o de nortear futuros projetos. Apenas serão comentadas as principais diferenças entre os modelos PI e JMARTI, por serem estes os mais aplicados.

De acordo com Watson e Arrillaga (2003, p. 123), o modelo PI é indicado para modelagens de linhas de transmissão curtas, de até no máximo $15 \mathrm{~km}$, em que o tempo de viagem/excursão da onda entre pontos de descontinuidades da linha é menor que o tempo de integração da solução. Sendo assim, a partir de $15 \mathrm{~km}$ é necessária a utilização de modelos que levem em consideração a teoria das ondas viajantes.

Cabe adiantar que nas simulações foram utilizados o modelo PI e o modelo JMARTI. Inicialmente, escolheu-se o modelo PI, pois o comprimento da linha utilizada para os estudos é de 8,915 km. Cabe frisar que apesar desse modelo estar de acordo com o que indicam Watson e Arrillaga (2003, p.123), ele não leva em 
consideração freqüências diferentes da fundamental. Portanto, também foi escolhido um modelo dependente da freqüência, neste caso o modelo JMARTI, além do modelo $\mathrm{PI}$, para se obter resultados mais próximos dos reais frente às simulações de descargas atmosféricas e de situações de faltas (curtos-circuitos), ou seja, para as simulações de transitórios pertinentes ao estudo.

Pelo software ATP, essa escolha entre o modelo PI e/ou JMARTI é feita no momento da inclusão dos dados no componente LCC. Através desse componente é que se calcularão os parâmetros elétricos representativos da linha de transmissão em análise.

\section{SISTEMA DE 34,5 kV}

Pelo fluxograma apresentado em Figura 3-9, seguem-se, então, as simulações computacionais que dizem respeito ao sistema de $34,5 \mathrm{kV}$. Primeiro mediante a situação de regime permanente e, posteriormente, sob situações adversas (transitórias).

Vale frisar que para melhor analisar as possíveis ocorrências, devem ser realizadas simulações de descargas atmosféricas, faltas monofásicas, bifásicas e trifásicas com e sem o envolvimento do terra. Apesar do maior número de ocorrências sobre um sistema elétrico qualquer ser referente às situações monofásicas, e de esse tipo de falta apresentar a maior variação entre as magnitudes das tensões durante os curtos, os curtos-ciruitos bifásicos e trifásicos também devem ser simulados, pois os transitórios podem resultar em picos de tensão consideráveis e indesejáveis para o sistema.

\section{SISTEMA DE $69 \mathrm{kV}$}

Após a validação da modelagem realizada para o sistema de $34,5 \mathrm{kV}$, podese continuar com as simulações, realizando alterações no sistema inicialmente 
modelado para analisar qual será o seu comportamento quando aplicada a tensão escolhida para sua nova operação, ou seja, de 69 kV.

Sendo assim, tem-se agora a etapa de simulações pertinentes ao sistema de $69 \mathrm{kV}$, que é uma das etapas mais importantes do procedimento, sem menosprezar a importância das etapas anteriores, pois sem elas não se teria um modelo com o qual seria possível continuar com as simulações. Essa etapa será de suma importância na definição do re-projeto da linha futuramente repotenciada. É nessa etapa que se terá idéia da magnitude das tensões que serão encontradas no sistema, devido aos curtos-circuitos e descargas atmosféricas passíveis de ocorrência, após a sua repotenciação concluída.

Como apontado sobre o sistema de $34,5 \mathrm{kV}$, no de $69 \mathrm{kV}$ também devem ser caracterizadas situações de faltas monofásicas, bifásicas e trifásicas com e sem o envolvimento do terra, bem como de descargas atmosféricas. Esses surtos deverão ser aplicados em várias partes do sistema e deverão ser analisadas as tensões e correntes enfrentadas pelo sistema em vários pontos espalhados pela linha. Dessa maneira, será possível ter o conhecimento das condições operativas e nãooperativas a que esta linha estará sujeita.

\section{ANÁLISE DOS RESULTADOS}

As simulações computacionais indicarão uma gama de resultados muito ampla, e por isso, considera-se interessante colocar um módulo em específico para uma análise dos resultados obtidos durante as mesmas.

Cabe frisar que nesta etapa do trabalho, tem-se conhecimento de todas as estruturas existentes em campo, seus respectivos estados físicos e de suas cadeias de isolação. Portanto, de posse desses dados e dos resultados das simulações computacionais, é importante realizar uma analise das sobretensões geradas pelos 
surtos em todas as estruturas, ou pelo menos nas mais críticas, e que seja feita uma comparação com a classe de isolação encontrada na estrutura e o nível de tensão encontrado nas simulações computacionais.

Desta maneira, além das simulações do sistema elétrico, evidencia-se também a necessidade de se modelar e estudar o comportamento dos isoladores associados, já que destes, dependerá a correta operação dos sistemas, tanto o de 34,5 como o de $69 \mathrm{kV}$ almejado. Logo, no capítulo 5, será apresentado como tais estudos foram direcionados neste trabalho.

\subsubsection{3 - MELHORIAS DO DESEMPENHO DA LINHA}

Ao se repotenciar uma linha de transmissão, busca-se, aumentar sua capacidade de transmissão, evitando assim, a construção de novas linhas e a liberação de novas faixas de servidão. Busca-se, também, um aumento no desempenho dessa linha, pois há uma preocupação em manter o serviço de transmissão atendendo aos requisitos de qualidade da energia que, por exemplo, primam pela minimização das interrupções.

Nessa etapa é necessário que se faça um estudo sobre o aumento do nível básico de isolamento $(\mathrm{NBI})$ da linha contra impulsos (descargas) atmosféricos, curtos-circuitos e quanto à própria operação normal do sistema.

Como fato, tem-se que todas as estruturas devem atender as distâncias mínimas de segurança exigidas pela norma NBR5422 (ABNT, 1985), bem como a classe de isolação.

Também deve ser realizado, um estudo técnico pertinente às funções de proteção, operação e confiabilidade. A integração do sistema resultante com os 
demais sistemas com que ele interage e/ou vai interagir também merece um estudo detalhado.

\subsubsection{4 - RE-PROJETO DA LINHA DE TRANSMISSÃO}

Após a realização de todos os estudos necessários, deve-se proceder com o re-projeto da linha de transmissão. Todos os pontos que não atendam aos resultados das simulações do sistema de $69 \mathrm{kV}$ e à norma NBR 5422, como estruturas do tipo "A" com isoladores pino de 34,5 kV, deverão ser ou substituídos ou alterados de maneira que atendam aos requisitos mínimos de operação em um sistema de $69 \mathrm{kV}$.

Para a realização dessas alterações pode ser contratada uma empresa especializada na área de projetos de linhas de transmissão para que possa ser feito um novo projeto da linha existente, contendo as alterações necessárias para a aprovação do projeto de repotenciação da linha.

Depois de atendidas todas as etapas do procedimento, ressalta-se que o processo de elevação da tensão operativa deve obedecer a determinados requisitos técnicos, como (Oliveira (2000, p. 24)):

a) O desempenho e o NBI da linha de transmissão repotenciada devem ser os mesmos que os de uma linha construída originalmente com a tensão igual à repotencializada.

b) Como anteriormente colocado, a alteração deve manter as características das estruturas como, por exemplo, as distâncias entre os condutores e entre os condutores e o solo, objetivando a minimização dos custos. No entanto, as condições de segurança 
devem ser respeitadas de acordo com os critérios estabelecidos na norma NBR 5422. Qualquer violação desses critérios implica em realizar alterações nas estruturas para adequação às normas técnicas. Algumas dessas alterações são apresentadas a seguir:

- Redução do comprimento da cadeia de isoladores, buscando uma solução que não comprometa o desempenho da linha em relação às sobretensões.

- Retensionamento dos condutores até o limite de $23 \%$ de sua carga de ruptura na condição de estado de tração normal (EDS - everyday stress), para garantir as distâncias mínimas de segurança.

- Retensionamento do cabo pára-raios, quando existentes.

- Ancoragem do cabo condutor inferior nas estruturas de suspensão, para se obter as distâncias mínimas de segurança, se os casos anteriores não atingirem tal objetivo.

- Substituição e/ou implantação de novas estruturas se os procedimentos anteriores não forem suficientes para obter as distâncias mínimas de segurança.

Finalmente, ressalta-se que a adoção da alternativa de elevação da tensão operativa para repotenciação de uma linha requer um novo estudo de coordenação da proteção, a verificação das distâncias mínimas de segurança entre condutores e entre condutores e o solo, e uma análise que contemple a avaliação do desempenho da linha quanto à máxima tensão operativa, surtos de manobra e surtos atmosféricos. 
Ressalta-se que para qualquer alteração física nas estruturas como, aumento nas distâncias entre condutores, inclusão de novas estruturas ou alteração da mesma, deverão ser realizadas novas simulações computacionais para certificarse de que a configuração final alcançada não acarrete problemas no desempenho da linha frente a condições normais e anormais de operação.

\section{4 - ASPECTOS AMBIENTAIS DA REPOTENCIAÇÃO}

De acordo com a resolução do CONAMA (Conselho Nacional do Meio Ambiente) 237/1997, a transmissão de energia elétrica está incluída como um dos itens sujeitos ao licenciamento ambiental (Brasil, 1997). Assim, a resolução SMA-5 de 7 de fevereiro de 2007, da Secretaria de Estado do Meio Ambiente de São Paulo, resolve que a implantação, repotenciação e recabeamento (recondutoramento) de linhas de transmissão dependem de licenciamento ambiental nos seguintes casos (São Paulo, 2007):

- Linhas com extensão superior a $3 \mathrm{~km}$, para obras em faixas de passagem novas e existentes, situadas em áreas de baixa criticidade ambiental.

- Linhas com extensão superior a $20 \mathrm{~km}$, para o recabeamento em áreas de baixa criticidade ambiental.

- Linhas de qualquer extensão situadas em áreas de maior criticidade ambiental.

Áreas de baixa criticidade ambiental correspondem a áreas urbanas, pastagens, culturas etc., que não exijam supressões de vegetação em estágio médio avançado e áreas de baixa fragilidade geomorfológica, que não exijam 
desapropriações e/ou realocações, e que não estejam localizadas em áreas ambientalmente protegidas.

Observa-se, portanto, que obras para repotenciação de linhas de transmissão estão sujeitas ao licenciamento ambiental. No entanto, os impactos ambientais devidos à repotenciação são menores do que os relacionados à construção de novas linhas de transmissão, tendo em vista que se busca reaproveitar as torres existentes, sendo desnecessário criar novas faixas de passagem. Assim, como os critérios para se obter o licenciamento ambiental têm se tornado muito rígidos nos últimos anos, os custos necessários para licenciar novos projetos de linhas de transmissão podem aumentar significativamente os custos totais da realização da obra, além de provocar atrasos em sua execução. Esse fato contribui para tornar a repotenciação das linhas uma solução mais rápida e menos dispendiosa para a expansão do sistema de transmissão de energia elétrica.

Paralelamente às restrições ambientais, no que diz respeito à passagem da linha de transmissão por áreas de preservação ambiental, deve-se também voltar à atenção às perturbações elétricas que podem influenciar o ambiente. Logo, recomenda-se realizar um conjunto de estudos visando avaliar a intensidade dos campos elétricos e magnéticos, rádio interferência e ruídos auditivos nas proximidades da linha de transmissão (da Costa et. al, 2001). Nesses estudos, os seguintes itens devem ser verificados:

- Se a relação sinal/ruído é compatível com os valores-limite determinados pela legislação vigente.

- Se as intensidades dos campos elétricos e magnéticos estão dentro dos limites estabelecidos pelas normas nacionais e internacionais. 
Após a apresentação destes apontamentos referentes ao procedimento a ser adotado, serão apresentadas algumas das simulações computacionais realizadas referentes à linha estudada. Este trabalho não tem a pretensão de abordar todos os aspectos das simulações computacionais envolvidas em um projeto de repotenciação de linhas, porém, trará uma boa idéia a respeito das simulações pertinentes e necessárias para tal objetivo. 


\section{Capítulo 4 Simulações Computacionais no Processo de Repotenciação de Linhas de Subtransmissão}

Conforme observado nos fluxogramas já apresentados, as simulações computacionais representam uma etapa de grande importância durante o processo de estudos da repotenciação das linhas de subtransmissão. Por isso, entende-se que seria importante reservar um capítulo específico sobre essas simulações, embora não seja o objetivo deste documento tratar em específico de todas as peculiaridades do sistema em análise.

Sendo assim, no item 4.1 serão tratados os aspectos relacionados à modelagem computacional da linha em análise. No item 4.2, as simulações pertinentes aos transitórios eletromagnéticos decorrentes de curtos-circuitos aplicados serão ilustradas. Ressalta-se que apesar de serem necessárias diversas simulações, variando impedância de falta, ponto de incidência do curto-circuito e ponto de medição, para este documento, apenas as simulações decorrentes dos curtos-circuitos aplicados para um ponto próximo ao meio da linha serão abordadas. Já para o item 4.3 as situações decorrentes das descargas atmosféricas serão analisadas. Cabe adiantar que para este último item, foram caracterizadas duas descargas atmosféricas sobre o sistema em análise, uma em um ponto próximo ao meio da linha e outra na extremidade da usina geradora, com o objetivo de demonstrar o amortecimento causado pelos parâmetros intrínsecos da linha na corrente de descarga. 


\section{1 - MODELAGEM DA LINHA VIA A INTERFACE ATPDRAW}

A linha foi inicialmente modelada de uma forma simplificada, como se pode observar na Figura 4-1 (PRIKLER, 2007), que apresenta oito componentes LCC, cada um representando um trecho em específico da linha. Vale destacar que foram feitas aproximações quanto às distâncias entre condutores, uma vez que a linha apresenta estruturas diversificadas. Estas aproximações foram feitas considerando sempre a estrutura mais problemática quanto às distâncias entre condutores e entre o condutor e o solo. Trata-se como estrutura problemática as mais baixas e que apresentam distâncias menores entre os condutores, podendo ter a isolação comprometida após a elevação da classe de tensão operativa da linha.

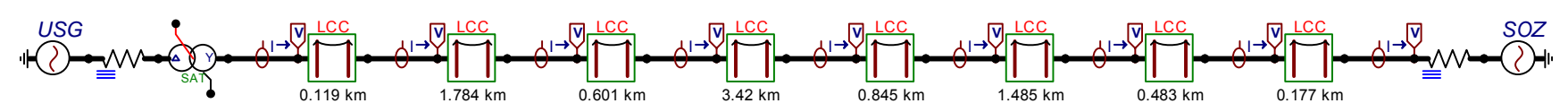

Figura 4-1 - Modelo simplificado da linha

O software ATP permite a possibilidade da utilização de seu componente LCC (Line/Cable Constants) de forma gráfica através da interface gráfica do ATPdraw, conforme ilustra a Figura 4-2. 


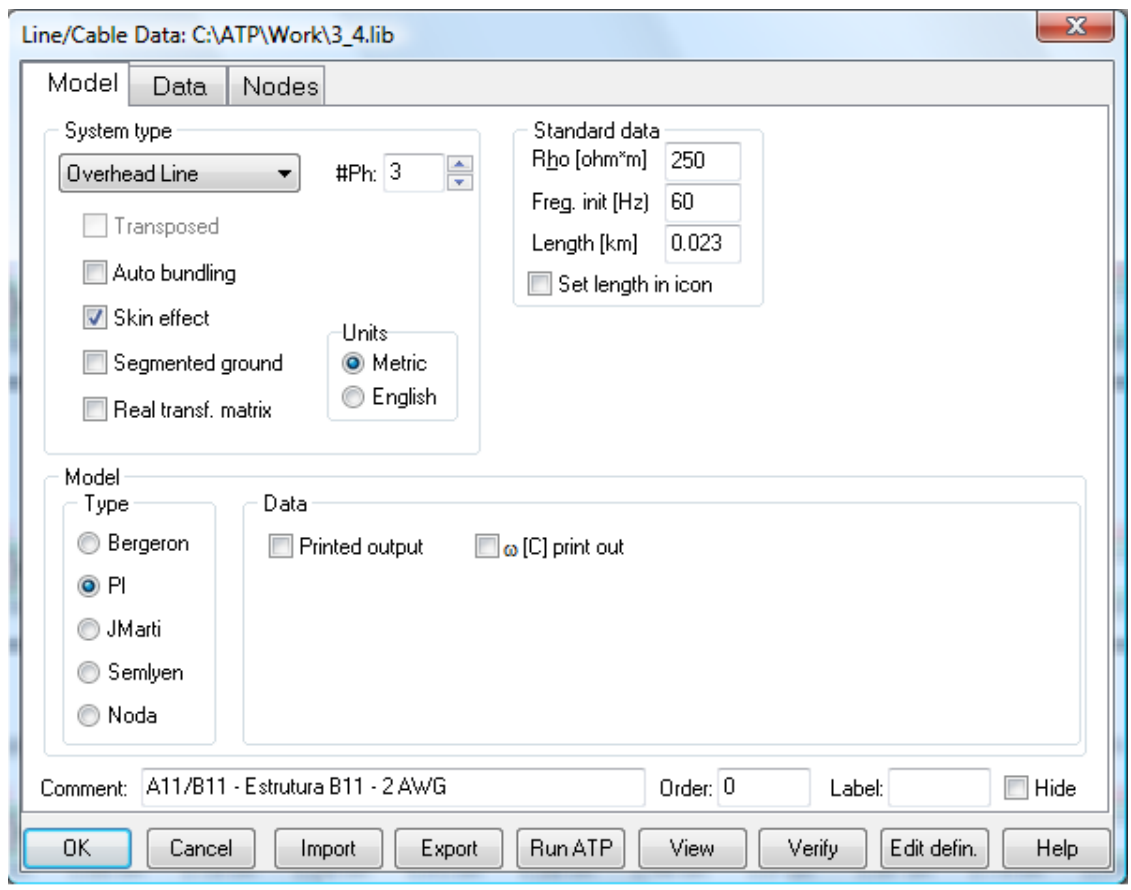

Figura 4-2 - Tela inicial do componente LCC

Na Figura 4-2, pode-se analisar a tela de seleção do modelo matemático que será utilizado pelo software para os cálculos dos parâmetros elétricos da linha. Nesta tela, pode-se também inserir o valor da resistividade do solo, a freqüência, o comprimento da linha e o tipo de sistema em implementação, como por exemplo, a linha trifásica aérea, motivo em estudo.

A Figura 4-3 ilustra o procedimento da entrada dos dados que representam os condutores do sistema em análise. Por ela, pode-se configurar o raio interno e externo do condutor, sua resistência, as distâncias horizontais e as alturas dos condutores na torre e no meio vão em relação ao solo. 


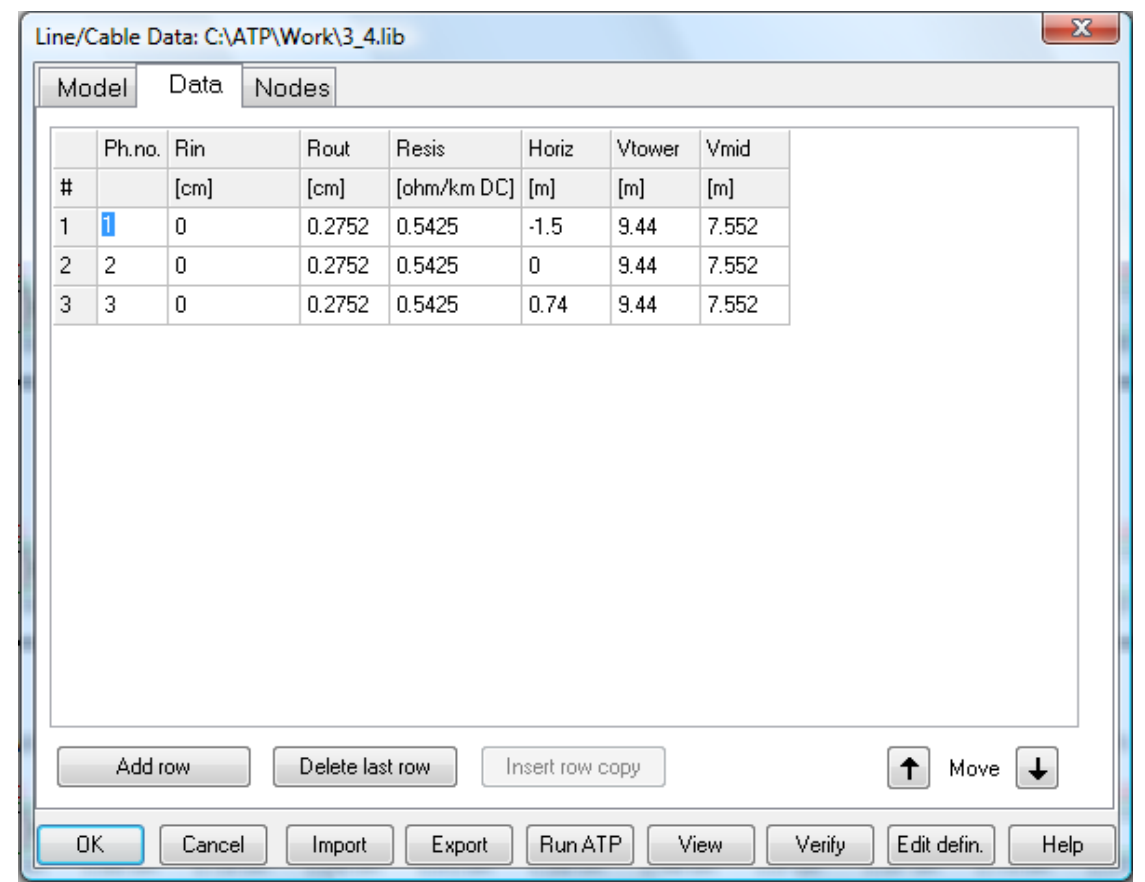

Figura 4-3 - Tela para a entrada dos dados representando os condutores do sistema simulado

\section{2 - SIMULAÇÕES SOBRE O SISTEMA EM ANÁLISE}

Após ter modelado a linha desejada, devem ser aplicados os diversos tipos de curtos-circuitos e descargas atmosféricas a que a linha possivelmente estará sujeita em campo.

Para as simulações de curtos-circuitos no sistema de 34,5 kV serão utilizados dois tipos de modelagem. Uma simplificada, contendo apenas oito trechos, e uma detalhada, contendo cinquenta e três trechos. A idéia da realização de simulações utilizando-se do modelo detalhado é de se analisar as tensões em todas as estruturas existentes na linha. Cabe adiantar que durante as simulações de 34,5 kV será possível perceber que os resultados apresentados pelo modelo simplificado, quando comparado ao modelo detalhado, não apresentam diferenças consideráveis. Contudo, a escolha pelo modelo detalhado se justifica pela possibilidade de se analisar todas as estruturas, e não um conjunto das mesmas. 
Como fato, tem-se que os curtos-circuitos deverão ser aplicados em vários pontos da linha, monitorando-se os transitórios gerados, também em vários pontos. Neste sentido, ressaltam-se três principais pontos para a aplicação do curto-circuito: a extremidade da linha conectada a usina geradora, um ponto posicionado próximo ao meio da linha e a extremidade conectada à subestação. Para cada ponto de aplicação do curto-circuito é importante realizar medidas no ponto de aplicação do curto e nos outros dois citados. Além de alterar o ponto de incidência e o de medição do curto, ressalta-se a importância na variação das impedâncias de curto entre valores que representam um curto-circuito franco e um curto-circuito de alta impedância (0 e $100 \Omega$, respectivamente). Outro item que deve ser alterado é o ângulo de incidência da falta entre 0 e 90 graus.

Essas simulações trarão um bom conhecimento a respeito do comportamento da linha frente aos curtos-circuitos que possam vir a ocorrer sobre o sistema em análise.

Da mesma forma, devem ser realizadas simulações contemplando as descargas atmosféricas, aplicando-as nos pontos acima citados e seguindo o mesmo raciocínio para a realização das medições.

Neste contexto, o item 4.2.1 apresentará as simulações realizadas para o sistema de 34,5 kV, simplificado e detalhado. O item 4.2.2 apresentará o sistema com as devidas alterações necessárias para as simulações de distúrbios no sistema de $69 \mathrm{kV}$, e o item 4.2.3 abordará o comportamento da linha frente às descargas atmosféricas aplicadas. 


\subsection{1 - SIMULAÇÕES SOBRE O SISTEMA DE 34,5 KV}

Nesta etapa serão apresentados alguns resultados de simulações de transitórios eletromagnéticos realizadas na linha de $34,5 \mathrm{kV}$. A simulação de transitórios eletromagnéticos neste sistema tem o intuito de validar o modelo computacional da linha em análise. Realizou-se a simulação em duas etapas, uma considerando o modelo simplificado, e outra o modelo detalhado, o que virá a demonstrar a semelhança entre os dois resultados. Cabe lembrar que os curtoscircuitos foram todos aplicados e medidos em um ponto próximo ao meio da linha apenas para ilustrar os resultados encontrados.

\subsubsection{1 - SIMULAÇÕES SOBRE O SISTEMA DE 34,5 KV REDUZIDO}

Nesse tópico, será tratado o sistema modelado de maneira simplificada, utilizando-se os componentes LCC (Line/Cable constants), disponíveis via interface ATPdraw, conforme observado na Figura 4-1. O modelo matemático utilizado para a realização das simulações das situações de faltas pertinentes ao estudo foi o modelo PI, e os parâmetros inseridos para caracterizar os componentes LCC são parâmetros reais coletados durante a etapa de levantamento e cadastramento da linha.

Os curtos-circuitos foram aplicados dispondo-se do sistema modelado conforme apresentado pela Figura 4-4, onde se pode notar uma ligação caracterizando uma falta monofásica. Os demais tipos de curtos-circuitos serão aplicados apenas modificando-se essa ligação. 


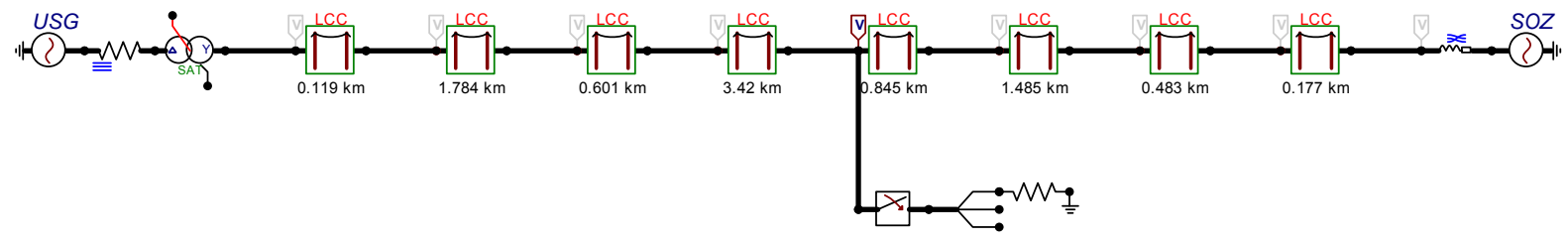

Figura 4-4 - Modelo simplificado representando uma situação de falta monofásica.

As faltas monofásicas são, conforme mencionado no capítulo 3 , as que apresentam a maior variação nas magnitudes de tensão durante um curto-circuito. A Figura 4-5 ilustra as formas de ondas trifásicas da tensão após ter sido aplicada uma falta com resistência de $10 \Omega$ envolvendo a fase "A", com um ângulo de incidência de $0^{\circ}$, no meio da linha.

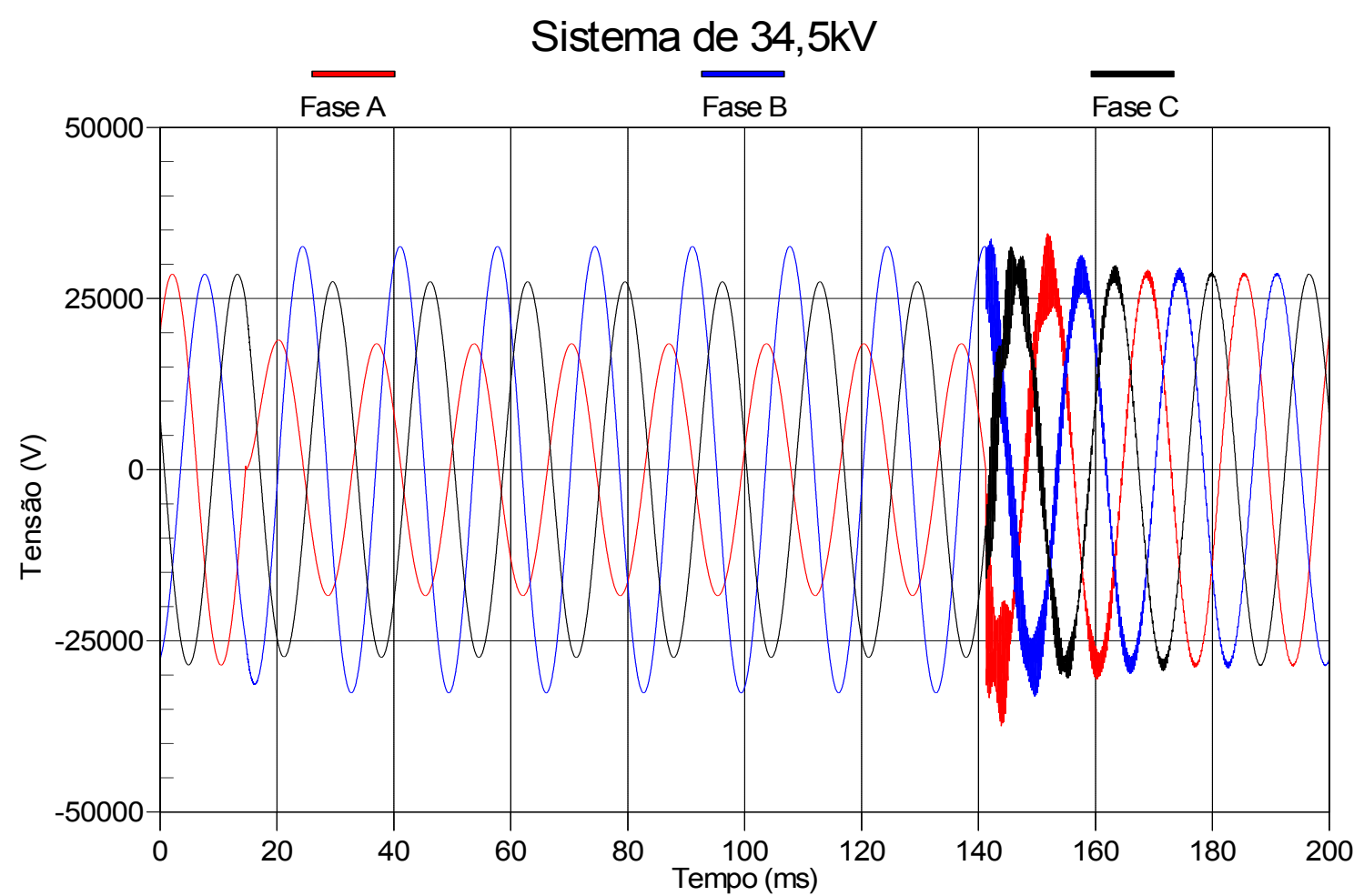

Figura 4-5 - Formas de ondas da tensão nas fases "A", "B" $e$ "C" após a ocorrência de um curto-circuito no meio da linha, envolvendo a fase "A" com conexão a terra, resistência e ângulo de incidência da falta de $10 \Omega \mathrm{e} 0^{\circ}$, respectivamente.

Para visualizar o efeito causado pelos curtos bifásicos, este curto foi modelado com uma impedância de $10 \Omega$. A Figura 4-6 representa as três fases após 
o curto bifásico ter sido aplicada no meio da linha. As medidas foram tomadas no ponto de aplicação da situação de falta.

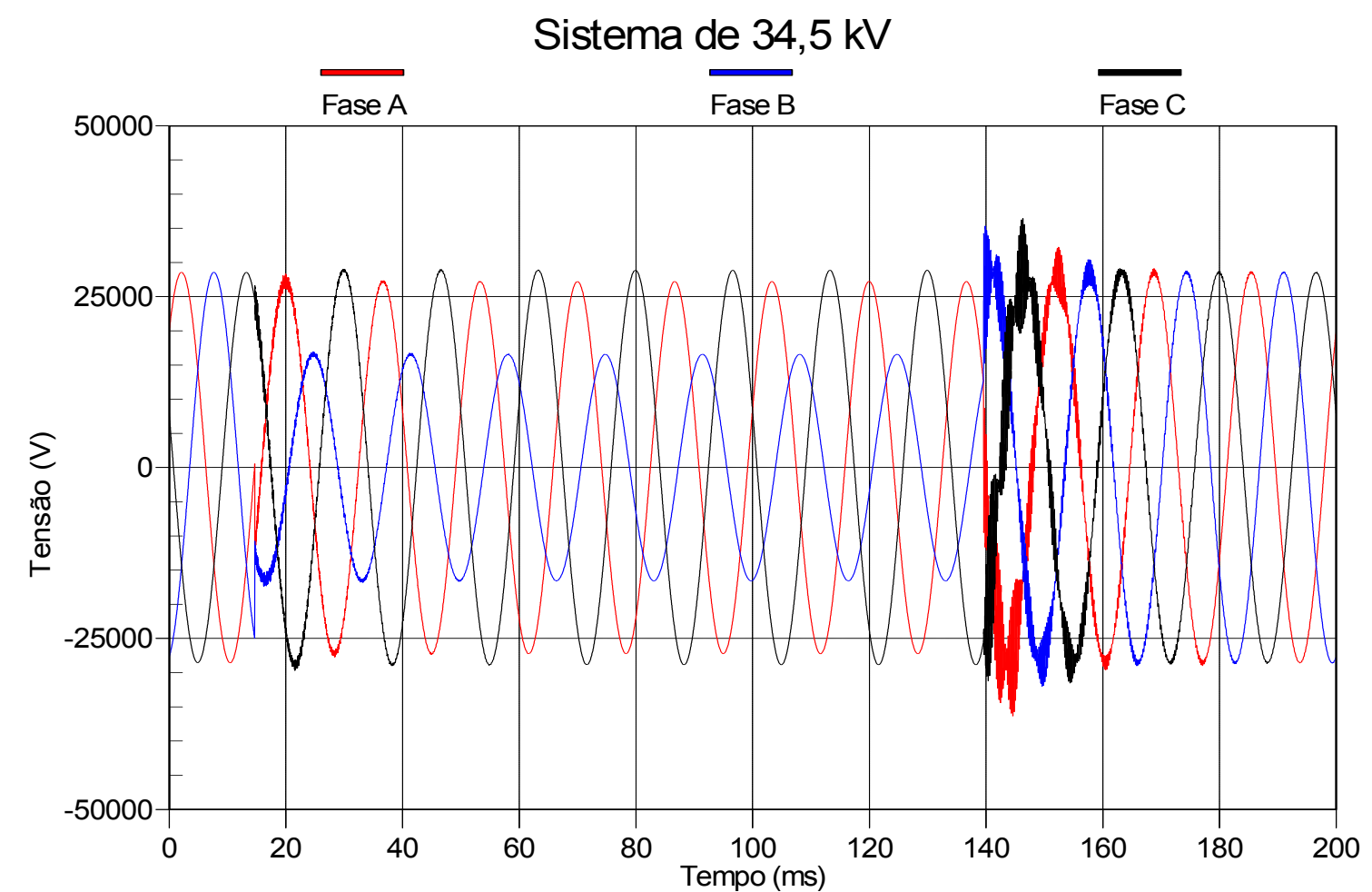

Figura 4-6 - Formas de ondas da tensão nas fases " $A$ ", "B" $e$ " $C$ " após a ocorrência de uma falta bifásica envolvendo as fases " $A$ " $e$ " $B$ " do sistema em análise, com uma resistência $e$ ângulo de incidência da falta de $10 \Omega$ e $0^{\circ}$, respectivamente.

Já a Figura 4-7 ilustra os efeitos sobre as tensões trifásicas para uma situação de curto bifásico com conexão ao terra (“AB-T"), aplicada sobre as mesmas condições anteriormente citadas. 


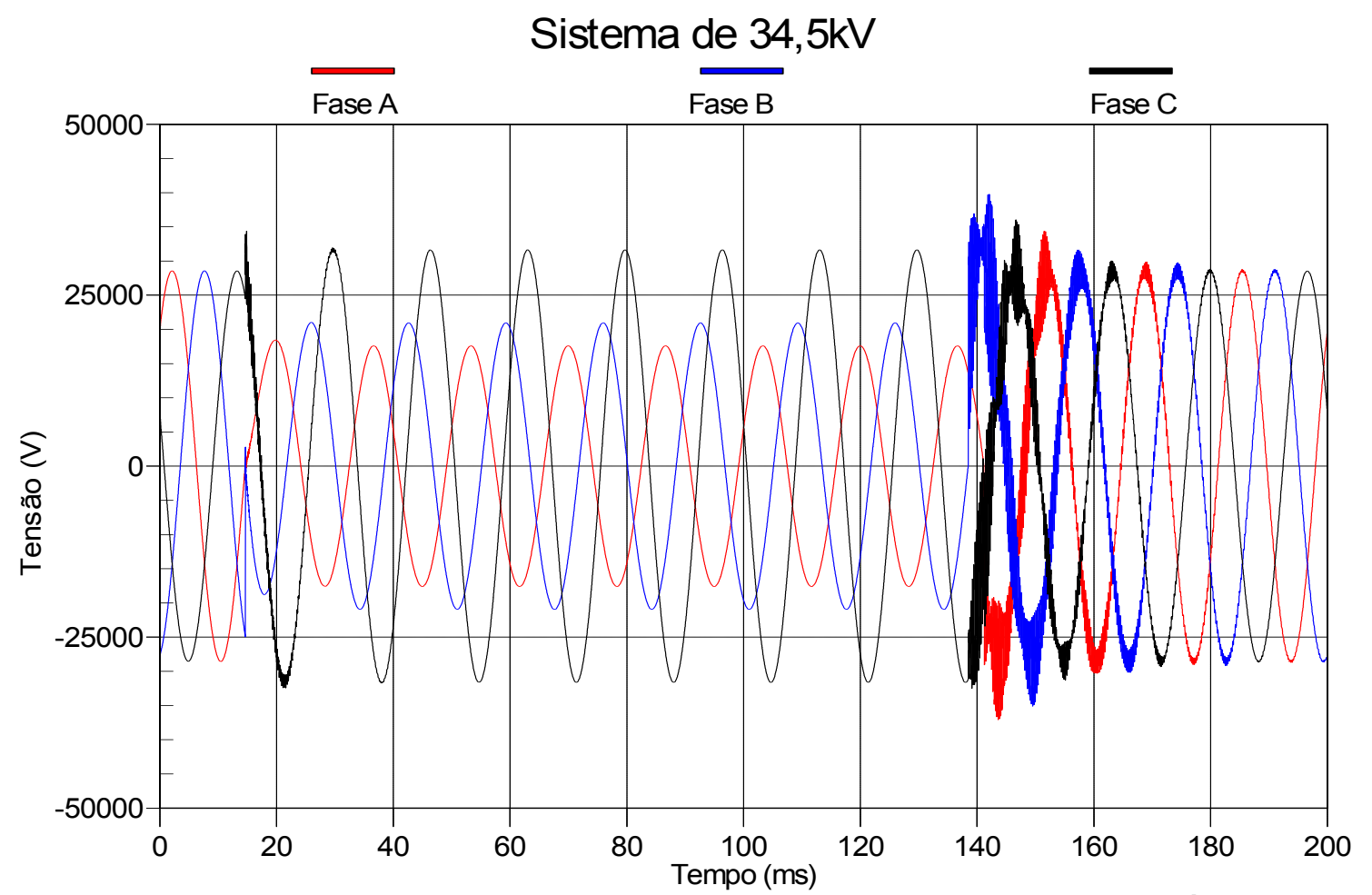

Figura 4-7 - Formas de ondas da tensão nas fases "A", "B" $e$ "C" após a ocorrência de uma falta bifásica com o envolvimento do terra (“AB-T”), com uma resistência e ângulo de incidência da falta de $10 \Omega \mathrm{e} 0^{\circ}$, respectivamente.

Vale relembrar que os curtos trifásicos não são muito comuns nos sistemas elétricos, pela própria disposição dos condutores. Mesmo assim, essas situações devem ser simuladas de maneira a se obter um amplo conhecimento do comportamento da linha frente a todos os possíveis casos, com o intuito de se verificar as piores condições em termos de corrente. A Figura 4-8 representa as tensões nas três fases em curto. 


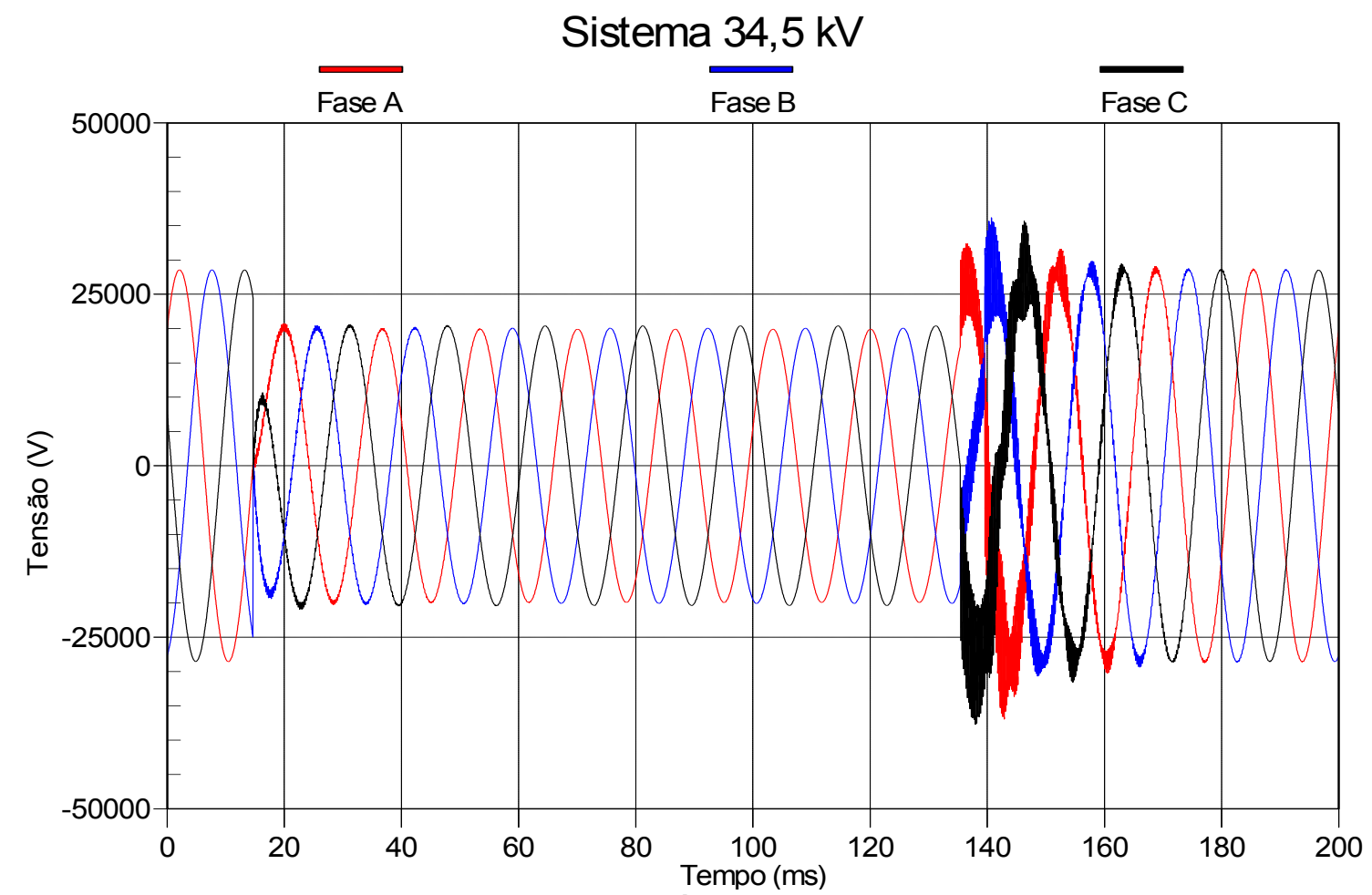

Figura 4-8 - Forma de onda da tensão nas três fases devido a uma falta trifásica aplicada no meio da linha do sistema em análise com uma resistência e ângulo de incidência da falta de 10 $\Omega$ e $0^{\circ}$, respectivamente.

Apesar de não apresentar muitas diferenças com relação à amplitude das tensões, quando comparada com a situação anterior, fez-se uma representação do curto trifásico envolvendo o terra na Figura 4-9. 


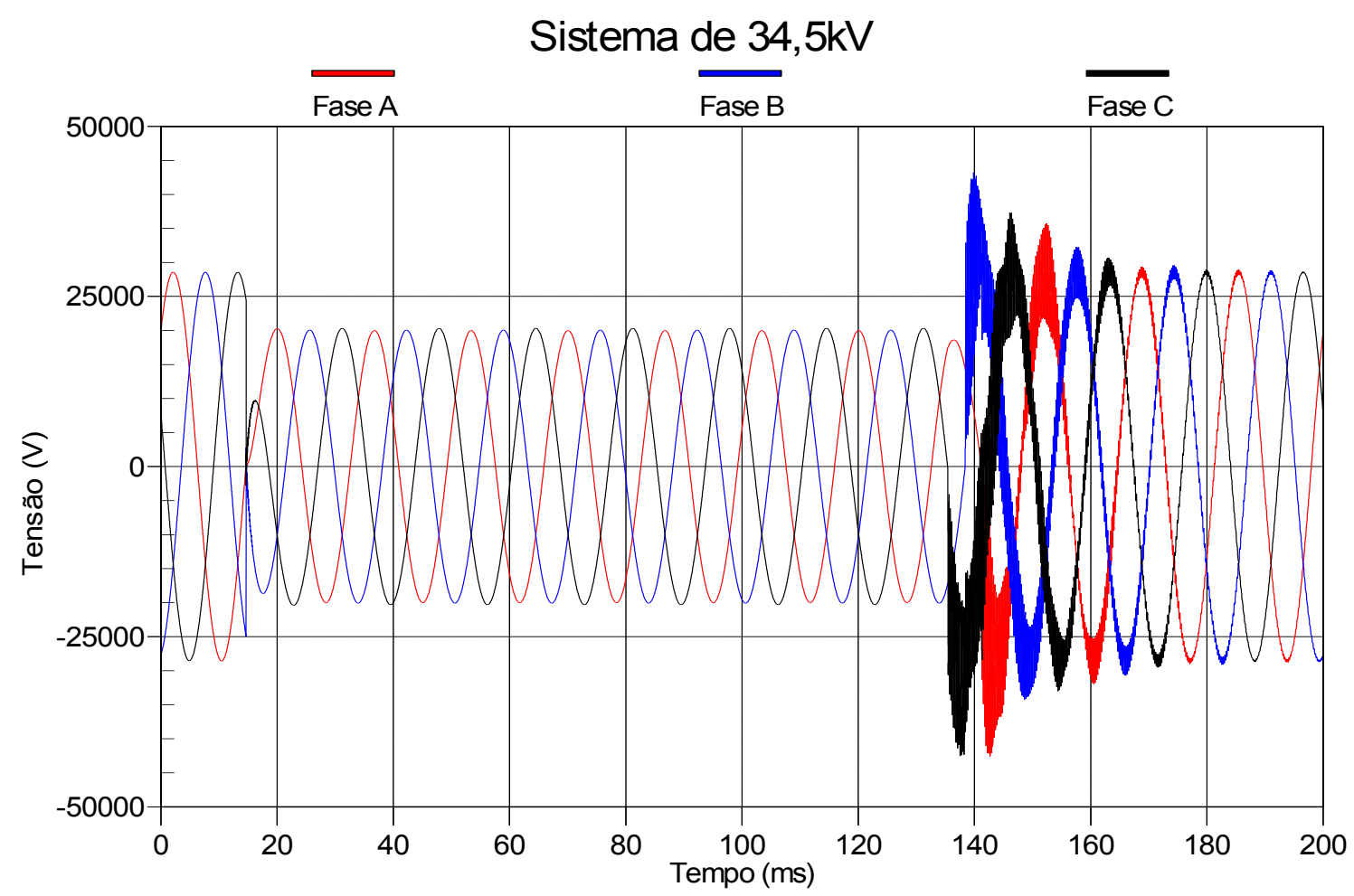

Figura 4-9 - Forma de onda da tensão nas três fases devido a uma falta trifásica envolvendo o terra, aplicada no meio da linha do sistema em análise, com uma resistência e ângulo de incidência da falta de $10 \Omega$ e $0^{\circ}$, respectivamente.

\subsubsection{2 - SIMULAÇÕES SOBRE O SISTEMA DE 34,5 KV DETALHADO}

O sistema expandido (detalhado) foi modelado com o principal intuito de se realizar leituras (medições) em todos os trechos existentes na linha. Sendo assim, os componentes LCC foram inseridos nessa modelagem representando todos os vãos existentes na linha. A Figura 4-10 representa a linha de transmissão modelada utilizando-se desses componentes. 


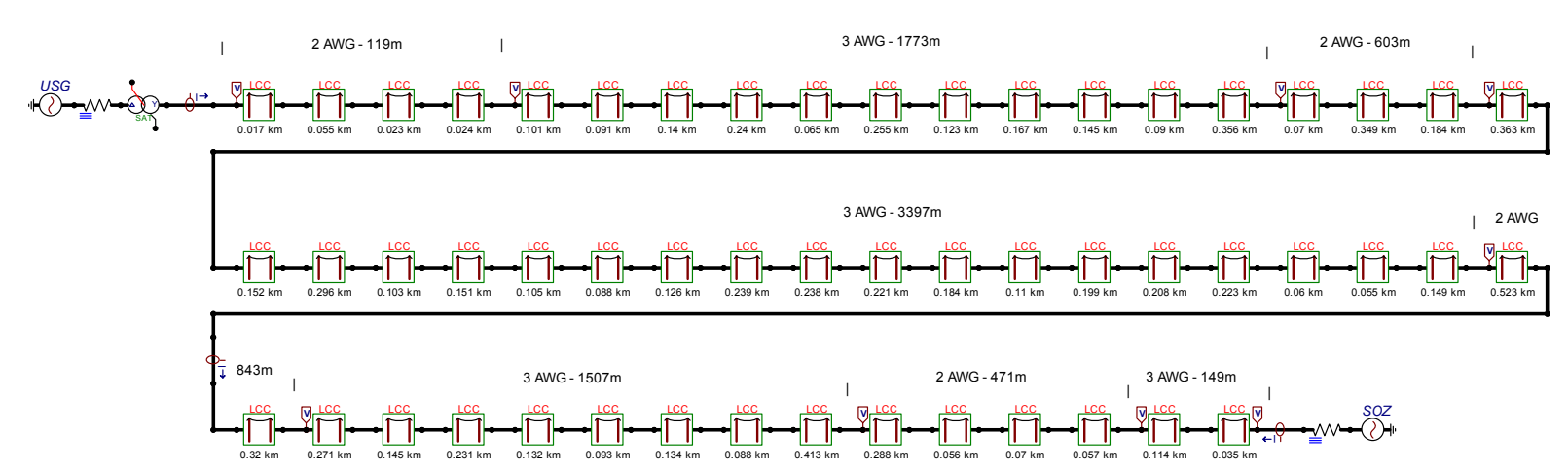

Figura 4-10 - Modelagem da linha de 34,5 kV expandida (modelo detalhado).

O sistema representado pela Figura 4-10 possui 53 trechos configurados, caracterizados pelas alturas dos condutores na estrutura e no meio vão em relação ao solo, distâncias entre condutores, dimensões e resistência dos condutores e resistividade do solo.

Assim como no sistema reduzido, os procedimentos adotados serão os mesmos em relação ao sistema expandido, representando-se as possíveis situações de faltas que possivelmente podem ser evidenciadas em campo.

A Figura 4-11 representa o sistema expandido com os componentes necessários para a aplicação das situações de faltas (curtos-circuitos).

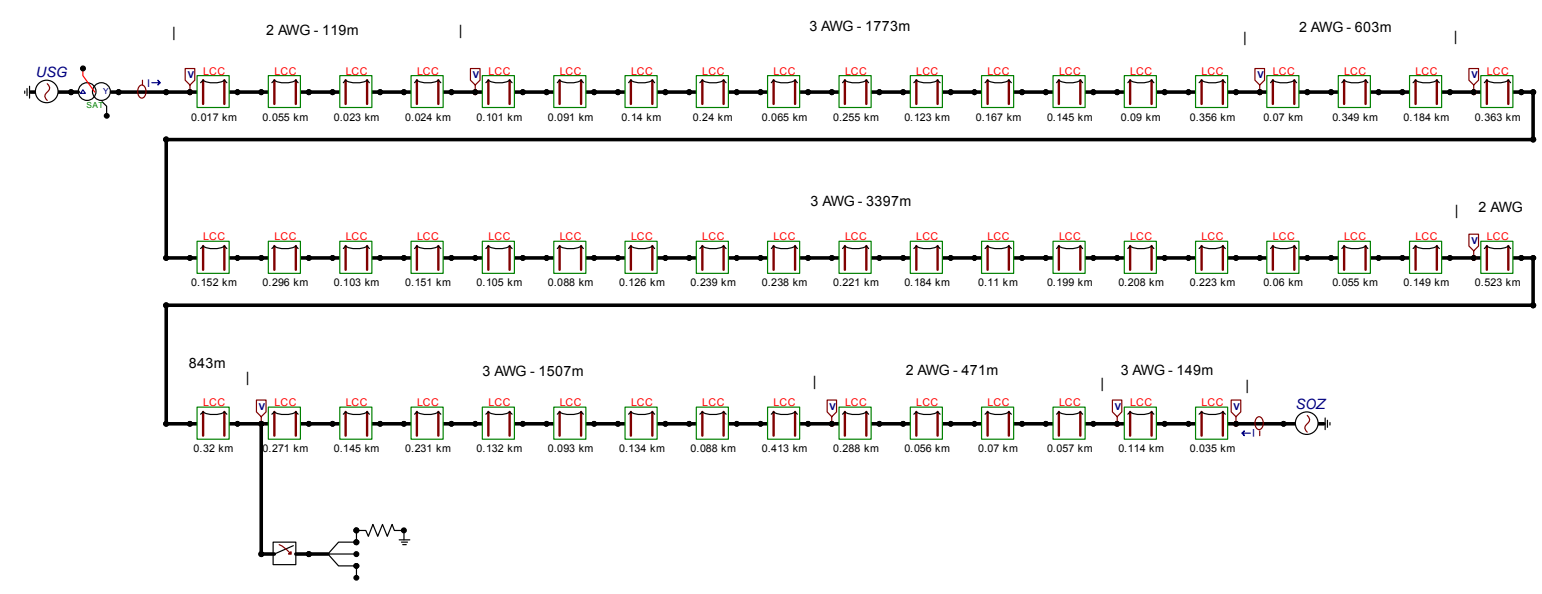

Figura 4-11 - Modelagem de uma falta monofásica aplicada na linha em estudo.

Na Figura 4-12 pode-se visualizar a forma de onda da tensão nas três fases devido a um curto aplicado na fase "A", com ângulo de incidência de $0^{\circ}$, a um ponto 
posicionado a aproximadamente na mesma distância dos curtos-circuitos aplicados sobre o modelo reduzido. O curto foi aplicado com uma impedância de $10 \Omega$, sendo as medições realizadas no ponto de defeito.

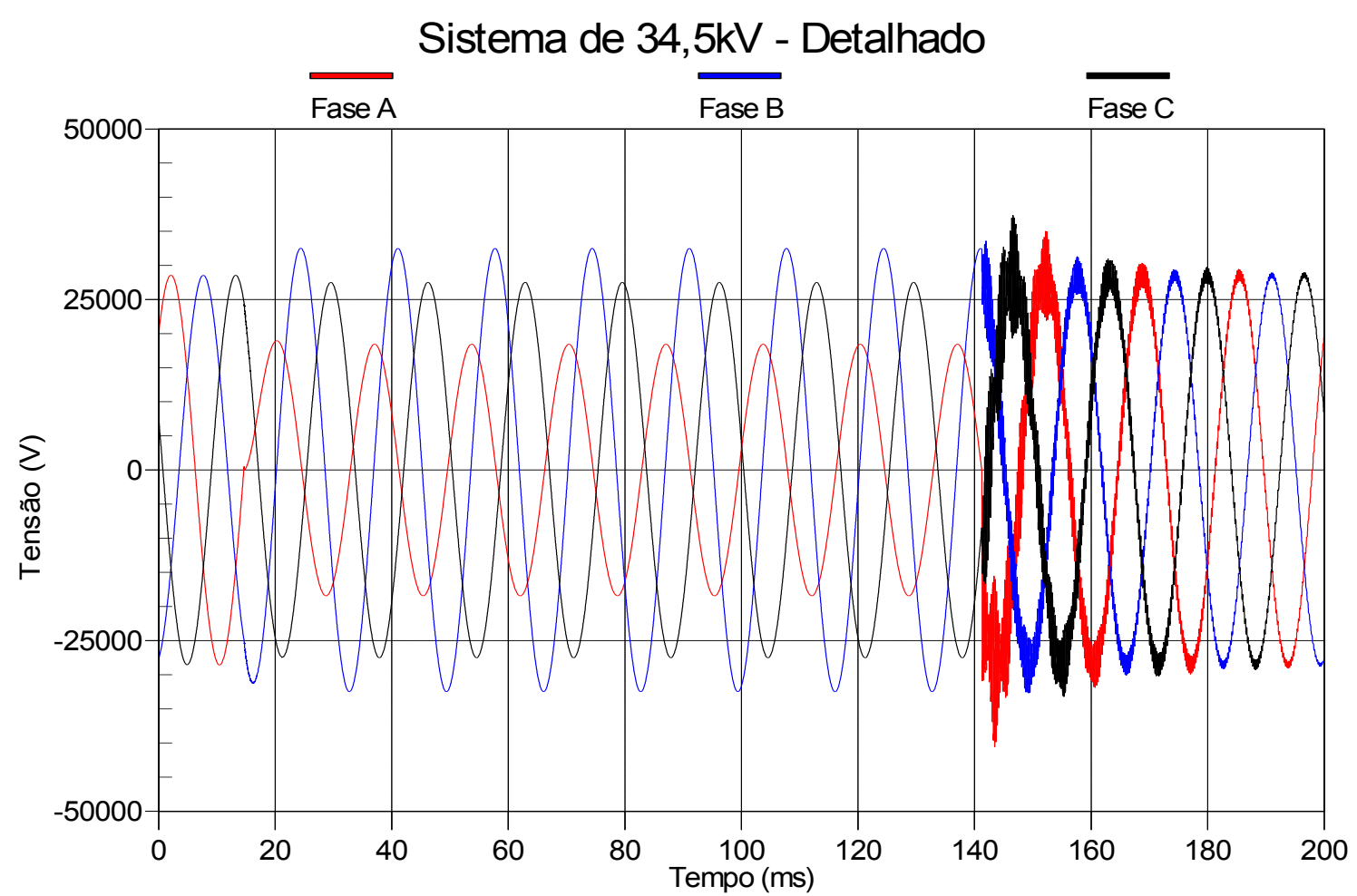

Figura 4-12 - Formas de ondas da tensão nas fases "A", "B" e "C" após a ocorrência de uma falta na fase " $A$ " do sistema em análise, com uma resistência e ângulo de incidência da falta de $10 \Omega$ e $0^{\circ}$, respectivamente.

Os demais curtos foram realizados utilizando-se do mesmo modelo do curto monofásico, somente fazendo as alterações necessárias para caracterizar as situações bifásicas e/ou trifásicas desejadas.

Pode-se observar pela Figura 4-13 que a variação das fases durante um curto bifásico aplicado é menor do que a variação apresentada por um curto monofásico, mostrada na Figura 4-12. 


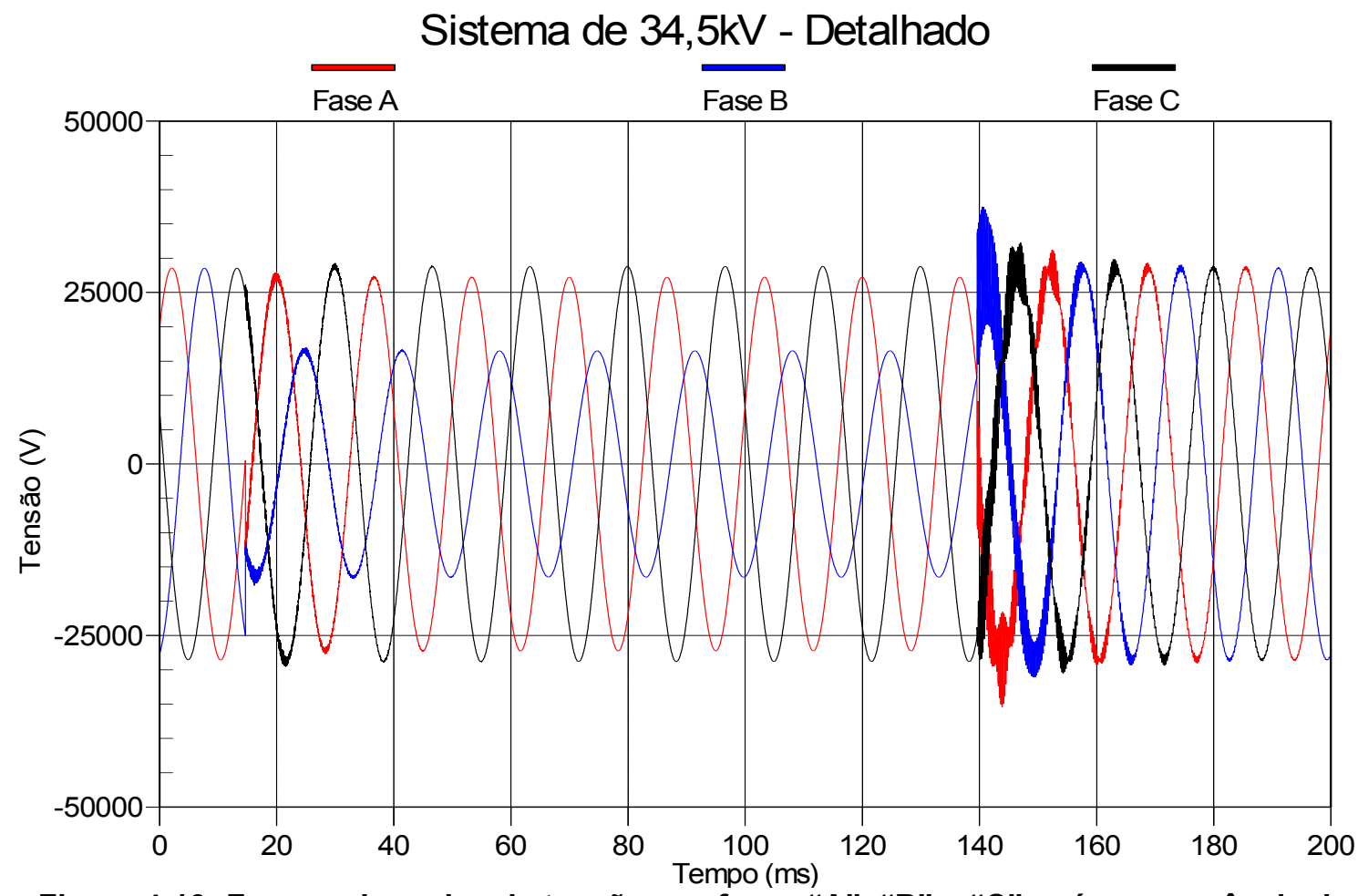

Figura 4-13- Formas de ondas da tensão nas fases " $A$ ", "B" $e$ "C" após a ocorrência de uma falta bifásica envolvendo as fases " $A$ " e " $B$ " do sistema em análise, com uma resistência $e$ ângulo de incidência da falta de $10 \Omega$ e $0^{\circ}$, respectivamente.

A Figura 4-14 ilustra a mesma situação de curto anteriormente aplicada, diferindo apenas no envolvimento do terra. 


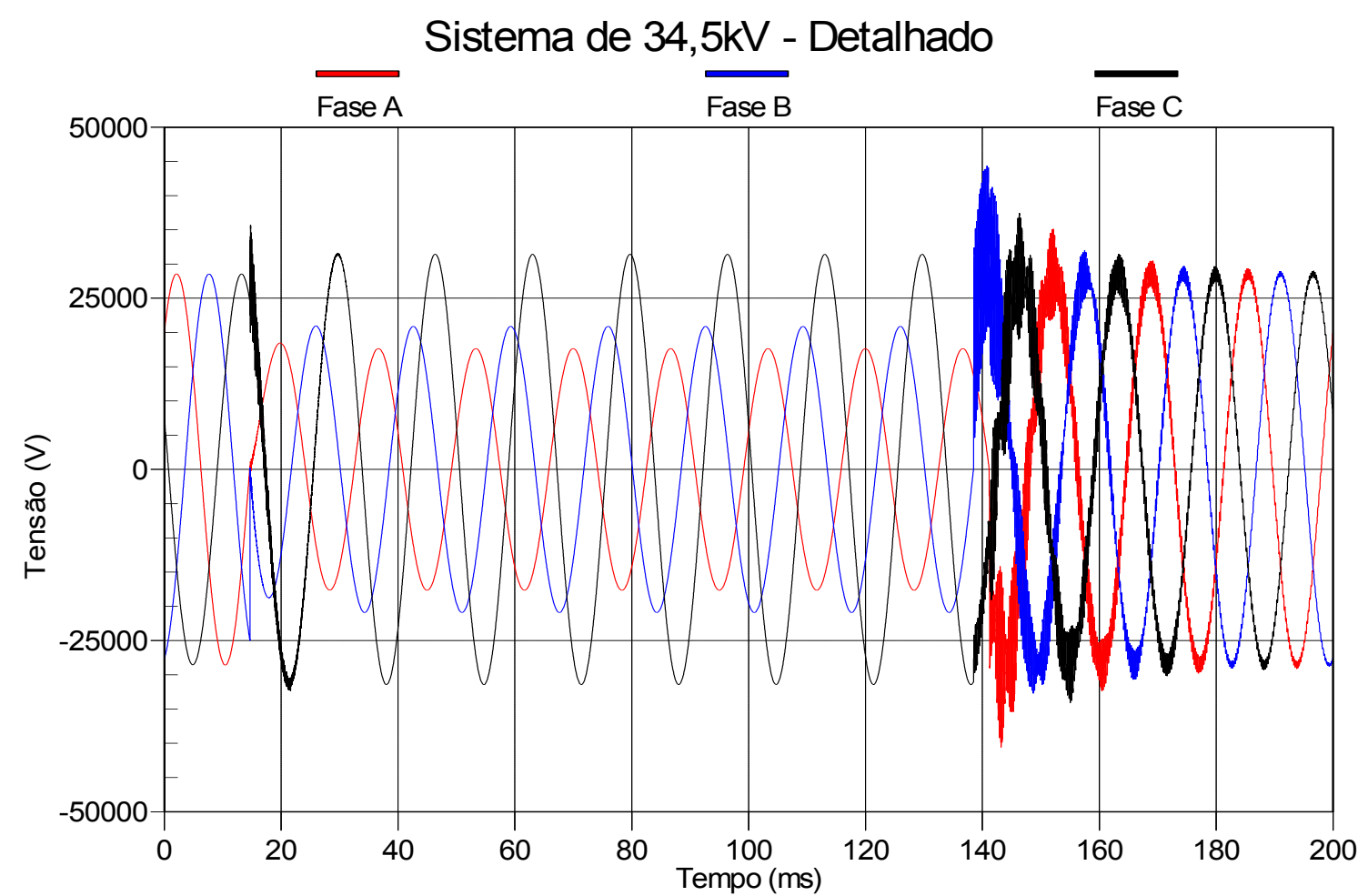

Figura 4-14 - Formas de ondas da tensão nas fases "A", "B" $e$ " $C$ " após a ocorrência de uma falta bifásica com o envolvimento do terra (“AB-T”), com uma resistência e ângulo de incidência da falta de $10 \Omega \mathrm{e} 0^{\circ}$, respectivamente.

É possível notar, nas Figura 4-15 e Figura 4-16, que as formas das ondas de tensão durante um curto trifásico são menores do que os valores em regime normal de operação. Portanto, esta será um tipo de situação de defeito que menos influenciará nos estudos de isolamento da linha.

Contudo, atenção a parte deve ser dada quando da retomada do sistema à condição normal de operação. Salienta-se que para todos os tipos de defeitos aplicados, não foram considerados e implementados os dispositivos de proteção que estarão atuando e imprimindo ao sistema, e em conseqüência, às formas de ondas das tensões trifásicas, comportamentos peculiares em função da intervenção provocada. 


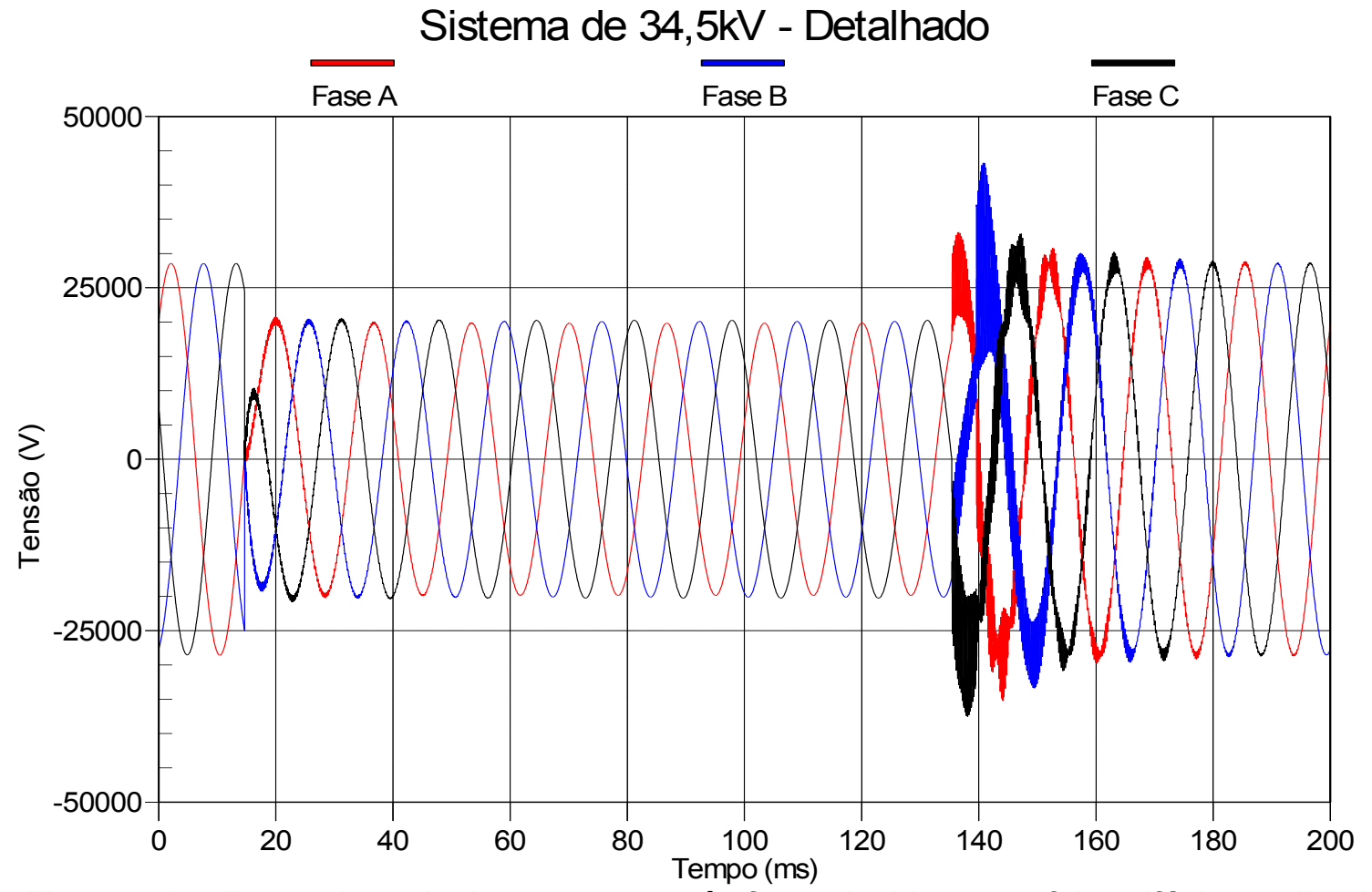

Figura 4-15 - Forma de onda da tensão nas três fases devido a uma falta trifásica, aplicada no meio da linha do sistema em análise, com uma resistência e ângulo de incidência da falta de 10 $\Omega$ e $0^{\circ}$, respectivamente.

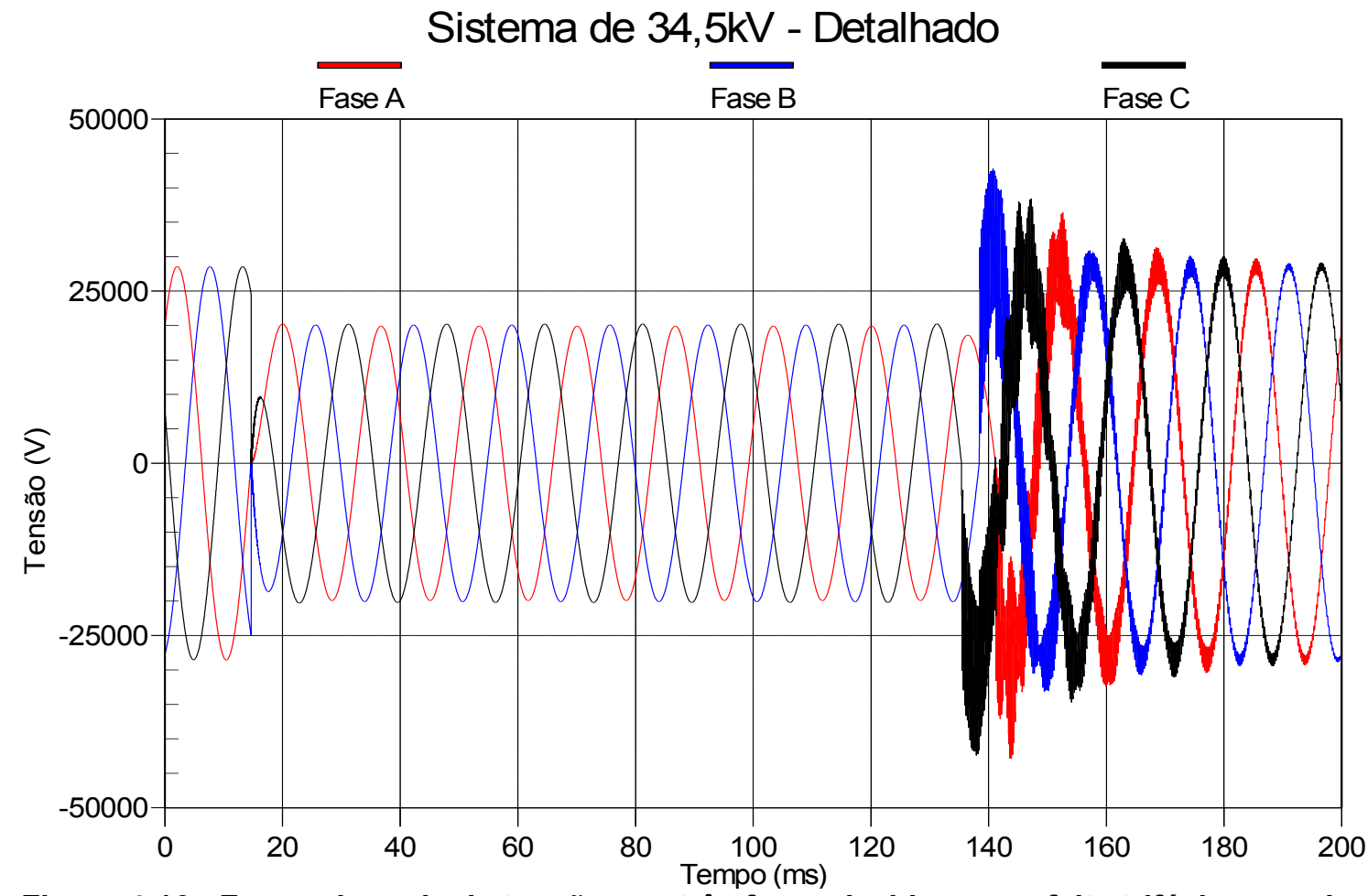

Figura 4-16 - Forma de onda da tensão nas três fases devido a uma falta trifásica envolvendo o terra, aplicada no meio da linha do sistema em análise, com uma resistência e ângulo de incidência da falta de $10 \Omega$ e $0^{\circ}$, respectivamente. 


\subsubsection{3 - CONCLUSÕES PARCIAIS SOBRE AS SIMULAÇÕES REALIZADAS SOBRE O SISTEMA DE 34,5 KV}

Infere-se das simulações realizadas no sistema de $34,5 \mathrm{kV}$, reduzido e expandido, importantes informações quanto ao funcionamento da linha de transmissão. As diferenças apresentadas pelo sistema reduzido com relação ao expandido não são significativas, porém, ainda assim, deve-se insistir na expansão de maneira que se possa ter acesso aos valores de tensão que surgirão em todas as estruturas existentes no sistema. Apesar de não se ter abordado as simulações por completo, sabe-se da importância de se analisar situações de curtos-circuitos e de descargas atmosféricas em vários pontos da linha, bem como da observância das magnitudes de tensão resultantes, durante um surto, em todas as estruturas da linha.

\subsection{2 - SIMULAÇÕES SOBRE O SISTEMA EXPANDIDO DE 69 KV}

As simulações realizadas para o sistema de $69 \mathrm{kV}$ seguiram os mesmos moldes e passos utilizados para as simulações de $34,5 \mathrm{kV}$. O modelo utilizado também foi o mesmo (cf. Figura 4-10), salvo as devidas alterações necessárias, como a alteração do transformador, ligado à usina, e a mudança da classe de tensão no barramento da subestação, incluindo os valores de impedância positiva e negativa, calculados a partir da potência de curto-circuito do barramento de $69 \mathrm{kV}$, ao invés de utilizar o de 34,5 kV anteriormente aplicado.

A Figura 4-17 representa um curto monofásico aplicado na linha com resistência de $10 \Omega$. Vale observar que a amplitude alcançada pela onda de tensão da fase "B", durante o curto aplicado na fase "A", atinge valores um pouco superiores 
ao regime nominal de operação, e o transitório que surge na eliminação do curto, atinge valores acima de $80 \mathrm{kV}$. Contudo, cabe colocar que este valor elevado não trará problemas, pois o transitório permanece por um curto período de tempo e, além disso, o curto deverá ser eliminado pelo sistema de proteção, fazendo com que o retorno do sistema ao regime não apresente um transitório dessa magnitude.

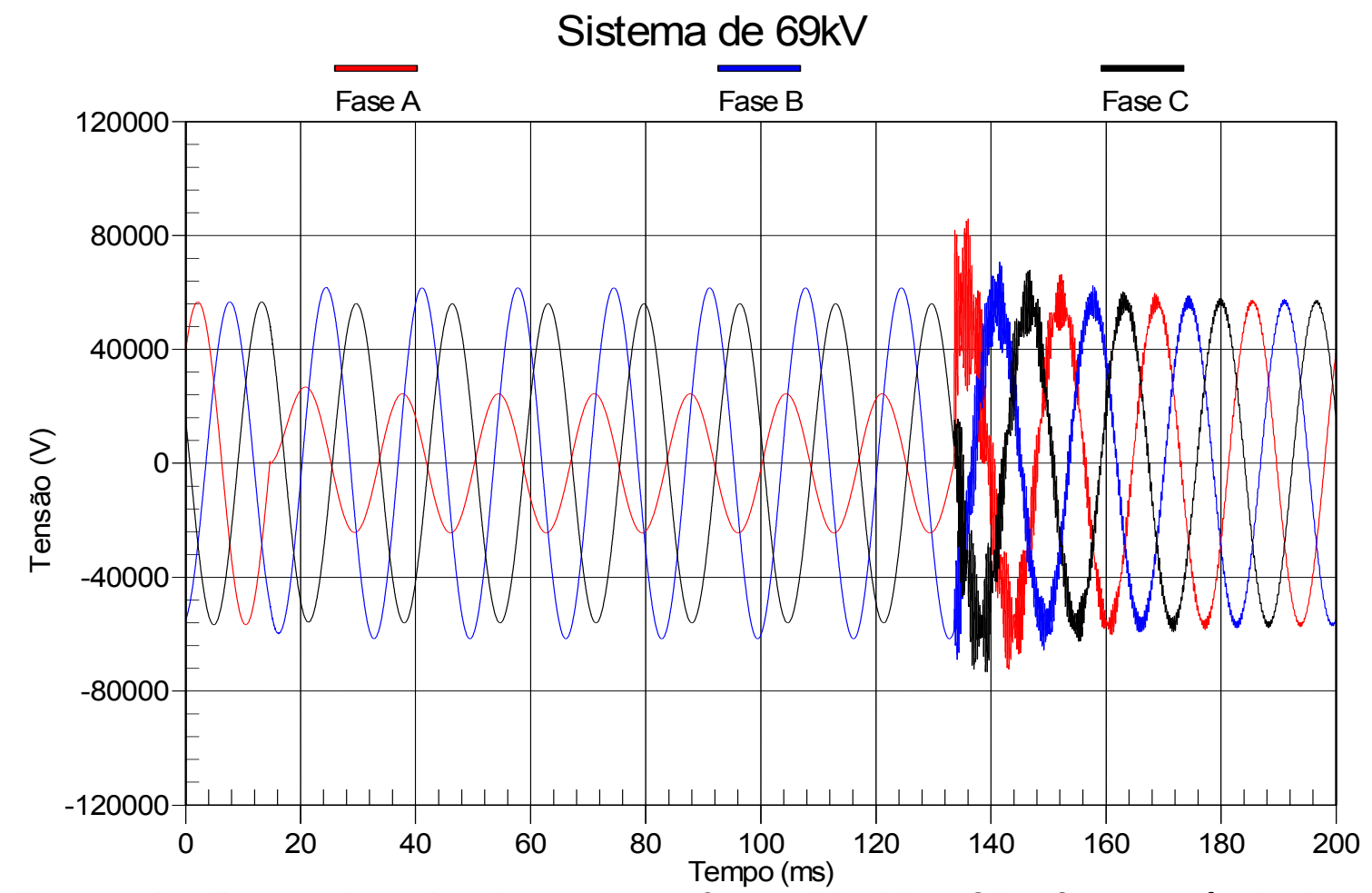

Figura 4-17 - Formas de ondas da tensão nas fases "A", "B" e "C" após a ocorrência de uma falta na fase "A" do sistema em análise, com uma resistência e ângulo de incidência da falta de $10 \Omega$ e $0^{\circ}$, respectivamente.

Já os curtos bifásicos apresentaram elevações menores na amplitude da tensão da fase que não está envolvida. A Figura 4-18 apresenta esse tipo de curto aplicado na linha considerando uma resistência de curto de $10 \Omega$. 


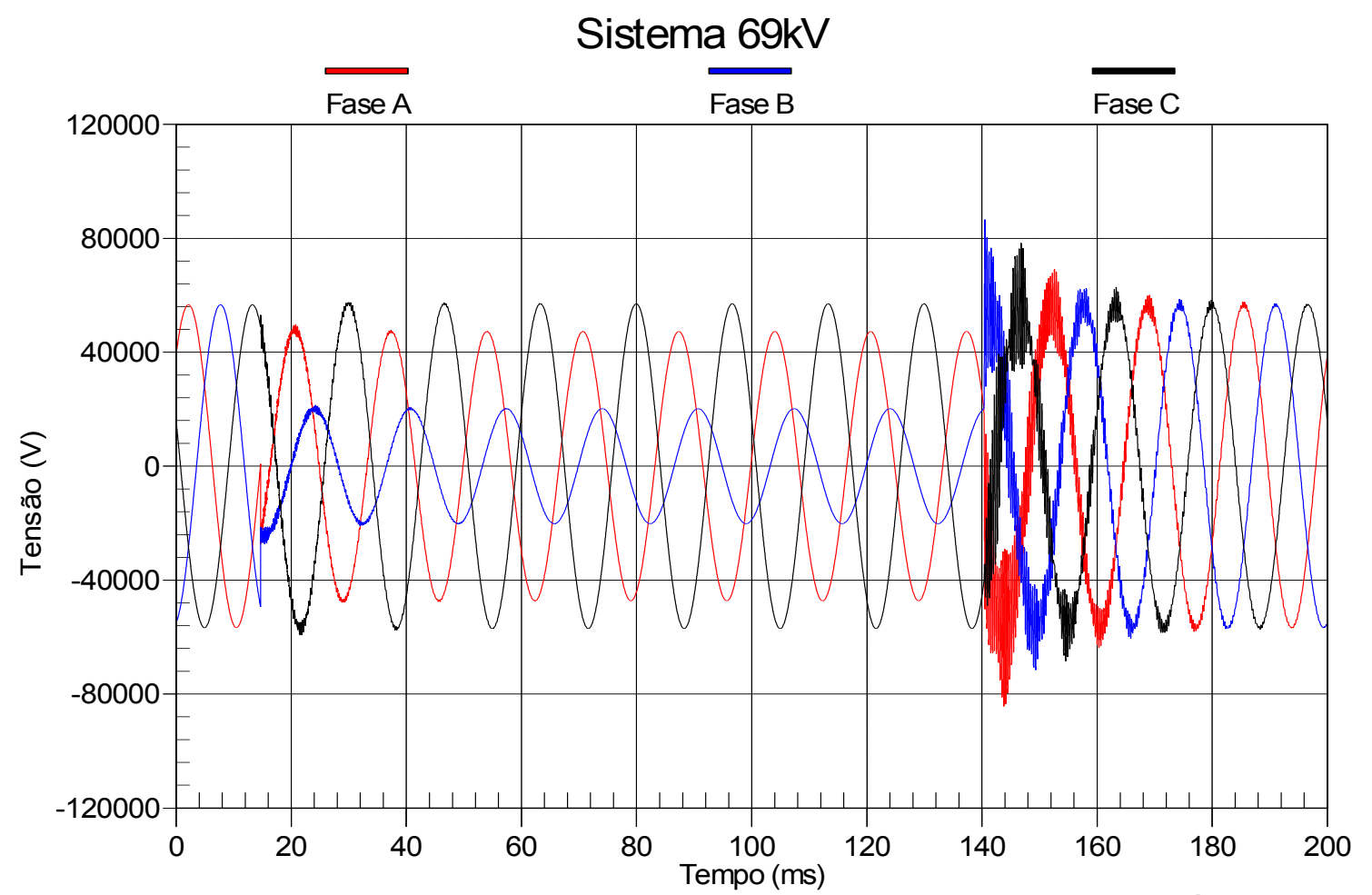

Figura 4-18- Formas de ondas da tensão nas fases "A", "B" $e$ "C" após a ocorrência de uma falta bifásica ("AB"), com uma resistência e ângulo de incidência da falta de $10 \Omega$ e $0^{\circ}$, respectivamente.

O curto bifásico ilustrado pela Figura 4-18 apresentou um transitório da mesma forma como o curto bifásico, com o envolvimento do terra da Figura 4-19. Isso ocorre, pois no equivalente que representa a subestação foi configurada a impedância de curto-circuito de sequência positiva e de sequência zero que pode ser uma das causas dos transitórios no sistema. 


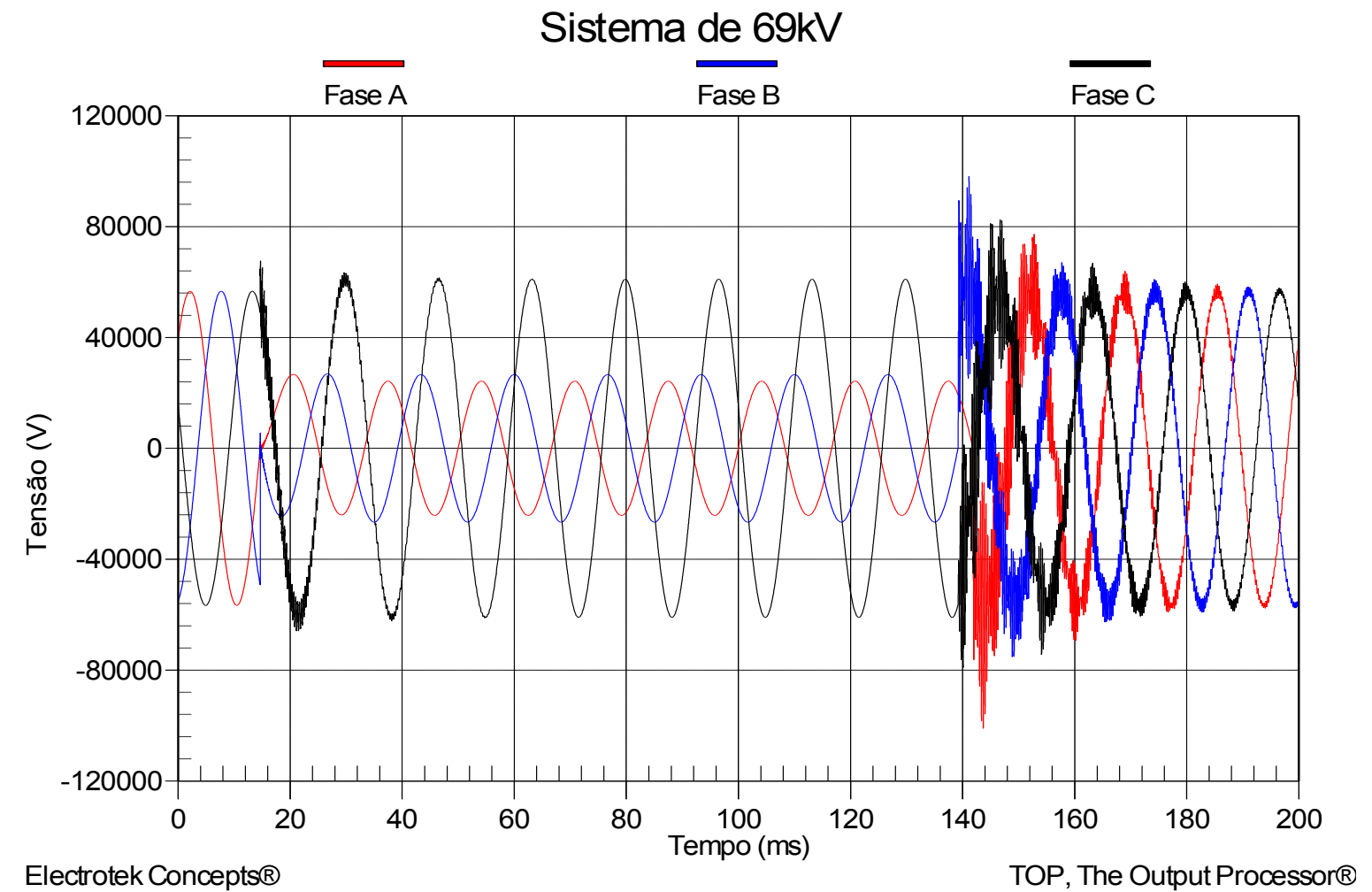

Figura 4-19- Formas de ondas da tensão nas fases "A", "B" $e$ "C" após a ocorrência de uma falta bifásica com o envolvimento do terra ("AB-T"), com uma resistência e ângulo de incidência da falta de $10 \Omega \mathrm{e} 0^{\circ}$, respectivamente.

Conforme pode ser observado, a fase "B" atingiu valores acima de $80 \mathrm{kV}$.

Porém, esse valor durou milésimos de segundos, não vindo a representar uma preocupação quanto à isolação da linha em análise.

As Figura 4-20 e Figura 4-21 ilustram uma situação de um curto trifásico, sem e com a presença do terra, respectivamente. 


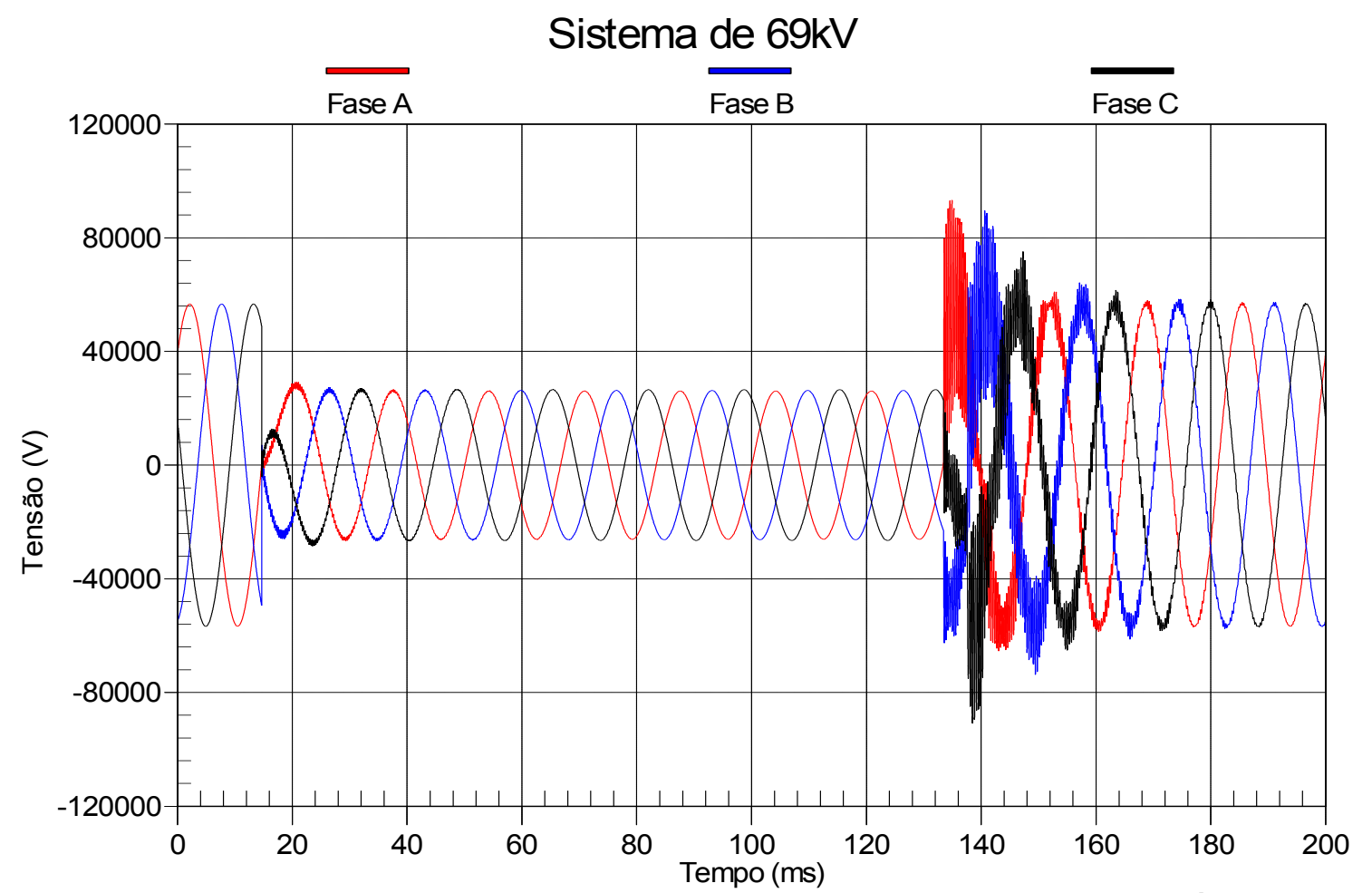

Figura 4-20 - Formas de ondas da tensão nas fases "A", "B" $e$ "C" após a ocorrência de uma falta trifásica, com uma resistência e ângulo de incidência da falta de $10 \Omega$ e $0^{\circ}$, respectivamente.

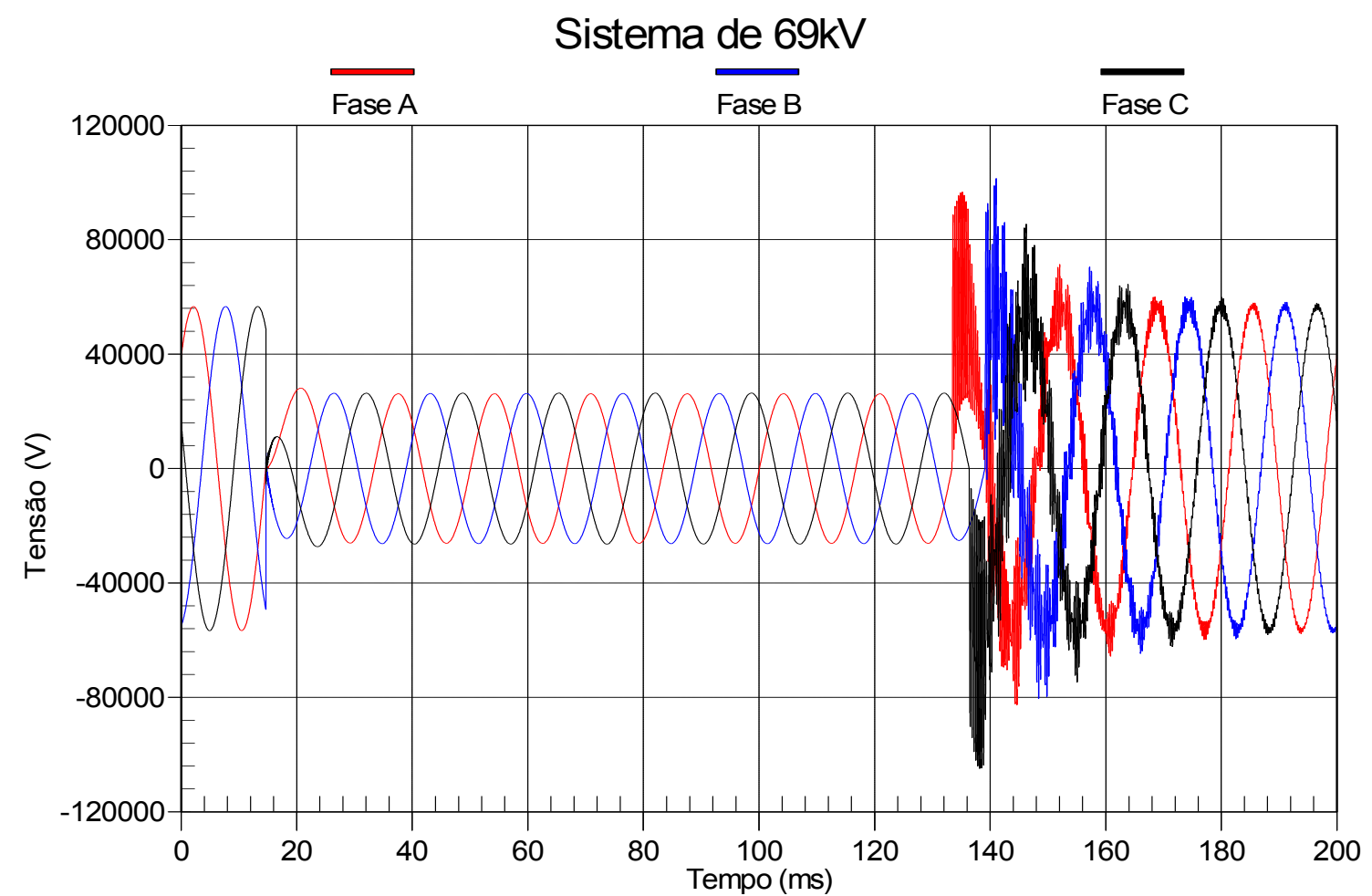

Figura 4-21 - Formas de ondas da tensão nas fases "A", "B" $e$ "C" após a ocorrência de uma falta trifásica, com o envolvimento do terra, com uma resistência e ângulo de incidência da falta de $10 \Omega$ e $0^{\circ}$, respectivamente. 
Conforme evidenciado, os curtos-circuitos trifásicos não apresentam elevação de tensão durante a presença do curto. Porém, assim como os demais tipos de curtos, podem surgir transitórios oscilatórios na eliminação destes.

\subsubsection{1 - CONCLUSÕES PARCIAIS SOBRE AS SIMULAÇÕES REALIZADAS SOBRE O SISTEMA $69 \mathrm{KV}$}

Observa-se através das simulações de curtos-circuitos realizadas que os valores mais altos encontrados foram quando da eliminação do curto propriamente dito, que foi feita simplesmente abrindo a chave responsável em caracterizar a situação de defeito sobre o sistema. Portanto, esse transitório não deverá existir quando o sistema de proteção da linha atuar eliminando o curto de maneira adequada e como o esperado.

Mesmo tendo a informação de que o transitório da eliminação do curto nestas simulações deverá ser menor com o funcionamento da proteção, e sabendose que as magnitudes de tensão nas três fases do sistema não apresentam elevação durante um curto trifásico, devem ser realizadas as simulações de todos os tipos de curtos. Estas simulações permitirão um amplo conhecimento da resposta da linha, bem como a preparação de futuros estudos direcionados à proteção, já que estes também fazem parte da metodologia em proposição.

\subsection{3 - DESCARGAS ATMOSFÉRICAS}

Cabe elucidar que as simulações das descargas atmosféricas serão aplicadas diretamente na linha de subtransmissão. A Figura 4-22 ilustra, 
graficamente, o modelo utilizado para aplicar uma situação representativa de uma descarga atmosférica em um ponto em específico da linha. Observa-se que as extremidades da linha estão aterradas, pois dessa maneira, é possível analisar somente o comportamento da descarga atmosférica na linha. Contudo, vale frisar que é possível analisar os valores das descargas atmosféricas juntamente com os valores de operação da linha em regime.

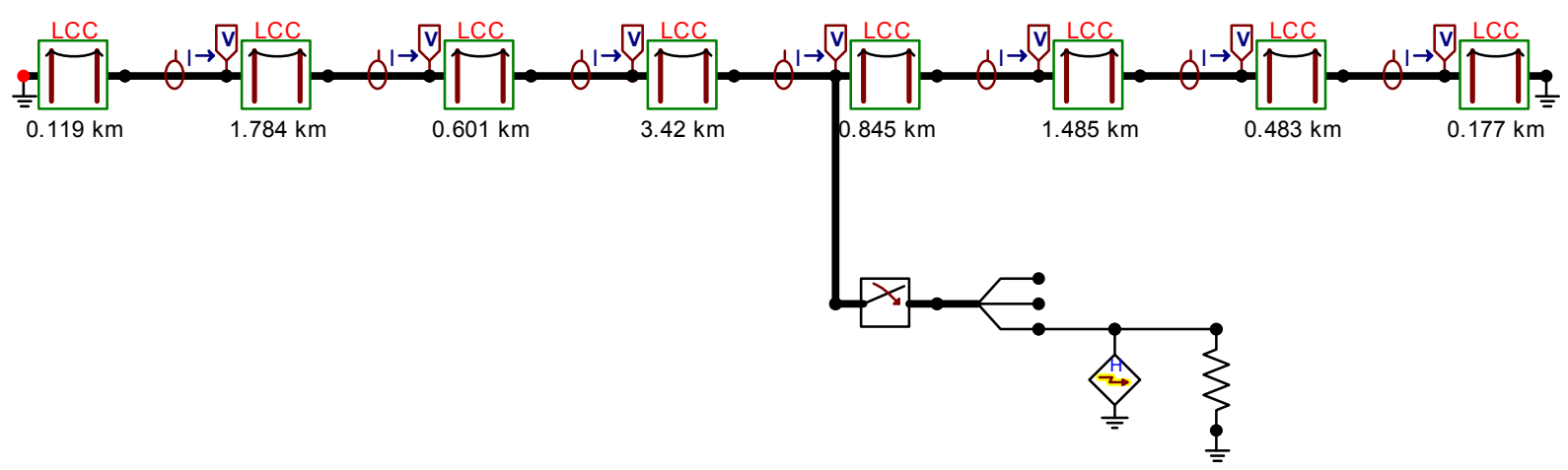

Figura 4-22 - Uma situação de descarga atmosférica aplicada diretamente sobre um ponto em específico do sistema em análise

De acordo com Diesendorf (1974, p. 47), sessenta e cinco por cento das descargas possuem uma corrente igual ou inferior a $10 \mathrm{kA}$, com um tempo de subida de $1,2 \mu$ s e um tempo de descida de $50 \mu$ s. Para simular uma situação de interesse representando uma descarga atmosférica, a corrente de descarga foi aplicada em um ponto específico da linha, em paralelo com um canal de impedância que varia entre 1000 e $3000 \Omega$ (DIESENDORF, 1974).

A fonte de corrente utilizada foi do tipo Heidler type 15 (EEUG, 1987), com uma resistência em paralelo, ambas configuradas de acordo com as indicações de Diesendorf (1974, p. 48).

A Figura 4-23 representa as formas de onda das tensões induzidas por uma descarga atmosférica, aplicada e medida no meio da linha, nas três fases do sistema. 
O que se nota, é que o valor da onda de tensão gerada pela descarga atinge valores maiores que $2000 \mathrm{kV}$ (IEEE STD 1410). É importante relembrar que, além dessa descarga ter sido aplicada diretamente, esse valor foi medido no ponto da descarga atmosférica, e que conforme se distancia o ponto de medição do ponto dessa descarga, obtém-se um valor menor em função da amortização (decréscimo) da corrente de descarga.

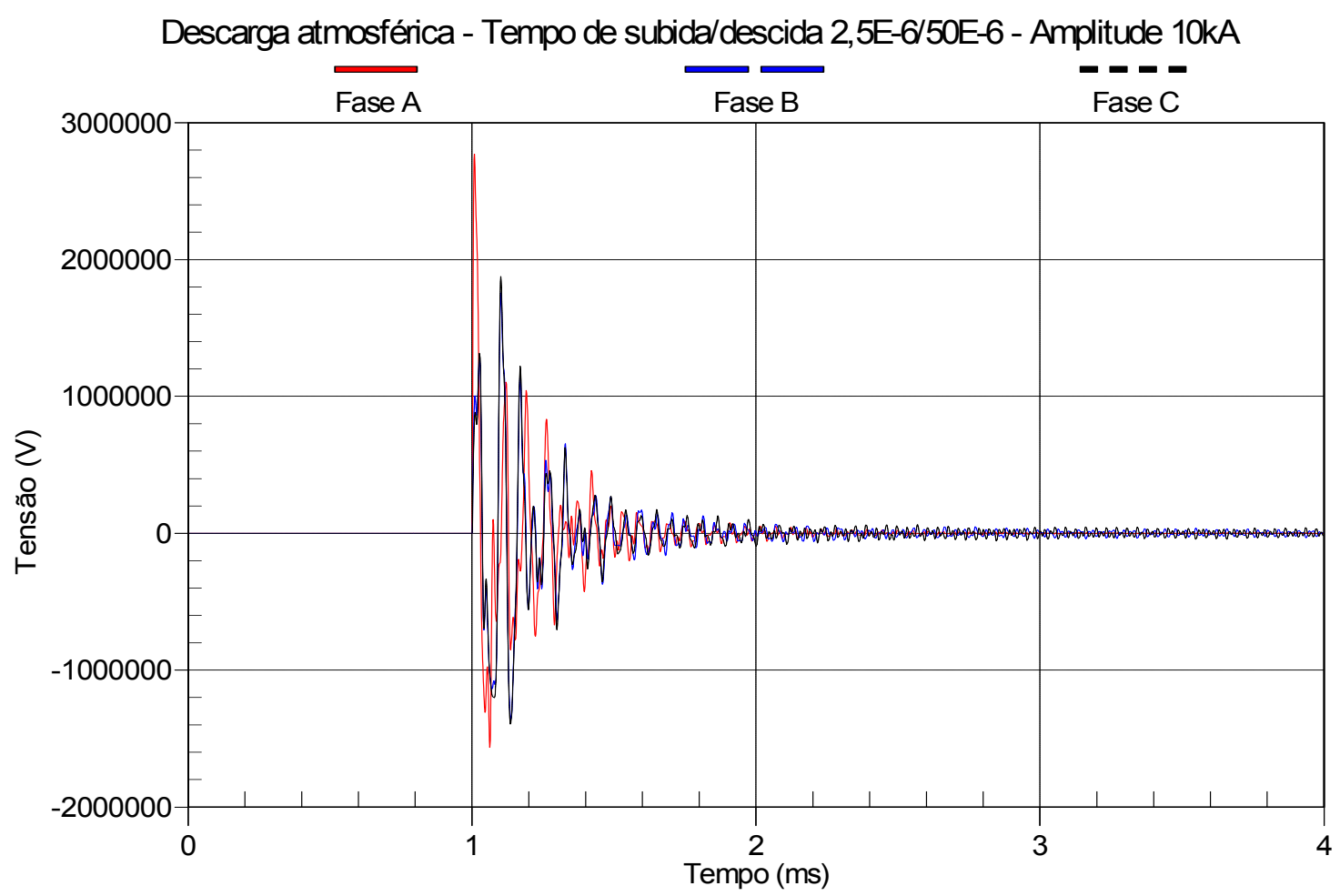

Figura 4-23 - Descarga atmosférica incidente sobre a fase "A" do sistema em análise, aplicada e medida próxima ao meio da linha.

Para melhor exemplificar o amortecimento da corrente de descarga, uma determinada situação foi aplicada na extremidade da linha conectada à usina de Salto Grande e medida em três pontos distintos: no ponto de incidência da descarga, em um ponto próximo ao meio da linha e na extremidade da linha conectada à subestação de Souzas.

A Figura 4-24 representa a forma de onda das tensões nas três fases devido a uma descarga aplicada na fase "A" próxima à usina. 


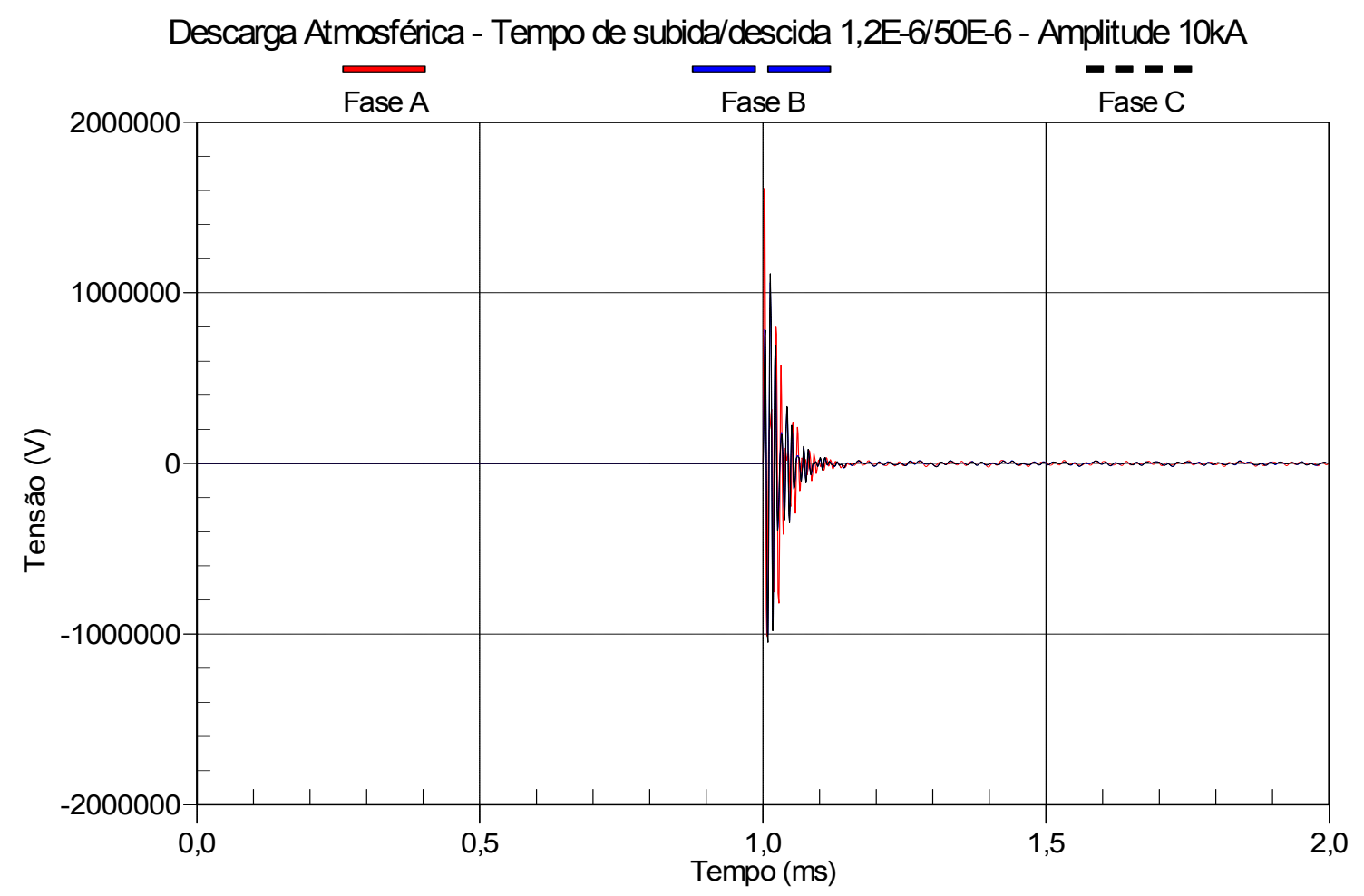

Figura 4-24 - Descarga atmosférica incidente na fase "A", aplicada e medida na extremidade da linha próxima à Usina de Salto Grande.

Na Figura 4-25, observa-se a forma de onda das três fases da tensão induzida pela descarga aplicada próxima à usina, porém medida no meio da linha, da mesma forma como a demonstrada na figura anterior. Nota-se uma redução na amplitude das tensões de aproximadamente $2000 \mathrm{kV}$ para $200 \mathrm{kV}$. Isso se deve ao amortecimento da linha, conforme anteriormente apontado. 


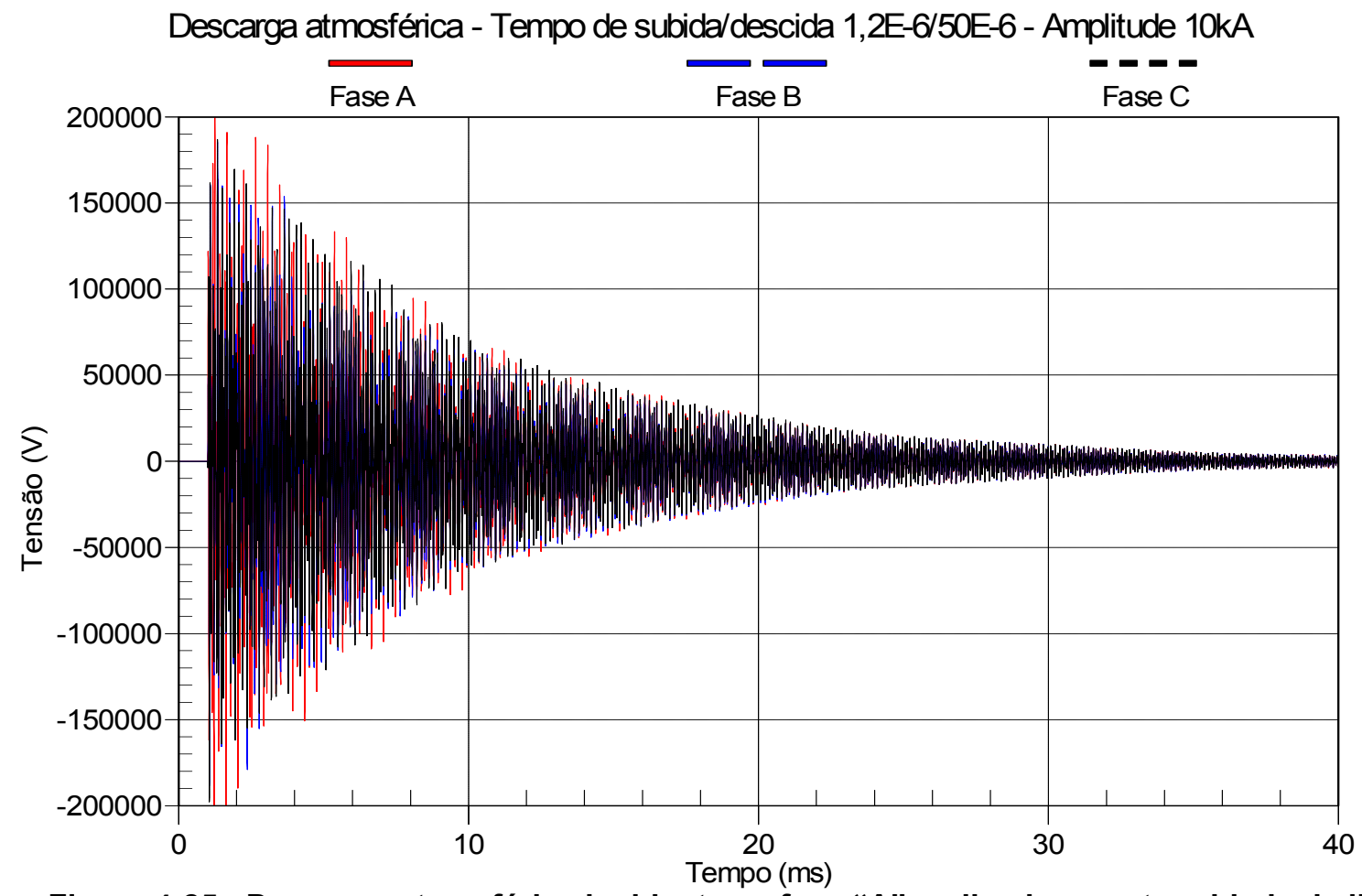

Figura 4-25 - Descarga atmosférica incidente na fase "A", aplicada na extremidade da linha próxima à Usina de Salto Grande e medida em um ponto próximo ao meio da linha.

A Figura 4-26 apresenta as formas de onda das tensões nas três fases do sistema medidas na extremidade da linha (subestação de Souzas), após a consideração de uma descarga atmosférica aplicada na extremidade da linha junto a Usina de Salto Grande. Nota-se uma redução nas amplitudes ainda maior do que a figura anterior, que representava a medição realizada no meio da linha. 


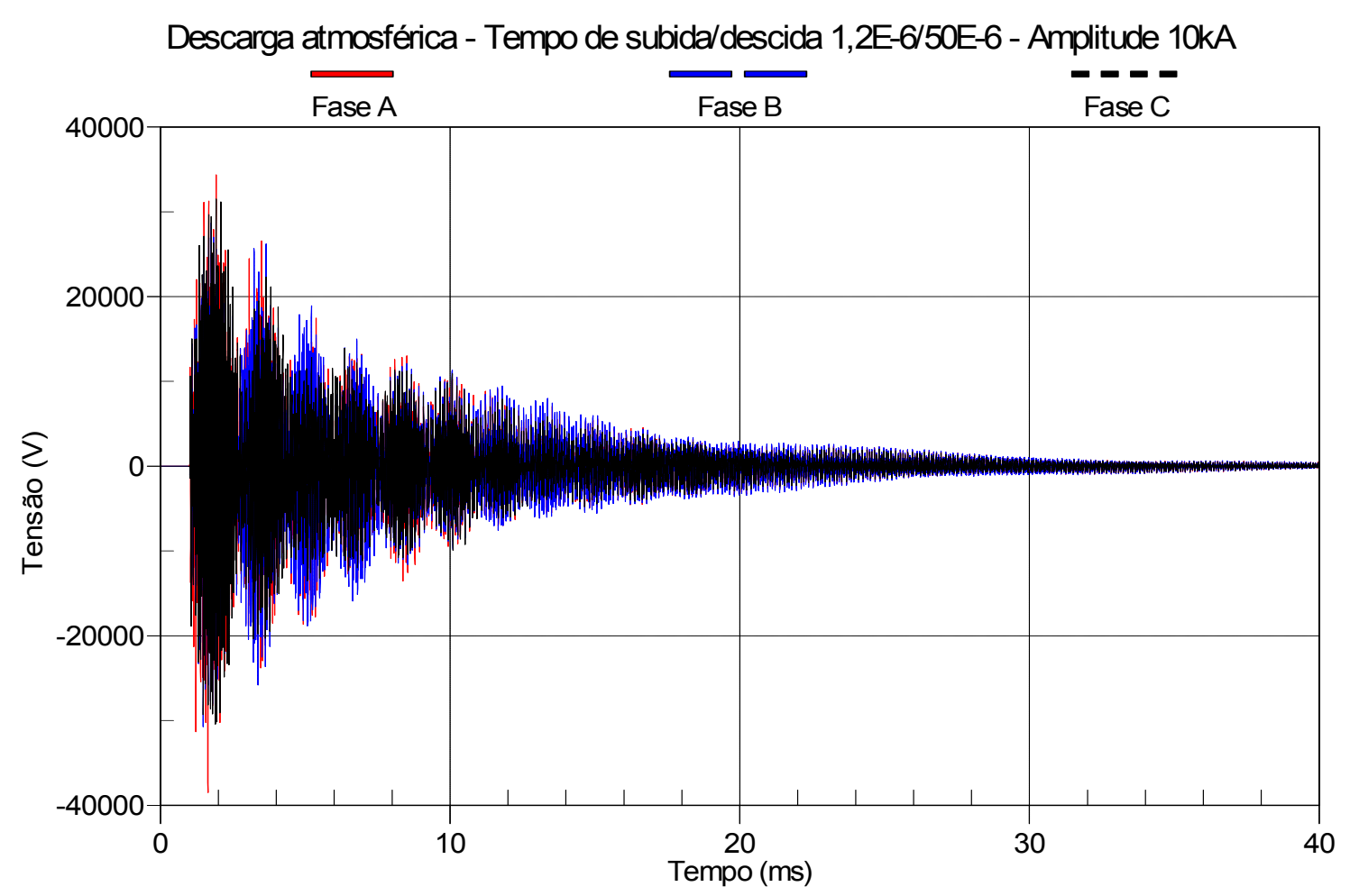

Figura 4-26 - Sobretensões originadas na extremidade da linha conectada à subestação de Souzas devido a uma descarga atmosférica aplicada na extremidade oposta da linha.

\subsubsection{1 - CONCLUSÕES PARCIAIS SOBRE AS SIMULAÇÕES DE DESCARGAS ATMOSFÉRICAS}

As simulações de descargas atmosféricas realizadas demonstram a importância de um estudo mais aprofundado com relação à proteção da linha. Apesar de não terem sido exploradas outras amplitudes de descargas, foram representadas algumas situações que nortearão um futuro estudo relacionado à aplicação de pára-raios nesta linha. 


\section{Capítulo 5 \\ Alternativas para a Melhoria de Desempenho}

Durante a repotenciação das linhas de subtransmissão, deve-se ter uma preocupação quanto à melhoria do desempenho destas frente aos possíveis desligamentos. Dessa forma, uma análise dos campos elétricos resultantes em torno das estruturas existentes na linha será de grande valia. Para a realização desse estudo, utilizou-se dos valores obtidos através das simulações de transitórios eletromagnéticos, realizadas e demonstradas no capítulo anterior. Neste sentido, foram utilizadas as tensões obtidas no regime normal de operação da linha para o sistema de 34,5 e $69 \mathrm{kV}$ para ilustrar as simulações inseridas no item 5.1 que vem a seguir.

Já para o item 5.2, serão abordados os aspectos relacionados à proteção do sistema atual de $34,5 \mathrm{kV}$ e do futuro sistema de $69 \mathrm{kV}$, ressaltando a proteção existente e as mudanças necessárias para a operação da nova linha.

\section{1 - SIMULAÇÕES PERTINENENTES AOS ISOLADORES ASSOCIADOS AOS SISTEMAS DE 34,5 E $69 \mathrm{KV}$}

Após a realização das simulações de surtos sobre os sistemas de interesse (34,5 e $69 \mathrm{kV})$, é necessário realizar melhorias quanto ao desempenho dessa linha. Para isso, fez-se uma análise quanto à classe de isolação dos sistemas. Para essa análise, foram escolhidos softwares que fazem uso do método de elementos finitos para os cálculos dos campos elétricos e das linhas de potencial. Cabe colocar que existem alguns softwares comerciais que realizam esses cálculos como, por exemplo, o Coulomb 3D da Integrated Soft (Software, 2009), o Femlab da Comsol (Femlab®, 2004) e o Flux®, desenvolvido pela Cedrat (FLUX2D, 2007), que será 
utilizado no presente trabalho. O software Flux® foi escolhido pela disponibilidade do mesmo no laboratório onde este trabalho foi desenvolvido. Ressalta-se que nenhuma comparação de desempenho entre os softwares acima citados foi realizada.

Com relação ao método dos elementos finitos, cabe apenas colocar que este consiste em uma forma de resolução numérica para a solução de equações diferenciais parciais. Este método é muito aplicado para cálculos em diversos campos como mecânico estrutural e dos fluídos, e nesse caso em específico, para o cálculo dos campos elétricos, magnéticos e das linhas de potencial devidas a uma carga elétrica.

Pretende-se para este momento, apenas introduzir a modelagem inicial dos isoladores. Sendo assim, será mostrado somente o isolador modelado com suas linhas de potencial e seus campos elétricos.

Ressalta-se que para a obtenção dos resultados que vem a seguir, foi aplicada uma tensão de $28.169,13 \mathrm{~V}$ em um primeiro momento e, em seguida, uma tensão de 56.338,26 V. Esses valores correspondem aos valores da tensão de fase de pico para os sistemas de $34,5 \mathrm{kV}$ e de $69 \mathrm{kV}$, respectivamente.

Como primeiro passo, modelou-se o isolador de $34,5 \mathrm{kV}$ tipo pino utilizado nas estruturas do tipo "A" e "B", baseando-se em medidas do isolador real utilizado no sistema de $34,5 \mathrm{kV}$ em análise.

A Figura 5-1 demonstra um dos isoladores já modelado com a malha de elementos finitos utilizada para os cálculos. Nota-se que a malha é mais fina nas proximidades do isolador. Esta modelagem, apesar de aumentar o esforço computacional, é necessária para se obter resultados próximos aos reais. 


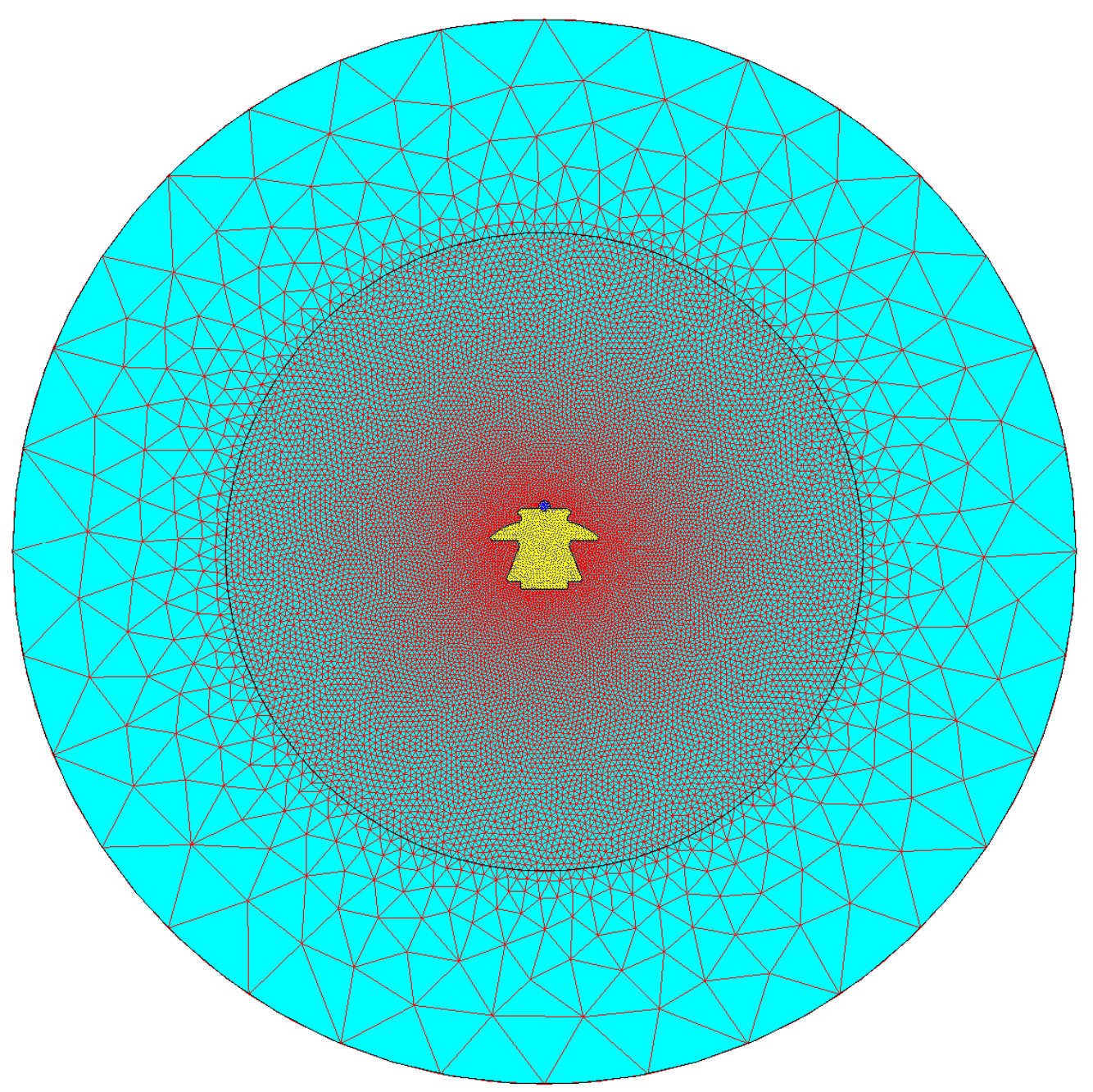

Figura 5-1 - Isolador modelado com a malha utilizada para os cálculos dos elementos finitos

A Figura 5-2 representa o mesmo isolador com as linhas de potencial geradas pela tensão no condutor, bem como um quadro com os valores das linhas de potencial. Conforme anteriormente apontado, a tensão aplicada neste caso foi de $28.169,13 \mathrm{~V}$.

Através das linhas de potencial, pode-se obter o valor da diferença de potencial entre duas linhas e, sabendo-se que a rigidez dielétrica do ar pode ser caracterizada pelo valor de uma tensão de $600 \mathrm{kV} / \mathrm{m}$ (IEEE STD 1410), tem-se uma distância de segurança para que não haja o arco elétrico. Cabe frisar que este estudo deve ser mais aprofundado levando em consideração os demais isoladores 
existentes na estrutura. Tal tarefa faz parte de outro trabalho em desenvolvimento relacionado ao projeto de P\&D inicialmente comentado.

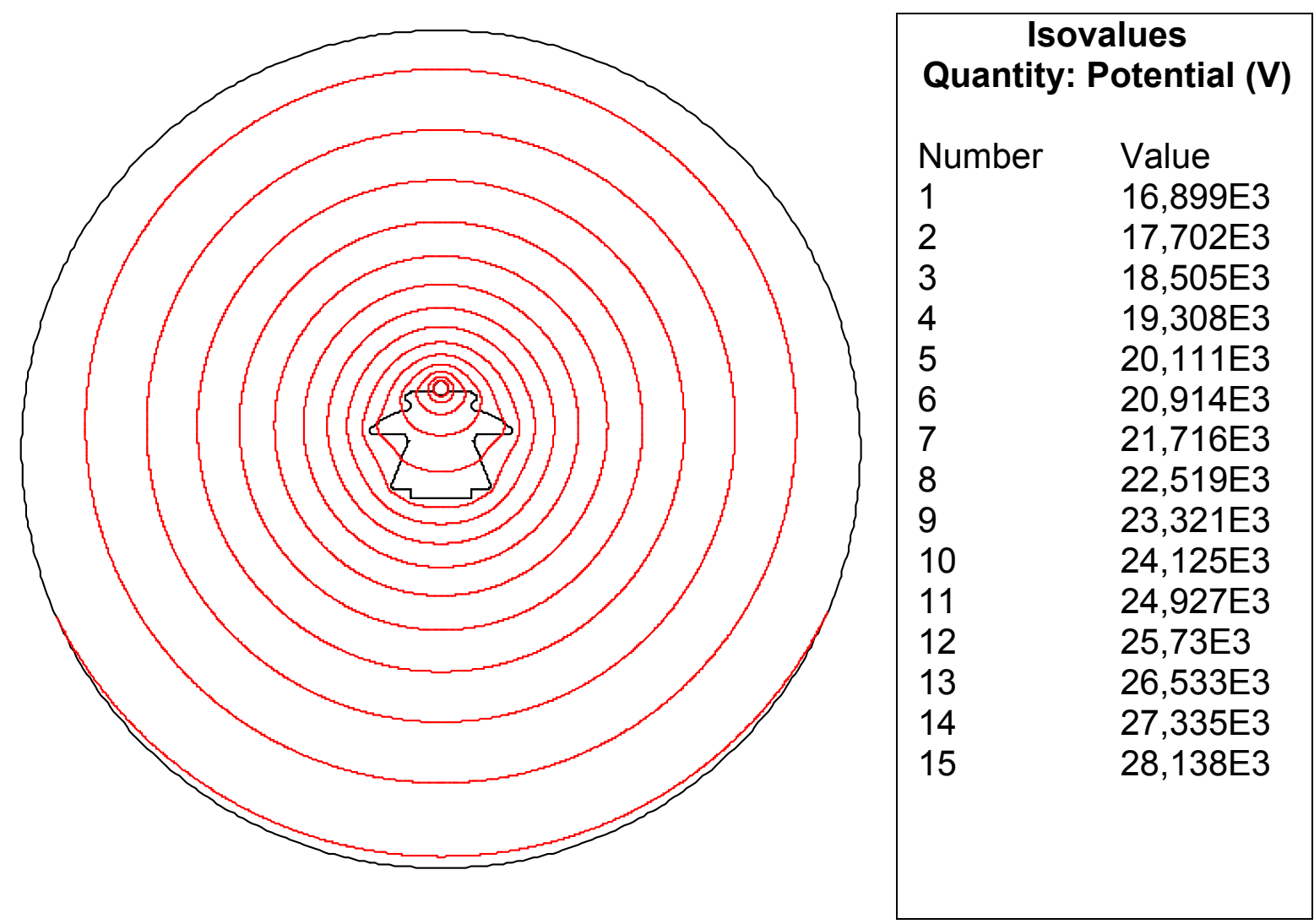

Figura 5-2 - Linhas de potencial para a tensão de pico de fase do sistema de 34,5 kV.

A Figura 5-3 representa o isolador em cores, mostrando os campos elétricos resultantes em torno do mesmo. O resultado apresentando os valores de campo elétrico é útil para os cálculos das linhas de potencial. Porém, tendo os resultados apresentados pelo software na forma de linhas de potencial, torna-se mais rápido o entendimento do fenômeno. 


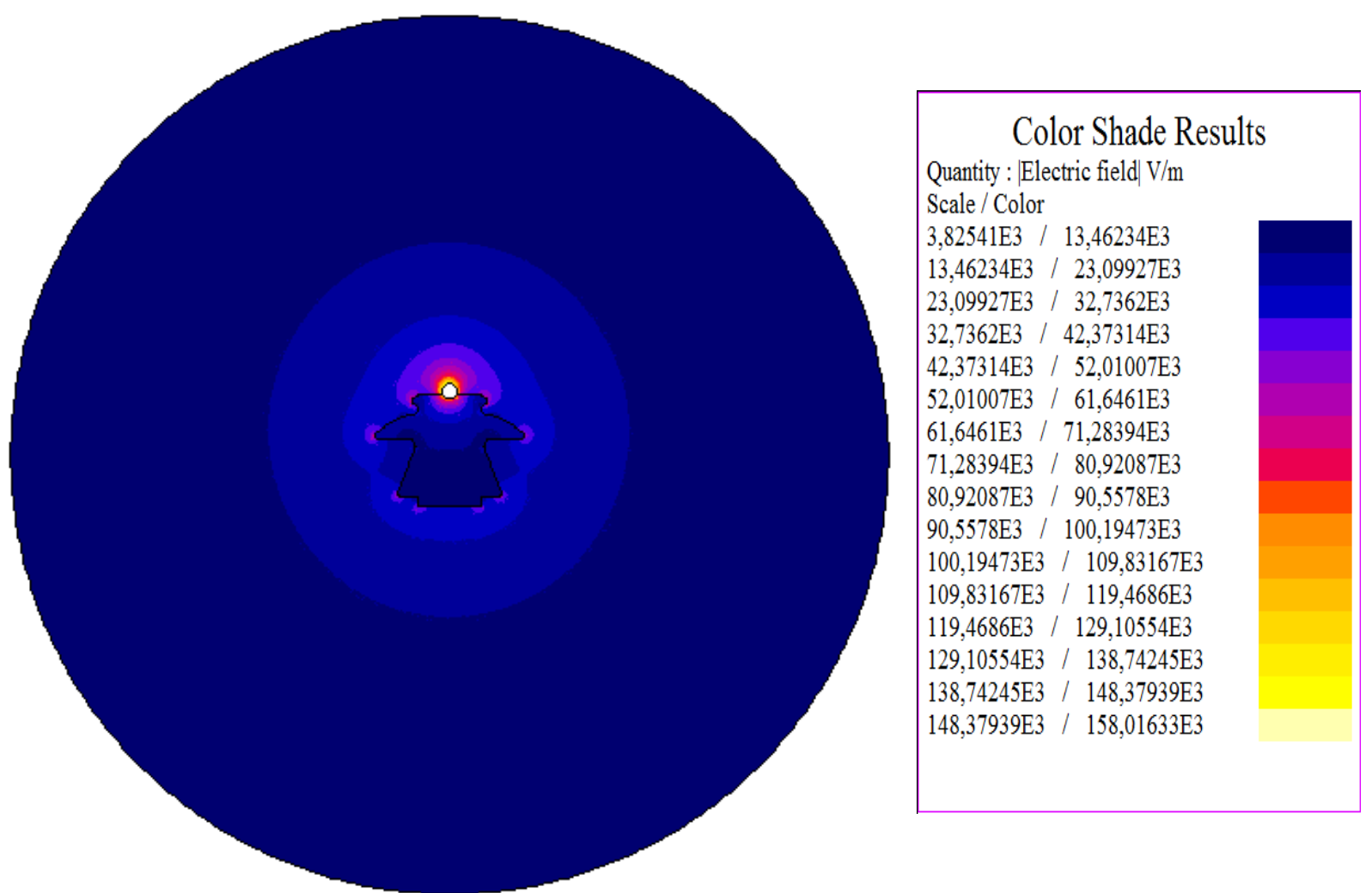

Figura 5-3 - Isolador com os campos elétricos associados representados por cores.

Para realizar as simulações respeitando o nível de $69 \mathrm{kV}$, fez-se uso do mesmo isolador e da mesma malha criada anteriormente para os cálculos de elementos finitos realizados pelo software. Porém, foi alterado o valor da tensão no condutor para a classe de $69 \mathrm{kV}$. Portanto o valor da tensão aplicada no condutor foi de $56.338,26 \mathrm{~V}$.

A Figura 5-4 representa o isolador com as linhas de potencial referentes à tensão de pico de fase para o sistema de $69 \mathrm{kV}$. 


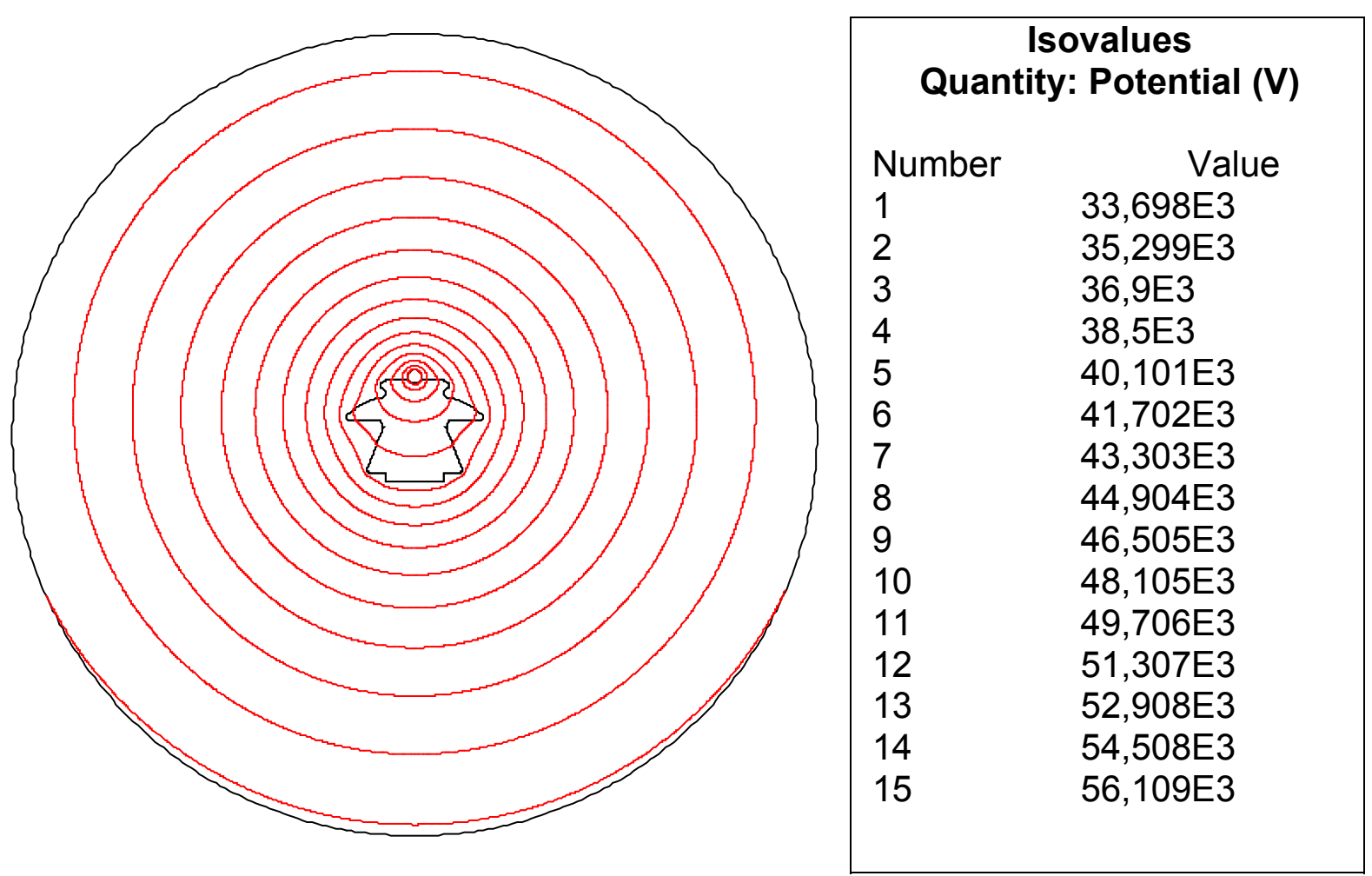

Figura 5-4 - Linhas de potencial para um isolador de $34,5 \mathrm{kV}$ com uma tensão aplicada no condutor de $69 \mathrm{kV}$.

A Figura 5-5 representa o isolador em cores, mostrando os campos elétricos em torno dele, devidos a uma tensão de $56.338,26 \mathrm{~V}$. 


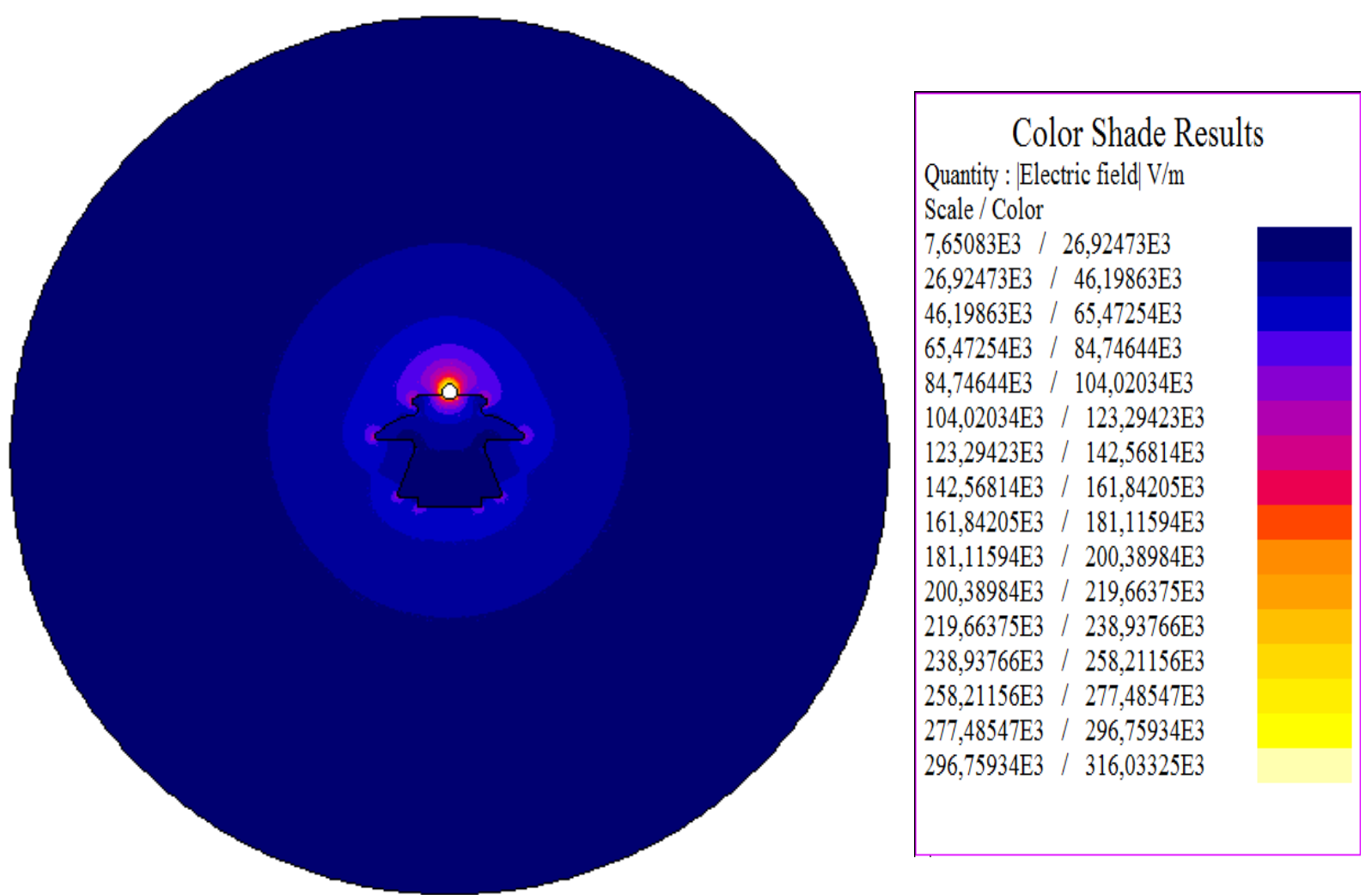

Figura 5-5 - Isolador com seus campos elétricos representados por cores e seus valores para uma tensão de $69 \mathrm{kV}$.

Pelas figuras apresentadas pode-se notar uma semelhança entre o sistema de 34,5 e o de $69 \mathrm{kV}$. Porém, os valores mostrados na tabela apresentam-se diferentes devido ao aumento da tensão no condutor.

Pretende-se com estas simulações, abordando campo elétrico e linhas de potencial, realizar simulações com a estrutura modelada por completo, incluindo os isoladores das três fases e a cruzeta. Para fixar melhor este desejo, realizou-se uma simulação contendo os três isoladores e registraram-se os resultados no mesmo formato como anteriormente apresentado para um isolador. A Figura 5-6 demonstra a forma de onda da tensão para as três fases do sistema, com destaque para o instante em que os valores foram tomados para a configuração da simulação via o software Flux®. 


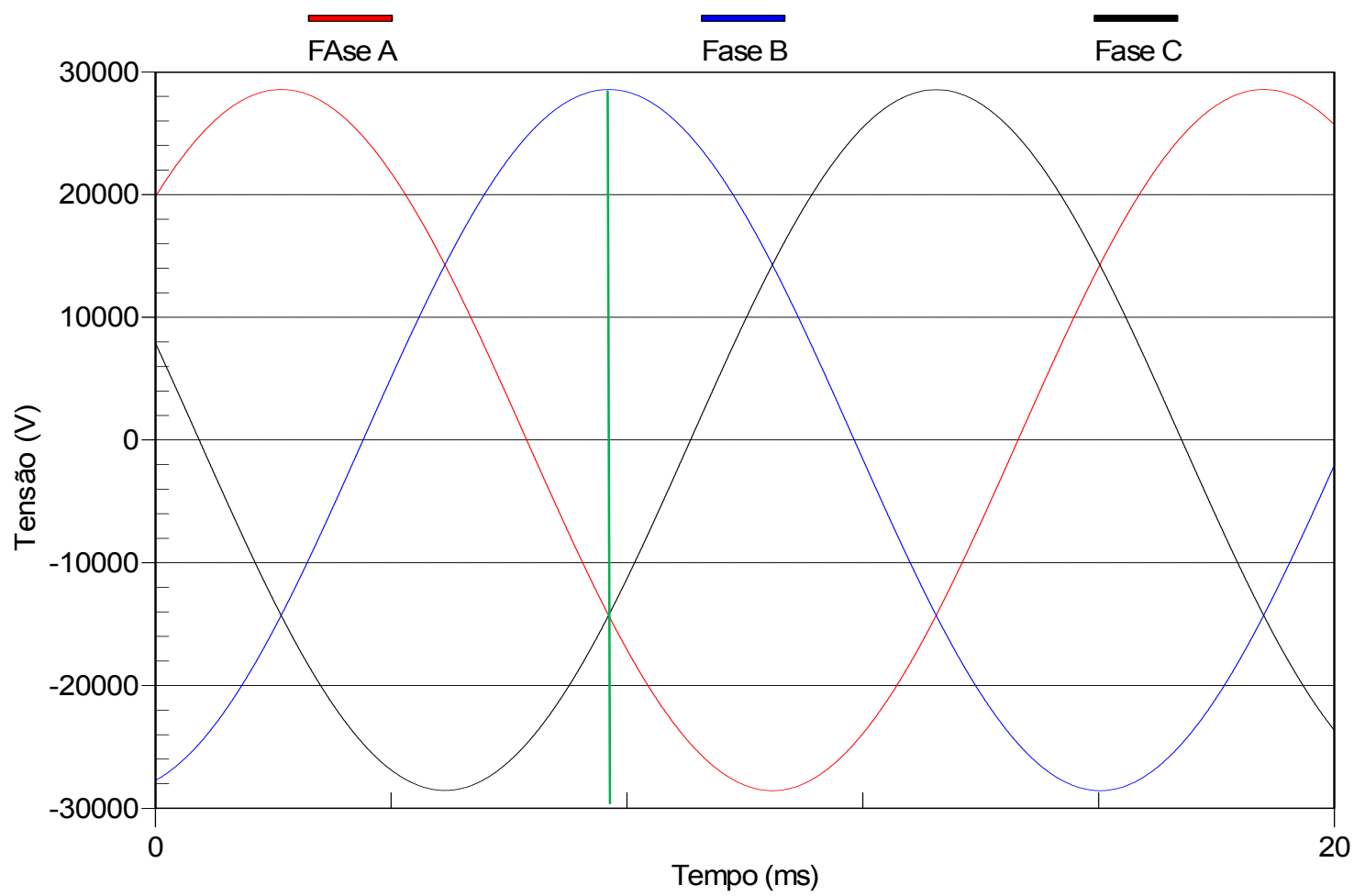

Figura 5-6 - Instante de tempo onde foram amostrados os valores de tensão de cada fase para a conseqüente aplicação nos condutores.

A Figura 5-7 demonstra as linhas de potencial em torno dos três isoladores com a respectiva tabela para os valores do potencial de cada linha. Cabe esclarecer que para o isolador interno, foi aplicada uma tensão de pico para o sistema de 34,5 kV, igual a $28.168,13 \mathrm{~V}$. Já para os dois isoladores posicionados na extremidade, foi aplicada uma tensão negativa com valores iguais a $-14.084,6 \mathrm{~V}$. Tais valores e fases foram aplicados em função da Figura 5.6 anteriormente apresentada. Este resultado é importante, pois através da diferença de potencial entre a linha próxima ao isolador central e a linha próxima ao isolador à direita, pode-se saber se surgirá um arco elétrico capaz de romper o dielétrico, que neste caso é o ar, com uma tensão de ruptura de $600 \mathrm{kV} / \mathrm{m}$ (IEEE STD 1410). 


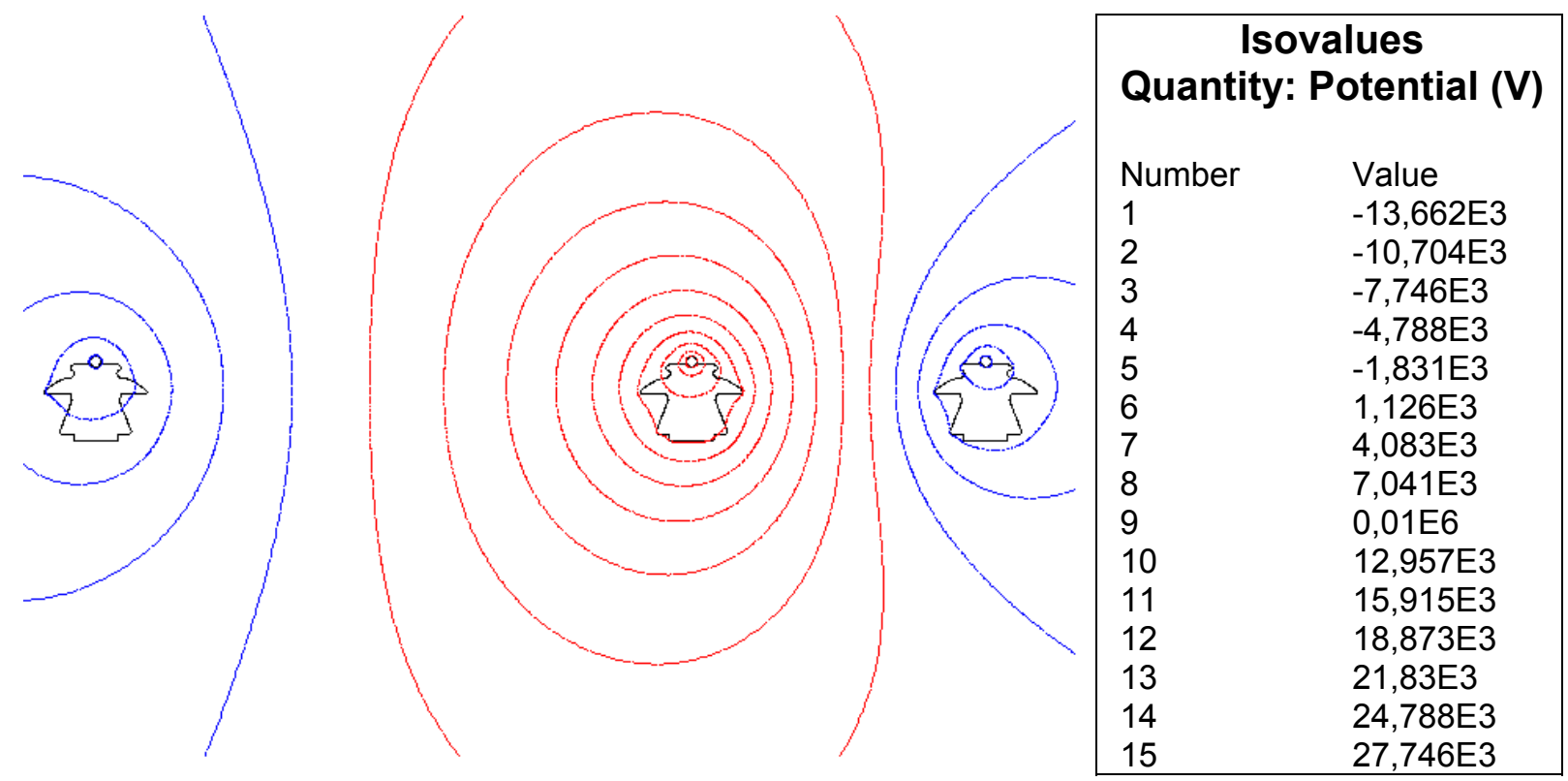

Figura 5-7 - Linhas de potencial observadas sobre os isoladores para um valor de tensão positivo para a fase "B" e negativo para as fases " $A$ " $e$ " $C$ ".

\section{A}

Figura 5-8 apresenta os valores do campo elétrico em torno dos isoladores, com cores mais claras para um aumento do campo elétrico, e cores escuras para a diminuição do campo elétrico. Por esta figura pode-se notar que a região entre o isolador central e o isolador à direita é a região mais problemática.

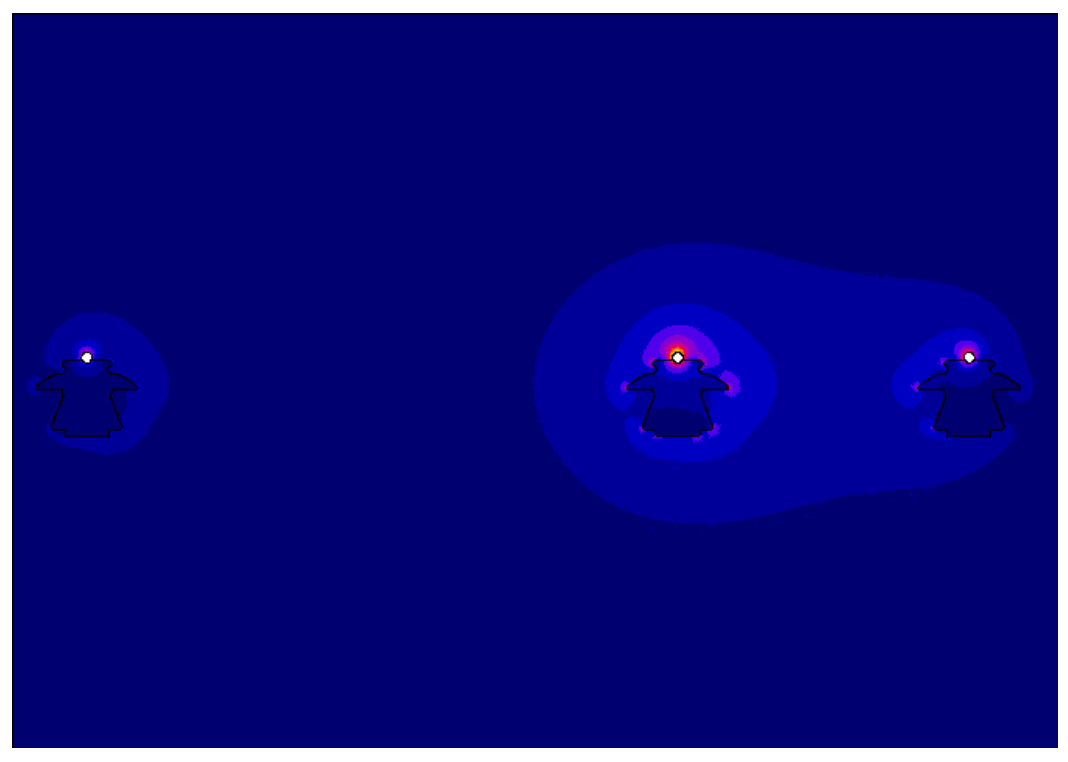

Color Shade Results Quantity : Electric field| V/m Scale / Color

211,59627 / 26,25027E3

$26,25027 \mathrm{E} 3$ / $52,28893 \mathrm{E} 3$

$52,28893 \mathrm{E} 3$ / 78,32759E3

$78,32759 \mathrm{E} 3$ / 104,36627E3

104,36627E3 / 130,40494E3

$130,40494 \mathrm{E} 3$ / 156,44359E3

$156,44359 \mathrm{E} 3$ / 182,48227E3

$182,48227 \mathrm{E} 3$ / 208,52094E3

208,52094E3 / 234,55961E3

$234,55961 \mathrm{E} 3$ / 260,59827E3

$260,59827 \mathrm{E} 3 / 286,63697 \mathrm{E} 3$

$286,63697 \mathrm{E} 3 / 312,67563 \mathrm{E} 3$

$312,67563 \mathrm{E} 3$ / 338,71428E3

$338,71428 \mathrm{E} 3$ / 364,75297E3

$364,75297 \mathrm{E} 3$ / 390,79163E3

$390,79163 \mathrm{E} 3$ / 416,83028E3

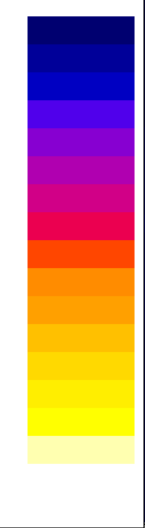


Figura 5-8 - Campo elétrico observado sobre os isoladores para um valor de tensão positivo para a fase " $B$ " e negativo para as fases " $A$ " $e$ " $C$ ".

Maiores detalhes e aspectos conclusivos sobre essa modelagem dos isoladores serão apresentados posteriormente, em função da perspectiva de continuidade da pesquisa apresentada.

\section{2 - PROTEÇÃO DO SISTEMA ATUAL E RESULTANTE}

Como prática, todos os sistemas de energia elétrica devem apresentar segurança e confiabilidade, sendo de suma importância para tal, um adequado sistema de proteção. Para os casos de linhas repotenciadas isso não é diferente. Portanto, fez-se um estudo do sistema de proteção atualmente instalado na linha de $34,5 \mathrm{kV}$, e um estudo sobre os equipamentos e as configurações utilizadas pela CPFL nas suas linhas de $69 \mathrm{kV}$.

\subsection{1 - PROTEÇÃO DO SISTEMA DE 34,5 KV}

A linha de transmissão escolhida para ser repotenciada é responsável por interligar a pequena usina hidroelétrica de Salto Grande à subestação de Souzas. É importante ressaltar que não existem, nessa linha, clientes conectados, o que direciona que a proteção do sistema seja feita apenas nas extremidades, ou seja, na entrada da subestação e na saída da usina.

Existem diversos dispositivos a serem empregados na configuração de um sistema de proteção. Comentando rapidamente, tem-se que o disjuntor é responsável por seccionar o circuito seja em operação normal, ou com o sistema em curto (MAMEDE , 2004). Este equipamento deve ser robusto o suficiente para que o 
sistema possa ser isolado eliminando rapidamente o arco elétrico gerado quando da sua abertura.

O disjuntor não opera sozinho na proteção do sistema, ele necessita de dispositivos que controlem sua operacionalidade. Os dispositivos utilizados para esse controle são os relés, que através de valores previamente ajustados e comparados com os valores medidos, detectam se existe ou não a necessidade da abertura do disjuntor. Existem, ainda, os transformadores de corrente e tensão, que são responsáveis por transformarem (adaptarem) as tensões e correntes medidas na linha a valores menores que possam ser analisados pelos relés e demais equipamentos de medição sem que ocorra a queima dos mesmos (ARAÚJO, et al., 2005).

Cabe afirmar que a proteção instalada na subestação em análise (sistema de $34,5 \mathrm{kV}$ ) conta com dois relés de sobrecorrente, responsáveis por detectar distúrbios e enviar o sinal, caso necessário, para a abertura do disjuntor.

Ambos os relés são de sobrecorrente, porém um é de sobrecorrente direcional de terra e o outro é de sobrecorrente direcional (ARAÚJO, et al., 2005). As correntes de entrada para os relés estão conectadas através de transformadores de corrente com a relação de transformação de 150/5A. A faixa de ajuste do relé de sobrecorrente direcional de terra para a unidade instantânea é de 0,01 a 2 vezes a corrente fase-terra medida e possui um ângulo máximo de torque de $60^{\circ}$ para a unidade direcional. A faixa de ajuste do relé de sobrecorrente direcional, também para a unidade instantânea, é de 2 a 40 vezes a corrente fase-terra medida e possui um ângulo máximo de torque de $45^{\circ}$, também para a unidade direcional.

Os dois relés instalados na extremidade da linha conectada à subestação são digitais da marca SEG (MRI1, 2009). 
Já na extremidade que está conectada à usina de Salto Grande, existe um relé digital do tipo MiCOM fabricado pela AREVA (MICOM, 2009), configurado utilizando as funções de sobrecorrente e sobrecorrente de terra.

A função de sobrecorrente é configurada através de três curvas inversas padronizadas pela IEC (Comissão Eletrotécnica Internacional) (CPFL, 2003), uma direcional para frente para um ajuste de corrente de 120 A. A segunda é não direcional com uma corrente ajustada para $160 \mathrm{~A}$, e a terceira é direcional para frente com uma corrente de $280 \mathrm{~A}$.

A função de sobrecorrente de terra é configurada, também utilizando três curvas inversas definidas pela IEC (CPFL, 2003). A primeira é direcional para frente com um ajuste de corrente de $20 \mathrm{~A}$. A segunda é não direcional com o ajuste de corrente de $40 \mathrm{~A}$, e a terceira possui um ajuste de corrente de $500 \mathrm{~A}$ e é direcional para frente. O relé ainda possui a sua função de religamento configurada para uma tentativa com 2,5 segundos. Outra função ativada no relé digital é a de localização de falta, além da gravação de distúrbios, sendo possível registrar as três correntes e tensões de fase, e ainda as correntes da fase a terra.

Os disjuntores instalados são isolados a óleo e possuem tensão nominal de 34,5 kV e tensão máxima de 38 kV.

\subsection{2 - PROTEÇÃO DO SISTEMA DE 69 KV}

Durante o processo de repotenciação, devem-se levar em consideração as alterações do sistema de proteção para que o mesmo suporte a nova classe de tensão aplicada e esteja ajustado para a correta proteção do sistema com relação aos curtos-circuitos que por ventura possam vir a acontecer. 
Para tanto, os dispositivos que operam especificamente na classe de tensão para o qual foram projetados, neste caso em específico de $34,5 \mathrm{kV}$, deverão ser alterados por dispositivos que suportem a nova classe de tensão (69 kV). Sendo assim, os transformadores de tensão e corrente instalados deverão ser substituídos para que suportem a classe de tensão de $69 \mathrm{kV}$. Os transformadores utilizados na conexão da linha com a extremidade da geração e da subestação também deverão se substituídos. Para essa linha em específico, não existem cargas conectas ao longo da linha, porém, ressalta-se que caso existam, deverá ser feita a substituição e adaptação para a correta conexão dessas cargas ao novo sistema de $69 \mathrm{kV}$, levando-se em consideração, os transformadores e a proteção instalada.

O padrão de proteção utilizado para as linhas da CPFL de $69 \mathrm{kV}$ é semelhante ao utilizado nesta linha de 34,5 kV (CPFL, 2003), com relés de sobrecorrente e sobrecorrente de terra, por isso se torna mais fácil a alteração da proteção para o sistema resultante. Sendo assim, maiores detalhes de alteração, deverão ser observados e considerados quando da real repotenciação do sistema elétrico.

Cabe comentar que, atualmente, a linha de 34,5 kV não é protegida contra prováveis situações de descargas atmosféricas. Sendo assim, um estudo mais aprofundado deverá ser posteriormente realizado, para se certificar da real necessidade da utilização de pára-raios na linha a ser repotenciada. Acredita-se que da afirmação de tal necessidade, com a conseqüente implantação dos mesmos, o desempenho da linha de $69 \mathrm{kV}$ frente às descargas atmosféricas será melhorado, reduzindo-se o número de prováveis desligamentos quando da ocorrência destes distúrbios. 


\section{Capítulo 6 Conclusões}

Disposto em seis capítulos, o presente trabalho teve por objetivo estabelecer um procedimento para a repotenciação de linhas de transmissão de $34,5 \mathrm{kV}$ para 69 KV. Para tanto, utilizou-se da experiência obtida com um trabalho em andamento para a repotenciação de uma linha de subtransmissão de uma concessionária local, considerando um caso teste em específico. Cabe frisar que, embora as conclusões apresentadas se refiram especificamente a um estudo de caso, elas poderão servir como parâmetro para a realização de trabalhos semelhantes e futuros em quaisquer outras linhas de subtransmissão.

Como base para a elaboração do trabalho como um todo, acredita-se que a utilização dos fluxogramas criados e ilustrados no capítulo 3 foi de suma importância na realização desse projeto de pesquisa. Pelos mesmos, cada etapa pôde ser mais bem apresentada, evidenciando-se as características e/ou peculiaridades do sistema observadas em campo e fielmente consideradas no decorrer da pesquisa realizada.

Como ponto inicial, tem-se que para aumentar a capacidade de transmissão de uma linha de $34,5 \mathrm{kV}$ para $69 \mathrm{kV}$, deve-se escolher um, dentre os três métodos apresentados (alteração do limite térmico, recondutoramento e elevação da tensão operativa). Dos três, a elevação da tensão operativa se apresentou como um procedimento rápido e tecnicamente viável a ser executado. Tal afirmativa vem do fato de se poder aproveitar grande parte da estrutura do sistema de $34,5 \mathrm{kV}$ já instalado, respeitando-se também, as questões ambientais já implícitas. Além destes 
pontos, a importância do sistema a ser repotenciado frente às conexões existentes também foi outro fator importante observado.

Para uma melhor análise e compreensão do sistema, mesmo não sendo o enfoque central dessa dissertação, considera-se que as simulações computacionais foram indispensáveis aos estudos voltados à repotenciação. Dessa maneira, abordaram-se as principais simulações que devem ser realizadas, comparando um modelo simplificado com um expandido para as duas classes de tensão. Apesar de apresentarem semelhanças nos resultados, concluiu-se que ainda assim é interessante a realização das simulações utilizando um modelo expandido, pois assim será possível analisar as magnitudes das tensões em todas as estruturas existentes.

Outro aspecto importante e que não se pode deixar de incluir é o fato de se ter obtido altos valores para as tensões trifásicas em observação, durante as simulações de descargas atmosféricas, o que não está incorreto, pois foram descargas aplicadas diretamente aos isoladores, e não de forma induzida. Vale lembrar que, devido à baixa probabilidade de ocorrer uma descarga desse tipo, ficaria dispendioso preparar uma linha que pudesse suportar as magnitudes de tensão geradas diretamente sobre o sistema, uma vez que na maioria dos casos somente o isolador atingido seria destruído. Sendo assim, como ponto adicional a análise destas situações de descargas aplicadas, sugere-se a inclusão de pára-raios sobre o sistema simulado e energizado em $34,5 \mathrm{kV}$ e/ou em $69 \mathrm{kV}$.

Outra simulação conveniente para o contexto do trabalho é a consideração e estudo dos campos elétricos e magnéticos em torno dos isoladores. Apesar de não se ter realizado um aprofundamento nas simulações via o software FLUX ${ }^{\circledR}$, ficou clara a necessidade de se conhecer o comportamento dos isoladores e das 
estruturas envolvidas com relação à tensão aplicada, seja ela a de operação normal, ou devido a uma falta, ou descarga atmosférica, ou mesmo quando da elevação da classe de tensão.

Para os casos de curtos-circuitos simulados e apresentados no contexto deste trabalho, afirma-se que não houve situações que trouxessem risco à isolação da linha. Para esta afirmação, tomam-se como base os resultados evidenciados pelo software FLUX ${ }^{\circledR}$, observando-se principalmente a distância padrão entre os isoladores para a classe de $34,5 \mathrm{kV}$, e, considerando-se a mesma distância, entre isoladores apropriados, para a classe de $69 \mathrm{kV}$. Afirma-se que as situações mais conservadoras (piores situações) foram aplicadas sobre os modelos de linhas em análise, sem, até o momento desta pesquisa, apresentar indícios da inviabilidade técnica de tal repotenciação.

Pelo atual estágio das simulações de campos elétricos pode-se colocar que este não trará problemas quanto ao aumento da classe de tensão desta linha para 69 kV. Porém, estudos mais aprofundados deverão ser realizados durante a continuidade do projeto, bem como, uma melhor especificação sobre todas as estruturas existentes no caso teste analisado.

Quanto à etapa relacionada com a proteção do sistema, atual e resultante, uma vez que as filosofias de proteção adotadas pela companhia são iguais, pode ser feita a substituição dos equipamentos citados no item 5.2.2., para que se tenha uma proteção adequada e ajustada para operar na nova classe de tensão. Relembra-se que como princípio, busca-se aproveitar ao máximo a estrutura do sistema já existente. Logo, caso seja desejável uma melhora no sistema de proteção, com relação ao atual instalado, novas filosofias e/ou dispositivos deverão ser aplicados e coordenados com o sistema como um todo. 
Para finalizar, cabe colocar que a realização desse trabalho tanto que acadêmico, em conjunto com uma empresa concessionária, trouxe um ganho significativo com relação a uma desejável interação profissional entre as partes envolvidas. Embora o ideal seja sempre o máximo de interação possível, sabe-se que o crescimento pessoal e profissional reafirma-se com certas diferenças e críticas, que, quando construtivas, valorizam e permitem ainda mais o crescimento de todos os envolvidos.

\section{1 - CONTINUIDADE DA PESQUISA}

O resultado da pesquisa realizada até esse momento instiga à continuidade dos trabalhos, percebendo-se a necessidade de um aprofundamento nas simulações computacionais, desde as simulações de transitórios eletromagnéticos, até as simulações em que se dispõe da teoria dos elementos finitos para os cálculos dos campos elétricos e magnéticos a que ficam submetidos os isoladores. Ressalta-se que a idéia de se realizar simulações que abordem os resultados de campo elétrico em torno dos isoladores surgiu durante este projeto de pesquisa devido à necessidade de se conhecer o fenômeno existente e deve, portanto, ser muito mais explorada no futuro.

Além disso, a pesquisa poderá ter continuidade no intuito de:

1) Continuar com as análises e estudos de desempenho via simulações computacionais das duas configurações desejadas: rede primária de 34,5 kV e da linha de subtransmissão de $69 \mathrm{kV}$. 
2) Indicar os futuros materiais a serem agregados aos sistemas de subtransmissão (classe $69 \mathrm{kV}$ ).

3) Estudar tecnicamente as funções de proteção, operação, confiabilidade e integração do sistema resultante após a conversão entre estes níveis de tensão $(34,5$ - 69 kV).

4) Reconfigurar o antigo sistema de $34,5 \mathrm{kV}$ para um sistema de $69 \mathrm{kV}$, deixando-o atrativo e economicamente viável.

Outro aspecto que foge dos objetivos desta pesquisa, em específico, seria uma melhoria deste procedimento, adicionando aos estudos os passos necessários para a aplicação das demais técnicas de repotenciação, como a de alteração do limite térmico e a de recondutoramento da linha de transmissão. 


\section{Referências Bibliográficas}

ARAÚJO, C. A. S.; SOUZA, F. C.; CÂNDIDO, J. R. R.; DIAS, M. P. "Proteção de Sistemas Elétricos". 2ª Ed., Rio de Janeiro, Interciência, 2005.

ASSOCIAÇÃO BRASILEIRA DE NORMAS TÉCNICAS. NBR 5422: Projeto de linhas aéreas de transmissão: procedimentos. Fevereiro de 1985.

BEWLEY, L. V., "Travelling Waves on Transmission Systems", 2. ed. Ncw York, Dover, 1963.

BRASIL. Ministério do Meio Ambiente. Resolução CONAMA n² 237, de 19 de dezembro de 1997. Publicada no DOU n²47, de 22 de dezembro de 1997, seção 1, p. 30841-30843.

CHOWDHURI, P. "Power System Transients", The Eletric Power Engineering Handbook, Ed. L.L. Grigsby, Boca Raton: CRC Press LLC, 2001.

CPFL, Proteção - Relé Digital de Sobrecorrente de Fase e de Neutro - GED 139, 2003.

DA COStA, A., RUEDA, F. A., MARÇO, L. C., MORENO, R. F. (2001). Repotenciação de linhas de transmissão: aspectos técnicos e ambientais. In: XVI 
Seminário Nacional de Produção de Transmissão de Energia Elétrica (XVI SNPTEE), Uberlândia, 6 p.

DIESENDORF, W. "Insulation Coordination in High Voltage Electric Power Systems”. London, Butterworth, 1974.

DigSILENT GmbH, "DigSILENT PowerFactory V13.2 - Users Manual", DigSILENT GmbH, Gomaringen, Germany 2007.

DOMMEL, H. W. “Electromagnetic Transients Program Reference Manual: EMTP Theory Book", Portland, BPA,1986.

DUTRA, J. F., LAGO, F. F., CESAR, E. L., CARPEGGIANI, G., UEDA, S. M., SCHAUFFERT, W. (2005). Repotenciação e Recapacitação de LTs de 230 kV Através de Novos Cabos Condutores e Aumento da Capacidade de Carga dos Suportes. A Experiência da Eletrosul. In: XVIII Seminário Nacional de Produção de Transmissão de Energia Elétrica (XVIII SNPTEE), Curitiba, 6 p.

EEUG (1987). Alternative Transients Program Rule Book. LEC.

Femlab®. "Quick Start and Quick Reference”, 2004.

FLUX2D (2007) Finite element Software for electromagnetic Applications, version 10.2.4, Cedrat (CEE) Magsoft (USA) 
FONSECA, B. Q. A., CIMINI, C. A. Jr. (2003). Análise de Vida Útil de Cabos Condutores de Linhas Aéreas de Transmissão. In: XVII Seminário Nacional de Produção de Transmissão de Energia Elétrica (XVII SNPTEE), Uberlândia, 6 p.

FUCHS, R. D., “Transmissão de Energia Elétrica: Linhas Aéreas”; teoria das linhas em regime permanente. Rio de Janeiro, Livros Técnicos e Científicos; Itajubá, Escola Federal de Engenharia, Vol. 1, 1977.

FUCHS, R. D., "Transmissão de Energia Elétrica: Linhas Aéreas"; teoria das linhas em regime permanente. Rio de Janeiro, Livros Técnicos e Científicos; Itajubá, Escola Federal de Engenharia, Vol. 2, 1979.

HEDMAN, D. E. "Propagation on Overhead Transmission Lines. II Theory of Modal Analysis", IEEE Transactions on Power Apparatus and Systems, vol, 84, n. 3, p. 200-204, Mar. 1965.

HEDMAN, D. E. "Propagation on Overhead Transmission Lines. II: Earth Correction Effects on Practical Results", IEEE Transactions on Power Apparatus and Systems, vol. 84, n. 3, p. 205-211, Mar. 1965.

HEDMAN, D. E. "Theoretical Evaluation of Multiphase Propagation", IEEE Transactions on Power Apparatus and Syslems, vol. 90, pp. 2460-2471, Nov.-Dec. 1971. 
HEDMAN, D. E. "Teoria das Linhas de Transmissão". Santa Maria, Universidade Federal de Santa Maria, 1978, vol. 3 (Curso de Engenharia em Sistemas Elétricos de Potência, Série PTI).

HOMRICH, C. A. R. (2003). Estruturas Metálicas Compactas de 69 kV em Perímetro Urbano - Resultado da Aplicação de Materiais e Serviços em Linha de Transmissão na AES-Sul. In: XVII Seminário Nacional de Produção de Transmissão de Energia Elétrica (XVII SNPTEE), Uberlândia, 5 p.

IEEE "Guide for Improving the Lightning Performance of Electric Power Overhead Distribution Lines", IEEE Std 1410 TM-2004, (Revision of IEEE Std 1410-1997).

MAMEDE, J. P. Previsão da Manutenção de Disjuntores dos Alimentadores de Distribuição de Energia Elétrica pelo Método de Curto-circuito Probabilístico. 2004. 75 f. Dissertação (Mestrado em Engenharia Elétrica) - Universidade Estadual de Campinas - UNICAMP, Campinas, 2004.

MICOM, Proteção relés série 20, 30 e 40. Disponível em: <http://www.arevatd.com/solutions/US_35673_Air-Insulated\%20Substation.html >. Acesso em: 20 de out. de 2009.

MOREIRA, I. S., MELLO, J. L. S., PROSDÓCIMO, N., SOUZA, R. L. (1999). Reisolamento e Reformas de Linhas de Transmissão - A Experiência da COPEL. In: XV Seminário Nacional de Produção de Transmissão de Energia Elétrica (XV SNPTEE), Foz do Iguaçu, 6 p. 
MRI1 - Digital multifunctional relay for time overcurrent protection. Disponível em: <http://search.woodward.com/produkte_visitenkarte/template/pv_ausgabe.php?fea ture_1=33\&tld=pt>. Acesso em: 20 de out. de 2009.

NAIDU, S. R. "Transitórios Eletromagnéticos em Sistemas de Potência". Campina Grande, UFPB/Eletrobrás, 1985.

OLIVEIRA, C. M. F. Recapacitação de linhas de transmissão. 2000. 112 f. Dissertação (Mestrado em Engenharia Elétrica) - Pontifícia Universidade Católica do Rio de Janeiro, Rio de Janeiro, 2000.

Padrão CPFL (a), Estrutura do tipo "G”, desenho padrão n BX-A-9370-SP, 05 de agosto de 1970 .

Padrão CPFL (b), Estrutura do tipo "A", desenho padrão n BX-A4-11.826-Camp-SP, 30 de março de 1984.

Padrão CPFL (c), Estrutura do tipo "B", desenho padrão n BX-A4-11.828-Camp-SP, 03 de abril de 1984.

Padrão CPFL (d), Estrutura do tipo "E”, desenho padrão nº BX-A3-11.832-Camp-SP, 09 de abril de 1984. 
Padrão CPFL (e), Estrutura do tipo "HS", desenho padrão n BX-A3-11.836-CampSP, 07 de junho de 1984.

Padrão CPFL (f), Estrutura do tipo "HT", desenho padrão n BX-A3-11.844-CampSP, 04 de junho de 1984.

PRIKLER L., HOIDALEN H. K. “ATPDraw v5 User's Manual”, novembro 2007.

PROSDÓCIMO, N., MOKDESE, H (2001). Linhas de Transmissão Urbanas Compactas em 69 kV para Circuito Duplo: Novas Soluções Utilizadas pela COPEL na Transmissão de Energia Elétrica em Áreas Urbanas. In: XVI Seminário Nacional de Produção de Transmissão de Energia Elétrica (XVI SNPTEE), Campinas, $6 \mathrm{p}$.

PSCAD/EMTDC versão 4.2, PSCAD $^{\circledR} /$ EMTDC $^{\text {TM }}$ User'Guide, Manitoba HVDC Research Centre, Canadá, 2005.

São Paulo (2007). Secretaria de Estado do Meio Ambiente. Dispõe sobre procedimentos simplificados para o licenciamento ambiental de linhas de transmissão de energia e respectivas subestações, no território do Estado de São Paulo. Resolução SMA-5, 7 de fevereiro de 2007.

SEMLYEN, A., DABULEANU, A. Fast and Accurate Switching Transient Calculations on Transmission Lines with Ground Return Using Recursive Convolutions. Power 
Apparatus and Systems, IEEE Transactions on. Volume 94, Issue 2, Part 1, Mar 1975 Page(s): $561-571$.

SILVA, R. P. e BAUMANN, C. A. G. (1997). Repotenciação de linhas de transmissão: avaliação de novas tecnologias e concepções. In: XIV Seminário Nacional de Produção de Transmissão de Energia Elétrica (XIV SNPTEE), Belém, $6 \mathrm{p}$.

SILVA, A. O., RICCO, V. H. G, SANTIAGO, N. H. C., NOGUEIRA, R. L. S., NOEL, R., CAVAlcante, I., BORgeS, P. S. P. (2007). Reforma da Linha de Transmissão 230kV Bandeirantes - Brasília Geral. In: XIX Seminário Nacional de Produção de Transmissão de Energia Elétrica (XIX SNPTEE), Rio de Janeiro, 8 p.

SOFTWARE, Integrated Engineering, 2009. "Hybrid simulation tools for electromagnetic, thermal and structural design analysis". Disponível em: <http://www.integratedsoft.com/products/coulomb>. Acesso em: 27 jan. 2009.

STEPHAN, J. C. S., COSTA, C. F. (2007). Recapacitação, Repotenciação e Avaliação da Capacidade de Carga de Suportes e Fundações de Linhas Aéreas de Transmissão Segurança e Confiabilidade. In: XIX Seminário Nacional de Produção de Transmissão de Energia Elétrica (XIX SNPTEE), Rio de Janeiro, 8 p.

Watson, N, Arrillaga, J. "Power Systems electromagnetic transients simulation". Ed. The institution of Electrical Engineers. London: United Kingdom, 2003. 
WEDEPOHL, L. M. "Application of Matrix Methocls to the Solution of Travelling-Wave Phenomena in Polyphase Systems", Proceedings of the Institution of Electrical Engineers, vol. 110, n. 12, p. 2200-2212, Dec, 1963.

WIEDMER, R. S. et al. (2007). Recapacitação de Linhas de Transmissão 138kV Utilizando Cabo de Alumínio Liga 6201. In: XIX Seminário Nacional de Produção de Transmissão de Energia Elétrica (XIX SNPTEE), Rio de Janeiro, 8 p.

ZANETTA Jr., L. C., "Transitórios Eletromagnéticos em Sistemas de Potência". São Paulo, Editora da Universidade de São Paulo; 2003. 